\title{
The Petrochemistry of Jake_M: A Martian Mugearite
}

E.M. Stolper ${ }^{1}$, M.B. Baker ${ }^{1}$, M.E. Newcombe ${ }^{1}$, M.E. Schmidt ${ }^{2}$, A.H. Treiman ${ }^{3}$, A. Cousin $^{4,5}$, M.D. Dyar ${ }^{6}$, M.R. Fisk ${ }^{7}$, R. Gellert ${ }^{8}$, P.L. King 9 , L. Leshin ${ }^{10}$, S. Maurice ${ }^{5}$, S.M. McLennan $^{11}$, M.E. Minitti ${ }^{12}$, G. Perrett ${ }^{8}$, S. Rowland ${ }^{13}$, V. Sautter ${ }^{14}$, R.C. Wiens ${ }^{4}$, and the MSL Science Team.

${ }^{1}$ Caltech, Pasadena, CA 91125; ${ }^{2}$ Brock Univ., St. Catharines, ON L2T 3V8, Canada; ${ }^{3}$ Lunar \& Planet. Inst., Houston, TX 77058; ${ }^{4}$ LANL, Los Alamos, NM 87545; ${ }^{5}$ Institut de Recherches en Astrophysique et Planétologie, 31028 Toulouse, France; ${ }^{6}$ Mt. Holyoke College, South Hadley, MA 01075; ${ }^{7}$ Oregon State Univ., Corvallis, OR 97331; ${ }^{8}$ Univ. Guelph, Guelph, ON N1G 2W1, Canada; ${ }^{9}$ Res. School Earth Sci., ANU, Acton ACT 0200, Australia; ${ }^{10}$ RPI, Troy, NY 12180; ${ }^{11}$ SUNY, Stony Brook, NY 11794; ${ }^{12}$ APL, The Johns Hopkins Univ., Baltimore, MD 20723; ${ }^{13}$ Univ. Hawaii, Honolulu, HI 96822;

${ }^{14}$ LMCM, 75005 Paris, France;

Abstract: Jake_M, the first rock analyzed by the APXS instrument on the Curiosity rover, differs significantly in chemical composition from other known martian igneous rocks: It is alkaline ( $>15 \%$ normative nepheline) and relatively fractionated. Jake_M is similar compositionally to terrestrial mugearites, a rock type typically found at ocean islands and continental rifts. By analogy with these comparable terrestrial rocks, Jake_M could have been produced by extensive fractional crystallization of a primary alkaline or transitional magma at elevated pressure, with or without elevated water contents. The discovery of Jake_M suggests that alkaline magmas may be more abundant on Mars than on Earth and that $\bar{C}$ uriosity could encounter even more fractionated alkaline rocks (e.g., phonolites and trachytes).

\section{Introduction:}

Rock "Jake_M" (JM; named for JPL engineer Jake Matijevic) was the first sample imaged using the Mars Hand Lens Imager (MAHLI) and analyzed on sols 46 and 47 with the Alpha Particle X-ray Spectrometer (APXS) on the Mars Science Laboratory (MSL) $(1,2)$. Although the rock is an isolated fragment lacking field context (encountered $\sim 282$ $\mathrm{m}$ from the Bradbury landing site), its dark color and apparently fine-grained texture suggested prior to analysis that it was a relatively homogeneous (on a mm-to-cm scale) igneous rock and thus an appropriate sample with which to initiate the APXS analytical program and to analyze with ChemCam (3) using Laser-induced Breakdown Spectroscopy (LIBS). We report here chemical analyses of JM and an interpretation of their meaning for its petrogenesis. 


\section{Results and Discussion:}

Petrography:

$\mathrm{JM}$ is roughly pyramidal in shape $(\sim 50 \mathrm{~cm}$ on each of its three base edges and $\sim 50 \mathrm{~cm}$ tall; Fig. 1). The rock is dark gray and thinly coated by light-toned reddish-brown dust. Its upper surfaces have rounded hollows likely due to wind erosion and $<1-3 \mathrm{~mm}$ pits that could be vesicles. The lowest $\sim 2 \mathrm{~cm}$ of the rock has smoother surfaces that may reflect primary layering or the effects of wind erosion. Near-vertical fractures $(\sim 10 \mathrm{~cm}$ long) project upward from the base. Feldspar microphenocrysts have been tentatively identified in MAHLI images (4), but individual mineral grains could not otherwise be distinguished in optical images, perhaps due to the dust cover and/or polish by wind. Compositional variations among the 14 individual locations (see Fig. 1 and Supplementary Materials, Fig. S1) analyzed by LIBS using ChemCam show that the rock is heterogeneous on a length scale of $\sim 0.5 \mathrm{~mm}$. The heterogeneities observed by LIBS analyses suggest the presence of plagioclase (broadly consistent with oligoclase), Ca-rich pyroxene, olivine, and Fe-Ti-rich oxide(s) [(3); see also Supplementary Materials, Figs. S1-S4].

\section{Bulk composition and classification:}

The three APXS analyses (Table 1) were collected on two different spots; the listed uncertainties on the average (calculated after normalizing each analysis to $100 \mathrm{wt}$. \%, excluding $\mathrm{SO}_{3}, \mathrm{Cl}$, and trace elements) are due to variations between the three analyses that may partially reflect real differences between the two analyzed spots. The surface of JM was not brushed or abraded prior to analysis; in the Supplementary Materials we compare the JM analyses to both unbrushed (i.e., "as is") and physically abraded rock surfaces analyzed by the Mars Exploration Rovers (MERs). The CIPW norms (5) (Table 1) are based on the average JM composition and were calculated using molar $\mathrm{Fe}^{3+} /($ total $\mathrm{Fe}$ ) ratios of 0 and 0.15 . Although this range of $\mathrm{Fe}^{3+} /($ total $\mathrm{Fe})$ ratios brackets the ratios 
expected in basaltic melts at the estimated $f \mathrm{O}_{2}$ values of basaltic shergottites (e.g., 6 ), recent modeling suggests that mantle melting at higher $f \mathrm{O}_{2} \mathrm{~s}$ may have occurred early in the planet's history (7). However, even for a $\mathrm{Fe}^{3+} /$ total $\mathrm{Fe}$ value of 0.3 , normative nepheline is still $\sim 15$ wt. $\%$.

Based on either its calculated norm or inspection of its major-element composition, JM has a basaltic composition, and it is likely an igneous rock (although we cannot tell whether it is from a lava flow, an intrusion, a pyroclastic flow, or a volcaniclastic sediment deposited after minimal fractionation or alteration of primary igneous rocks). Moreover, with its $\sim 16-17 \%$ normative nepheline (Table 1) and its position on an alkalisilica diagram (Fig. 2), JM is an alkaline rock [with an alkalinity index (8) significantly higher than other known martian rocks]. It is also evolved (likely due to crystal fractionation) relative to most other known martian igneous rocks (Fig. 3): it has a low $\mathrm{MgO}$ content (4.4 wt. \%), albitic normative plagioclase (oligoclase, $\sim \mathrm{An}_{15}$ ), a molar $\mathrm{Mg} /\left(\mathrm{Mg}+\mathrm{Fe}_{\text {total }}\right)$ ratio of $\sim 0.43, \sim 40 \mathrm{ppm} \mathrm{Ni}$, and $\sim 270 \mathrm{ppm} \mathrm{Cr}$ (Ni and $\mathrm{Cr}$ values are from the two long-duration analyses listed in Table 1). Based on its $\mathrm{MgO}$ content, JM is more fractionated than most other martian rocks — of the analyses plotted in Fig. 3, only the basaltic shergottite Los Angeles (9), the rocks Wishstone and Champagne analyzed by the MERs (10), and the two estimated soil-free Pathfinder rock compositions $(11,12)$ have similar or lower $\mathrm{MgO}$ contents.

For terrestrial igneous rocks, chemical composition is generally not the sole criterion for classification. For JM, we have no other information and although it plots slightly above the nominal mugearite field on the alkali-silica diagram (this field is shown as the blue polygon in Fig. 2), the composition of the normative plagioclase (i.e., oligoclase; broadly consistent with the ChemCam results), the substantial normative nepheline and orthoclase, and the fact that it overlaps compositionally with many terrestrial rocks that 
have historically been called mugearites (Figs. 2b, S5) leads us to classify JM as a mugearite (13). Mugearites are a well-defined and widely distributed (though relatively uncommon) intermediate (i.e., fractionated) member of the terrestrial alkali-olivine basalt, hawaiite, mugearite, benmoreite, trachyte-phonolite magma series found in locations such as ocean islands and continental rifts (14-16). They generally contain normative nepheline, but nepheline as a phenocryst phase is relatively rare (14) so the absence of a nepheline signature in the ChemCam results is not inconsistent with JM's normative composition. Note that although JM actually plots in the nominal phonotephrite field in Fig. 2, in other respects the compositional comparison of JM to terrestrial rocks that have been called phonotephrites is no better (and arguably worse) than to rocks called mugearites (Fig. S5, S6).

\section{Comparison to other martian igneous rocks:}

Although there is overlap in some oxide concentrations, taken as a whole, the JM composition is distinct from all other known martian igneous rocks (Figs. 2, 3). In particular, compared to $\mathrm{JM}^{\prime}$ 's $\mathrm{Na}_{2} \mathrm{O}$ and $\mathrm{K}_{2} \mathrm{O}$ contents of $\sim 7$ and $\sim 2.1 \mathrm{wt}$. \%, respectively (Table 1), all martian meteorites and martian igneous rocks analyzed by Pathfinder and the MERs are significantly lower in sodium and potassium: the highest previously analyzed $\mathrm{Na}_{2} \mathrm{O}$ contents are only $\sim-5$ wt. \% (Backstay, Humboldt Peak, NWA 7034 meteorite, Wishstone, Champagne, and one of the estimated soil-free Pathfinder compositions; see Fig. 3f); the highest $\mathrm{K}_{2} \mathrm{O}$ contents of relatively unaltered martian rocks (17) are only $\sim 1$ wt. \% (Backstay, Humboldt Peak, Madeline English, and the soil-free Pathfinder compositions; Fig. 3g). There is, however, evidence from the nakhlite meteorites of K-rich martian liquids: (i) the presence of K-rich kaersutite in melt inclusions (18); (ii) highly fractionated glassy mesostasis in the nakhlites (19); and (iii) K-rich bulk melt inclusion compositions (20). Most martian meteorites and analyzed martian igneous rocks have higher $\mathrm{MgO}$ and $\mathrm{FeO}^{*}$ contents and lower $\mathrm{Al}_{2} \mathrm{O}_{3}$ contents 
than JM [Figs. 3c, d; see also (21)]; although there are exceptions for individual elements (e.g., the soil-free Pathfinder compositions, Wishstone, Champagne, and Los Angeles for MgO; Backstay, Wishstone, Champagne, and NWA 7034 for FeO*; and Wishstone and Champagne for $\mathrm{Al}_{2} \mathrm{O}_{3}$ ), no known martian rock overlaps $\mathrm{JM}$ in all three of these elements. The Ni (22-59 ppm) and $\mathrm{Cr}(\sim 270 \mathrm{ppm})$ contents of JM are among the lowest values for an unbrushed rock surface found on Mars to date; moreover, since martian dust is typically enriched in $\mathrm{Ni}$ by $\sim 10$ times JM values (22), JM probably contains even lower Ni than is suggested by the APXS analyses.

Although some Gusev samples are alkaline [i.e., they plot above the alkaline-subalkaline boundary curve in Fig. 2 (23) and have normative nepheline; e.g., Humboldt Peak] or transitional (i.e., they plot near the boundary curve and have only small amounts of either normative nepheline or hypersthene; e.g., Backstay, NWA 7034), no relatively unaltered samples are as alkali-rich relative to the alkaline-subalkaline boundary curve in Fig. 2 or as rich in normative nepheline as JM. Note that despite their positions in Fig. 2, Wishstone and Champagne are not nepheline normative. This is due to their extremely high bulk $\mathrm{P}_{2} \mathrm{O}_{5}$ contents of 5.2-5.3 wt. \%; only if $\mathrm{P}_{2} \mathrm{O}_{5}$ were $\sim 1$ wt. \%, a value more typical of Gusev Crater rocks, would these rocks be as strongly nepheline normative as their positions on Fig. 2 might suggest. [See also (24) for a discussion of how changing the normative phosphate-bearing mineral from apatite to Ca-merrillite affects the proportions of the other normative components.]

\section{Comparison to terrestrial compositions:}

As shown by a comparison between JM and lavas from Tenerife (one of the Canary Islands), there is an excellent correspondence between JM and fractionated alkaline basaltic rocks on Earth (Figs. 3, S5-S8). JM lies on or near the oxide-MgO trends for Tenerife for all oxides except $\mathrm{TiO}_{2}$. As is the case for JM, when compared with Tenerife 
lavas with the same $\mathrm{MgO}$ content, nearly all of the martian rocks plotted in Fig. 3 have substantially lower $\mathrm{TiO}_{2}$ contents than the Tenerife lavas, and this low $\mathrm{TiO}_{2}$ appears to be a characteristic of martian rocks generally. Nevertheless, even the $\mathrm{TiO}_{2}$ content of $\mathrm{JM}$ is not outside the range of fractionated terrestrial alkaline igneous rock compositions (Fig. S7a), and both JM and non-alkaline martian rocks overlap with terrestrial tholeiites in $\mathrm{TiO}_{2}-\mathrm{MgO}$ space (Fig. S7b). Although JM is slightly elevated in total alkalis relative to the Tenerife trend (Fig. 2) and at the upper end of a field defined by mugearite lavas (reflecting JM's high $\mathrm{Na}_{2} \mathrm{O}$ content; Figs. 3f, S5f), terrestrial alkaline suites span a wide range of total alkali contents at a given silica (or $\mathrm{MgO}$ ) content, with some being lower than JM [e.g., St. Helena, (25)] and others being higher [e.g., Tristan da Cunha, (25)].

The chemical similarity between JM and terrestrial igneous rocks is surprising given that the chemical compositions of SNC meteorites and of igneous rocks analyzed using APXS on the surface of Mars (after correction for or removal by brushing or abrasion of surface-correlated components such as dust) differ systematically in many respects from those of terrestrial igneous rocks [(e.g., 26, 27); see also (21)]. These distinctions remain even when martian meteorites are compared with Fe-rich terrestrial lavas (28). However, even JM's Fe/Mn ratio is within the range of comparable terrestrial igneous rocks [Fig. S8; terrestrial and martian bulk rock and olivine and pyroxene Fe/Mn ratios have historically been considered diagnostic of each planet, (29-32)]. Overall, were JM found on Earth, we would be hard pressed to tell from its whole-rock chemical composition that it is martian. In the discussion below, we use the fact that JM plots essentially on the alkaline rock series from Tenerife (Figs. 2, 3) as an aid to understanding one possible model for its petrogenesis.

Based on the differences in $\mathrm{S}$ and $\mathrm{Cl}$ contents from undisturbed $v s$. physically abraded martian rock surfaces, it is likely that much of the $\mathrm{S}$ and $\mathrm{Cl}$ in the APXS analysis of JM 
reflects a surficial component such as dust [after abrasion, $\mathrm{SO}_{3}$ and $\mathrm{Cl}$ contents of Gusev crater rocks/outcrops generally drop by $\sim 40-90 \%,(10)]$. However, there are haüynebearing terrestrial lavas, historically called "tahitites" (33), with major-element compositions broadly similar to JM and with elevated $\mathrm{S}$ and $\mathrm{Cl}$ contents. Analyses of such haüyne-bearing lavas (containing $50-58$ wt. $\% \mathrm{SiO}_{2}$ on a volatile-free basis) from the Georoc database (25) have 0.6-2.4 wt. \% $\mathrm{SO}_{3}$ and up to $0.8 \mathrm{wt} . \% \mathrm{Cl}$ [and some phonolitic lavas from Tenerife contain haüyne, (e.g., 34)]. Thus, although it cannot be quantified at this time, it is possible that non-negligible amounts of the $\mathrm{S}$ and $\mathrm{Cl}$ in the $\mathrm{JM}$ analysis are indigenous to the magma from which it formed rather than a secondary, surface-correlated feature.

\section{Petrogenesis of JM:}

Hypotheses for the origins of igneous rocks rarely rely on isolated chemical compositions but are constrained by field relations, petrography, and the compositional trends defined by related rocks. We lack these data for JM, but we are able to say with some confidence what its compositional features would signify if it formed by processes similar to those that have produced comparable terrestrial rocks. Although an infinite number of petrogenetic models could be constructed to account for a single rock composition such as JM, we emphasize again the strong compositional correspondence between JM and terrestrial mugearites (including its position close to the liquid-line-of-descent of Tenerife magmas). This correspondence provides a plausible context for interpreting the composition of JM and is at least permissive that the petrogenetic processes responsible for the compositional trends observed in these terrestrial lavas could be applicable to the evolution of JM.

Evolved terrestrial alkaline rocks including mugearites are generally produced by extensive crystal fractionation of alkaline or transitional magmas. Although in some cases 
this fractionation appears to occur in the upper mantle based on the presence of peridotite xenoliths in some mugearites and related rocks (35-37), it more commonly occurs in crustal magma chambers or at even shallower depth within a volcanic edifice (e.g., 15, 16, 38). With this in mind, we used $\operatorname{MELTS}(39,40)$ to simulate fractional crystallization of a primitive Tenerife melt composition over a range of pressures (1-6000 bar), water concentrations (0-3 wt. \%), and oxygen fugacities (QFM-1 to QFM+2).

A crucial constraint on the fractionation required to explain the trend of Tenerife magmas is the monotonic increase in the $\mathrm{Al}_{2} \mathrm{O}_{3}$ contents of the observed rocks with decreasing $\mathrm{MgO}$ content (at least down to 2 wt. \% MgO). As shown by MELTS calculations (Fig. 4), this monotonic change all the way down to $2 \mathrm{wt} \% \mathrm{MgO}$ cannot be produced by fractionation from a dry primitive basanite at $1 \mathrm{bar}$ - under these conditions, plagioclase saturation is reached at $\sim 7.8$ wt. $\% \mathrm{MgO}$, long before sufficient fractionation has occurred to produce residual liquids with $\mathrm{MgO}$ contents in the $2 \%$ range. As a result, residual liquids with $\mathrm{MgO}$ contents like those of JM (4-5 wt. \%) contain only $14-15$ wt. $\% \mathrm{Al}_{2} \mathrm{O}_{3}$ (i.e., less than the $\sim 15-19$ wt. $\% \mathrm{Al}_{2} \mathrm{O}_{3}$ in $\mathrm{JM}$ and terrestrial mugearites; Fig. S5). In order to produce residual melts with monotonically increasing $\mathrm{Al}_{2} \mathrm{O}_{3}$ contents at these $\mathrm{MgO}$ contents, plagioclase crystallization must be suppressed-it is well known that elevated water contents and elevated total pressure individually or together can suppress plagioclase crystallization (41-44). MELTS calculations confirm this: Starting with the primitive basanite at 4 kbar dry, the MELTS calculations predict that plagioclase saturation is indeed delayed relative to 1 bar crystallization, only being reached at liquid $\mathrm{MgO}$ contents of $\sim 4.8$ wt. \% (Fig. 4); in contrast, and as expected, clinopyroxene saturates earlier in the fractionation sequence relative to the calculated trend at 1 bar (Fig. 4). With the addition of $1 \mathrm{wt} . \% \mathrm{H}_{2} \mathrm{O}$ to the parental basanite at $4 \mathrm{kbar}$, plagioclase crystallization is even further suppressed; Fig. 4 shows that the model fractionation sequence only reaches plagioclase saturation at $\sim 2 \mathrm{wt} . \% \mathrm{MgO}$ and that clinopyroxene 
appearance is also somewhat delayed relative to the 4 kbar anhydrous calculation. Note that the points along the model liquid-lines-of-descent that mark the appearance of Ferich spinel are little affected over the ranges in pressure and water content investigated here (Figs. 4, S11). These calculations were all done at an $f \mathrm{O}_{2}$ fixed relative to the QFM buffer [i.e., at $\mathrm{QFM}+1$, an $f \mathrm{O}_{2}$ consistent with estimates from Fe-Ti oxides in Tenerife volcanics (38)]; under more oxidizing or reducing conditions Fe-rich spinel would appear earlier or later in the calculated liquid-line-of-descent.

Although the 4 kbar dry simulation of the Tenerife parental basanite suppresses plagioclase crystallization sufficiently to account for the high $\mathrm{Al}_{2} \mathrm{O}_{3}$ contents of $\mathrm{JM}$ and rocks from Tenerife with 4-5 wt. \% $\mathrm{MgO}$, the simulated fractionation trend provides a poor fit to the more evolved lavas from Tenerife (Fig. 4), which would require even further suppression of plagioclase crystallization to account for their even higher $\mathrm{Al}_{2} \mathrm{O}_{3}$ contents. In contrast, the 4 kbar simulation with 1 wt. $\% \mathrm{H}_{2} \mathrm{O}$ in the parent magma reproduces the observed trend in $\mathrm{Al}_{2} \mathrm{O}_{3}$ all the way down to $\sim 2$ wt. \% $\mathrm{MgO}$ (Fig. 4), reproduces reasonably well the trends of all of the other oxides (Fig. S11), and matches the water contents measured in melt inclusions from Tenerife lavas with phonolitic compositions (45). The simulation at $4 \mathrm{kbar}$ with $1 \mathrm{wt} . \% \mathrm{H}_{2} \mathrm{O}$ in the parental basanite magma, which reaches the $\mathrm{MgO}$ content of $\mathrm{JM}$ after $\sim 57 \%$ crystallization and with $\sim 2.3$ wt. $\% \mathrm{H}_{2} \mathrm{O}$ in the JM-like residual melt, provides the best fit to the overall Tenerife trend (see Fig. S12, which illustrates the degree to which the calculated liquid-lines-of-descent reproduce the compositional trend of the lavas as pressure and initial water content vary). Similar calculations by Beier et al. (46) using lavas from Sete Cidades volcano, Sao Miguel (in the Azores) produced comparable results, requiring 0.5 wt. $\% \mathrm{H}_{2} \mathrm{O}$ in the parent liquid and fractionation at $5 \mathrm{kbar}$ to reproduce the overall observed liquid-line-ofdescent. 
The point of these simulations and their comparisons to JM and to the overall Tenerife liquid-line-of-descent (Figs. 4, S11) is not whether a precise match can be achieved. As good as they are, MELTS calculations are no substitute for experiments in determining a fractionation path and its sensitivity to pressure, water content, other volatiles, and oxygen fugacity [e.g., the calculated best-fit liquid-line-of-descent does not include amphibole and yet amphibole is present in the more fractionated Tenerife lavas (38)]. Moreover, it is unreasonable to suppose that JM's bulk composition represents exactly a liquid composition or that the parent magma would be identical in all respects to one from Tenerife (indeed, as pointed out above, the $\mathrm{Na}_{2} \mathrm{O}$ and $\mathrm{TiO}_{2}$ contents of $\mathrm{JM}$ and the Tenerife trend do not match perfectly). The point of the comparison is simply that the overall trend of the Tenerife liquid-line-of-descent is captured reasonably well only if plagioclase crystallization is suppressed relative to low-pressure, dry conditions and that several kilobars of pressure (corresponding to up to a few tens of kilometers depth within Mars) and water contents in the parent magma of order $1 \mathrm{wt} . \% \mathrm{H}_{2} \mathrm{O}$ do this successfully. If the pressure were less than $\sim 1 \mathrm{kbar}$, the fits worsen because under these conditions not enough water is able to dissolve in the melt to suppress plagioclase crystallization sufficiently to reproduce the monotonic enrichment with fractionation observed in $\mathrm{Al}_{2} \mathrm{O}_{3}$ among the most highly evolved rocks from Tenerife. Nevertheless, as stated above, the 4 kbar anhydrous trend provides a reasonable fit to the JM compositions, and thus we cannot say with any confidence that the fractionation of JM requires $\sim 1$ wt. $\% \mathrm{H}_{2} \mathrm{O}$ in the parental magma; indeed, although the model 1 bar trend at 4-5 wt. \% $\mathrm{MgO}$ is low in $\mathrm{Al}_{2} \mathrm{O}_{3}$ relative to $\mathrm{JM}$, if we allowed for moderate plagioclase accumulation in $\mathrm{JM}$ or increased uncertainties in JM's stated composition, even fractionation under these conditions could not be ruled out. However, we can say with reasonable certainty that terrestrial magmas that are compositionally similar to JM require fractionation at both elevated pressure and water content. One way to resolve this for JM would be if more evolved alkaline lavas are discovered on Mars and if these, like comparable terrestrial 
magmas, have even higher $\mathrm{Al}_{2} \mathrm{O}_{3}$ contents than JM. If so, this would strengthen the requirement for a moderate pressure, hydrous liquid-line-of-descent to explain JM since it would be difficult to match such elevated $\mathrm{Al}_{2} \mathrm{O}_{3}$ contents at low pressure or without dissolved water. Although they are not definitive, the pits on the surface of JM (Fig. 1) may be wind-eroded vesicles, and this would be consistent with hydrous fractionation. Likewise, the inferred water content of JM ( $\sim 2$ wt. \% if we accept the analogy with Tenerife magmas) is also consistent with previous efforts to constrain the petrogenesis of martian magmas, which have concluded that they contained up to several wt. \% dissolved $\mathrm{H}_{2} \mathrm{O}$ (47-49). Measurements of water in amphiboles in Chassigny (50) also suggest that the mantle source region of Chassigny may have been relatively wet. In contrast, however, Filiberto and Treiman (51) have argued that magmas parental to the martian meteorites were chlorine-rich and water-poor, i.e., $<0.3$ wt. $\% \mathrm{H}_{2} \mathrm{O}$. Although extensive work has been done on the partitioning of $\mathrm{Cl}$ between silicate melts and $\mathrm{H}_{2} \mathrm{O}$-rich fluids (e.g., 52, 53), it is not clear from available experimental data (e.g., 54) whether $\mathrm{Cl}$ suppresses plagioclase crystallization to a similar degree as $\mathrm{H}_{2} \mathrm{O}$.

In order to explore whether any known martian igneous rocks could represent acceptable parent liquids for JM, we also performed MELTS calculations on Backstay, Humboldt Peak, and NWA 7034. In these cases, because there is no suite of lavas to constrain the liquid-line-of-descent as in the case of the Tenerife calculations, we only used MELTS simulations to determine whether parent liquids corresponding to these known martian igneous rocks could fractionate to produce a residual liquid corresponding to JM, and if so, what conditions would be required. None of the martian rock compositions have high enough alkali contents to produce a close match to JM under any conditions (Supplementary Materials; Figs. S13-S24). However, if we arbitrarily increased the alkali contents by an amount such that on fractionation the modeled alkali contents of the fractionated liquids matched those of $\mathrm{JM}$ at an $\mathrm{MgO}$ content of $\sim 4-5$ wt. \%, the alkali- 
enriched Backstay composition could produce a reasonable approximation of JM after a few tens of percent crystal fractionation (although we note that the required arbitrary increases in alkalis are not trivial).

\section{Origins of alkaline magmas on Mars:}

We have no constraints on conditions required on Mars to produce the parental alkaline or transitional liquids from which JM is presumed to have evolved by extensive crystal fractionation. On Earth, such parental magmas have been attributed to a variety of conditions and processes, including melting of lherzolite $+\mathrm{CO}_{2} \pm \mathrm{H}_{2} \mathrm{O}$ at elevated pressures (e.g., 55, 56, 57); melting of metasomatized lithospheric mantle (e.g., 58, 59, 60); and melting of pyroxenites and amphibolites (e.g., 60, 61, 62). Models for the origin of previously described alkaline and transitional martian magmas have called upon melting of a more alkali-rich mantle source [relative to that of the shergottites, (63)] and/or hydrous fractional crystallization of transitional magmas at pressures of a few kilobars (64).

Ratios of moderately volatile alkalis to refractory lithophile elements in martian rocks have been used to infer that the primitive martian mantle was richer in $\mathrm{Na}$ and $\mathrm{K}$ than the terrestrial mantle by as much as a factor of two (e.g., 65, 66-69). On this basis alone, although few alkaline martian rocks have been documented thus far, it would not be surprising if alkaline magmas derived from relatively alkali-rich sources (either primitive martian mantle or mantle that has been metasomatized by low-degree melts of relatively primitive mantle) were more common on Mars than they are on Earth [on Earth, alkaline lavas are rare from a planetary perspective, representing an estimated $<1$ vol. $\%$ of terrestrial igneous rocks, (e.g., 70)]. Note that based on trace-element and radiogenicisotope ratios, the average sources of most shergottite meteorites are inferred to have been depleted and in some cases highly depleted (i.e., melts have been extracted from 
these source regions prior to the melting events that produced the shergottites). This depletion of their sources could explain the low alkali (and alumina) contents characteristic of the shergottites. If the liquids extracted during these earlier depletion events were enriched in alkalis (i.e., because they formed as partial melts of relatively primitive martian mantle) and were emplaced into the crust and lithospheric mantle, they could have enriched and metasomatized portions of the martian mantle. Melting of such enriched sources might then have produced the magmas parental to alkaline rocks such as JM. The overall K-rich nature of analyzed rocks from the MSL mission thus far (71) could reflect the presence of such an enriched region in the mantle underlying Gale Crater.

Acknowledgments: Paula Antoshechkin provided insight concerning several aspects of MELTS and Sarah Lambart ran early MELTS calculations and provided initial compilations of terrestrial alkaline lavas. We would also like to thank two anonymous referees for constructive reviews of the manuscript and the Mars Science Laboratory Project engineering and management teams for their efforts in making the mission such a success. This work was supported by grants from the National Science Foundation, the National Aeronautics and Space Administration, the Canadian Space Agency, and the Centre National d'Études Spatiales. 


\section{Figure Captions:}

Fig. 1. Raw image of Jake_Matijevic taken by the Left Mastcam (0046ML0212000000E1) with overlain MAHLI at 26.9, 6.9, and $4.4 \mathrm{~cm}$ offsets from the front of the lens. The MAHLI projection on the left was taken at $4.4 \mathrm{~cm}$ (0047MH0011002000E1). Shadowing by the turret reduced the contrast in the inset MAHLI images, causing color differences with the Mastcam image. The filled red circles labeled JM1 and JM2 indicate the locations of the two APXS spots $(1.7 \mathrm{~cm}$ diameter). ChemCam raster spots are represented by yellow open circles; actual spot sizes are $\sim 0.45 \mathrm{~mm}$. Credit: NASA/JPL-Caltech/MSSS.

Fig. 2. Alkali-silica diagram. Compositional boundaries and rock names are from (72); the mugearite field is shown in blue. The dashed curve shows the alkaline/subalkaline boundary curve from Irvine and Baragar (23). (a) Colored symbols (see legend) show the three JM analyses (Table 1), normalized to $100 \mathrm{wt} . \%$ without $\mathrm{SO}_{3}, \mathrm{Cl}$, and trace elements; basaltic martian meteorites [the shergottite "Los Angeles" $(9,73)$ and the basaltic breccia NWA 7034 (74) are shown as distinct symbols]; martian rocks analyzed by the MERs $(10,75-77)$ and interpreted as igneous (including volcaniclastics); and the two soil-free Pathfinder compositions calculated by Wänke et al. (11) and Foley et al. (12). Errors bars associated with the NWA 7034 and Pathfinder compositions reflect either $1 \sigma$ uncertainties (NWA 7034) or the projection methods used to calculate a "soil-free" composition (Pathfinder). Note that NWA 7034 maybe a polymict breccia $(78,79)$. Larger filled colored circles labeled "Adirondack" through "Champagne" in the legend denote specific Mars surface rocks analyzed by the MERs. (b) Comparison of the three JM analyses (Table 1) with lavas from Tenerife in the Canary Islands (25) and with terrestrial lavas that have been called mugearites, including some from Tenerife (25). Only Georoc (25) analyses with oxides sums between 97 and 102.5 wt. \% are plotted and all have been normalized to 100 wt. $\%$ on a volatile-free (including sulfur and chlorine) basis.

Fig. 3. Oxide-MgO variation diagrams (wt. \%) comparing Tenerife lavas, the three Jake_M compositions (Table 1), and various martian igneous rock compositions (see caption to Fig. 2 for references and filters applied to the Tenerife lava compositions). (a) $\mathrm{SiO}_{2}-\mathrm{MgO}$; (b) $\mathrm{TiO}_{2}-\mathrm{MgO}$; (c) $\mathrm{Al}_{2} \mathrm{O}_{3}-\mathrm{MgO}$; (d) $\mathrm{FeO}^{*}-\mathrm{MgO}$; where $\mathrm{FeO}^{*}$ denotes all $\mathrm{Fe}$ as $\mathrm{FeO}$; (e) $\mathrm{CaO}-\mathrm{MgO}$; (f) $\mathrm{Na}_{2} \mathrm{O}-\mathrm{MgO}$; (g) $\mathrm{K}_{2} \mathrm{O}-\mathrm{MgO}$; (h) $\mathrm{P}_{2} \mathrm{O}_{5}-\mathrm{MgO}$. Error bars as in Fig. 2.

Fig. 4. (a) $\mathrm{Al}_{2} \mathrm{O}_{3}-\mathrm{MgO}$ and (b) $\mathrm{CaO}-\mathrm{MgO}$ variation diagrams comparing Tenerife lavas, the three Jake_M composition, and colored curves showing three MELTS fractional crystallization calculations described in the text (1 bar, anhydrous; 4 kbar, anhydrous; $4 \mathrm{kbar}, 1 \mathrm{wt} . \%$ water in the parental liquid composition; all three calculations were done at $f \mathrm{O}_{2}=\mathrm{QFM}+1$ where QFM is the quartz-fayalite-magnetite buffer). Phase abbreviations: $\mathrm{pl}=$ plagioclase, $\mathrm{Fe}-\mathrm{sp}=$ magnetite-rich spinel, $\mathrm{cpx}=$ clinopyroxene, $\mathrm{ol}$ $=$ olivine, $\mathrm{Cr}$-sp $=$ chromite-rich spinel; arrows point to the appearance of phases along 
the MELTS-modeled liquid-lines-of-descent. Compositions of the Tenerife lavas are from (25, see caption to Fig. 2); starting composition for the MELTS modeling is the average of Tenerife lavas with $12-13.5 \mathrm{wt} . \% \mathrm{MgO}$ and is reported in the Supplementary Materials along with further details of the MELTS calculations. 


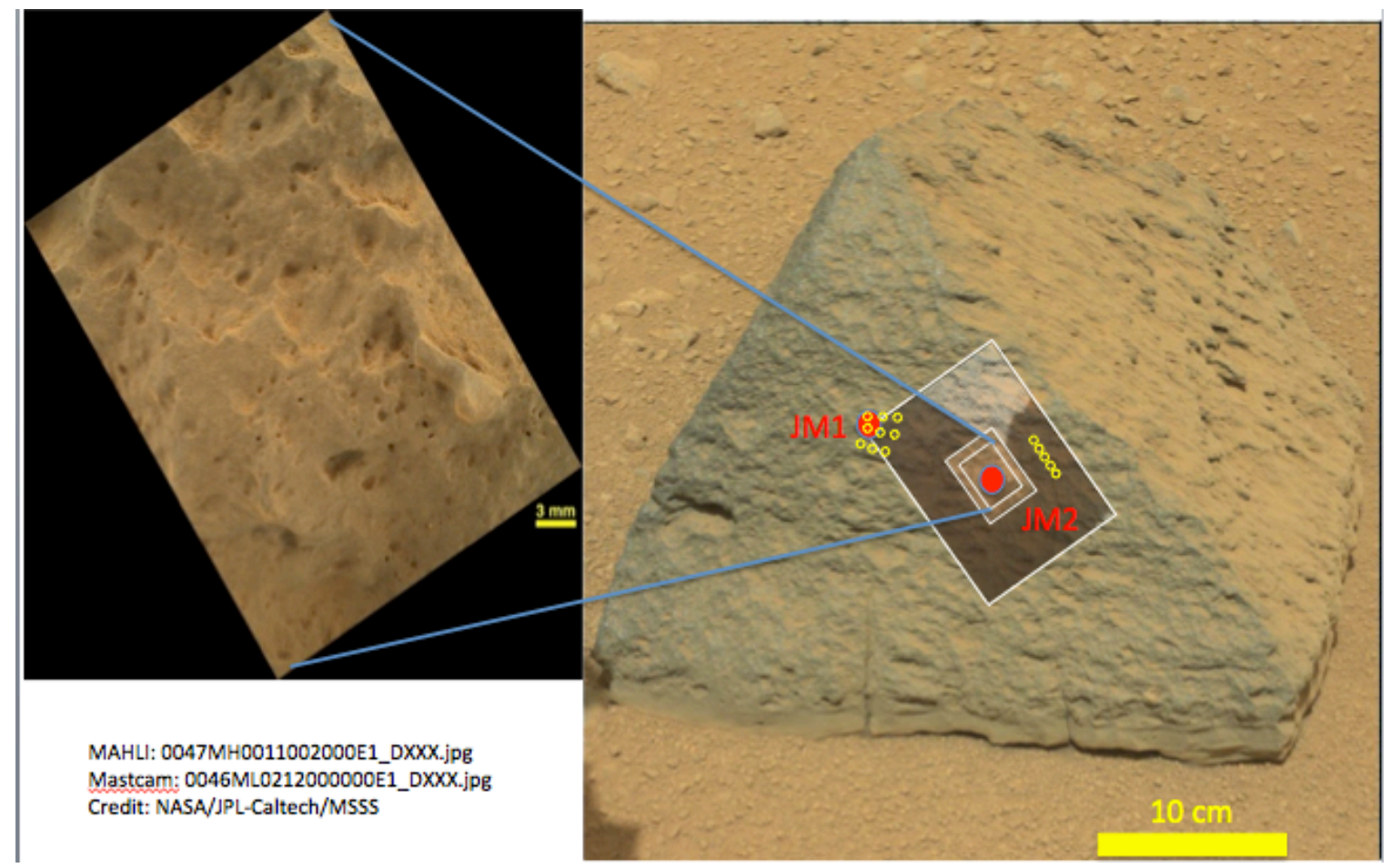

Fig. 1. 

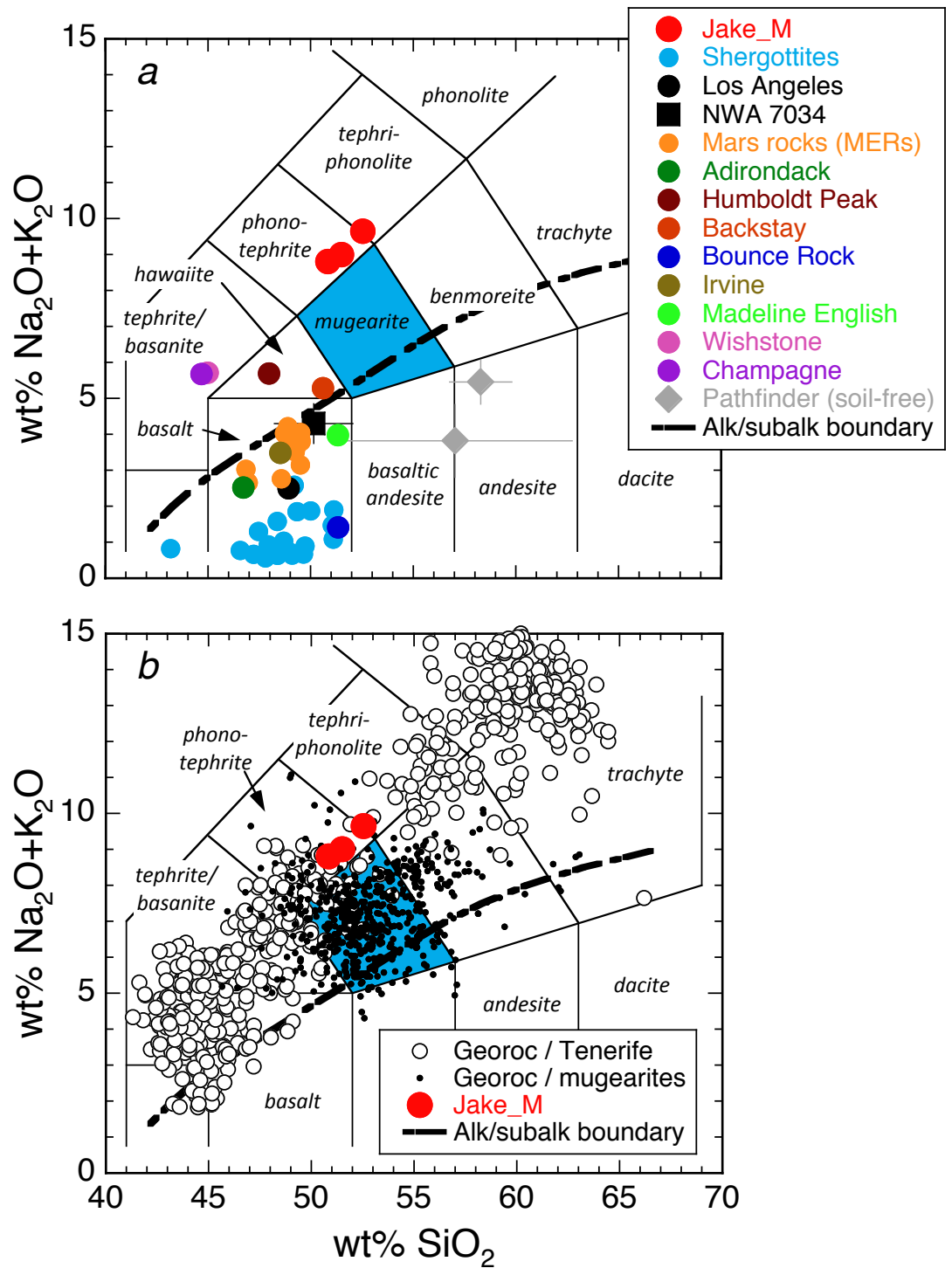

Fig. 2. 

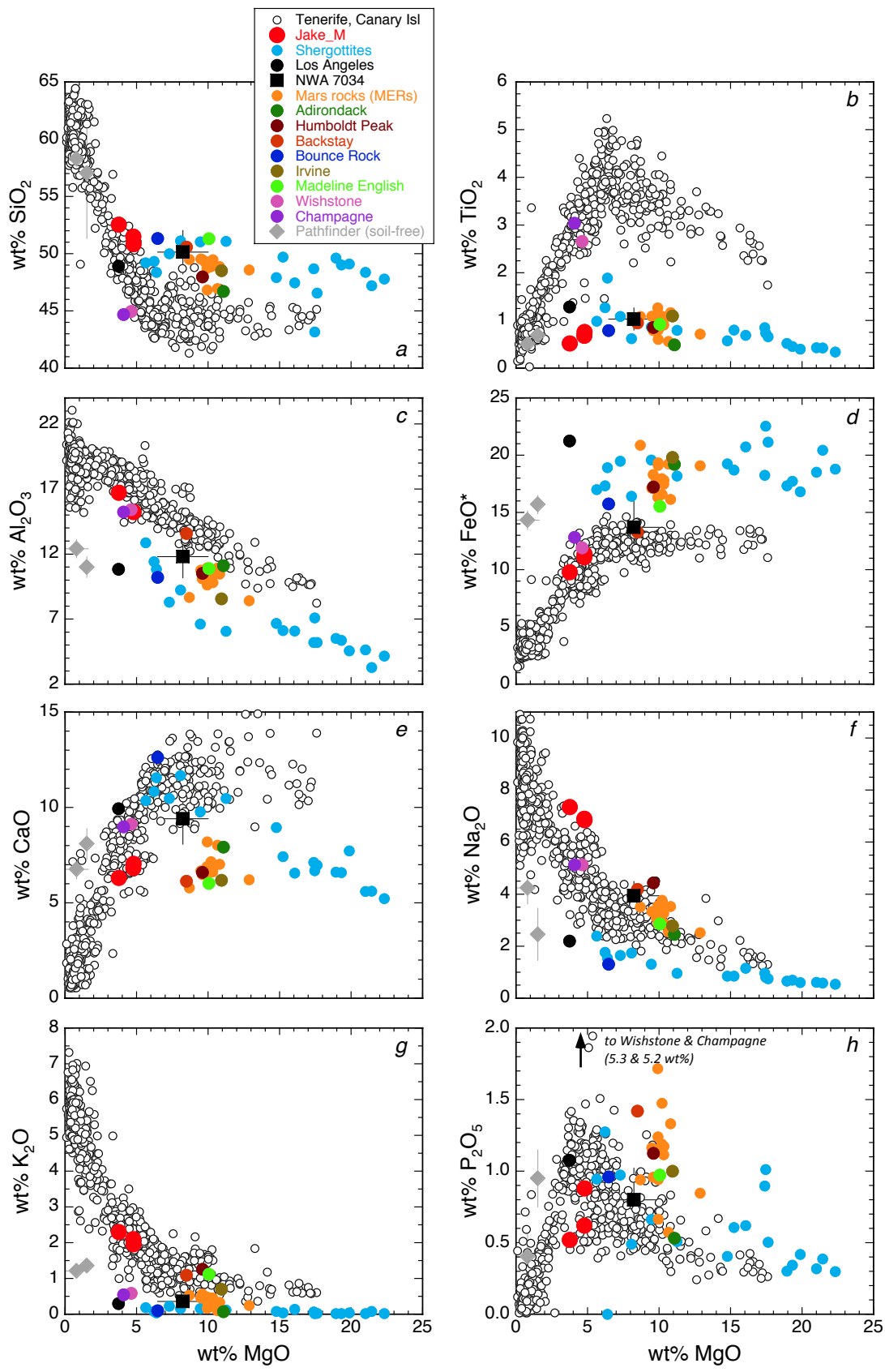

Fig. 3 

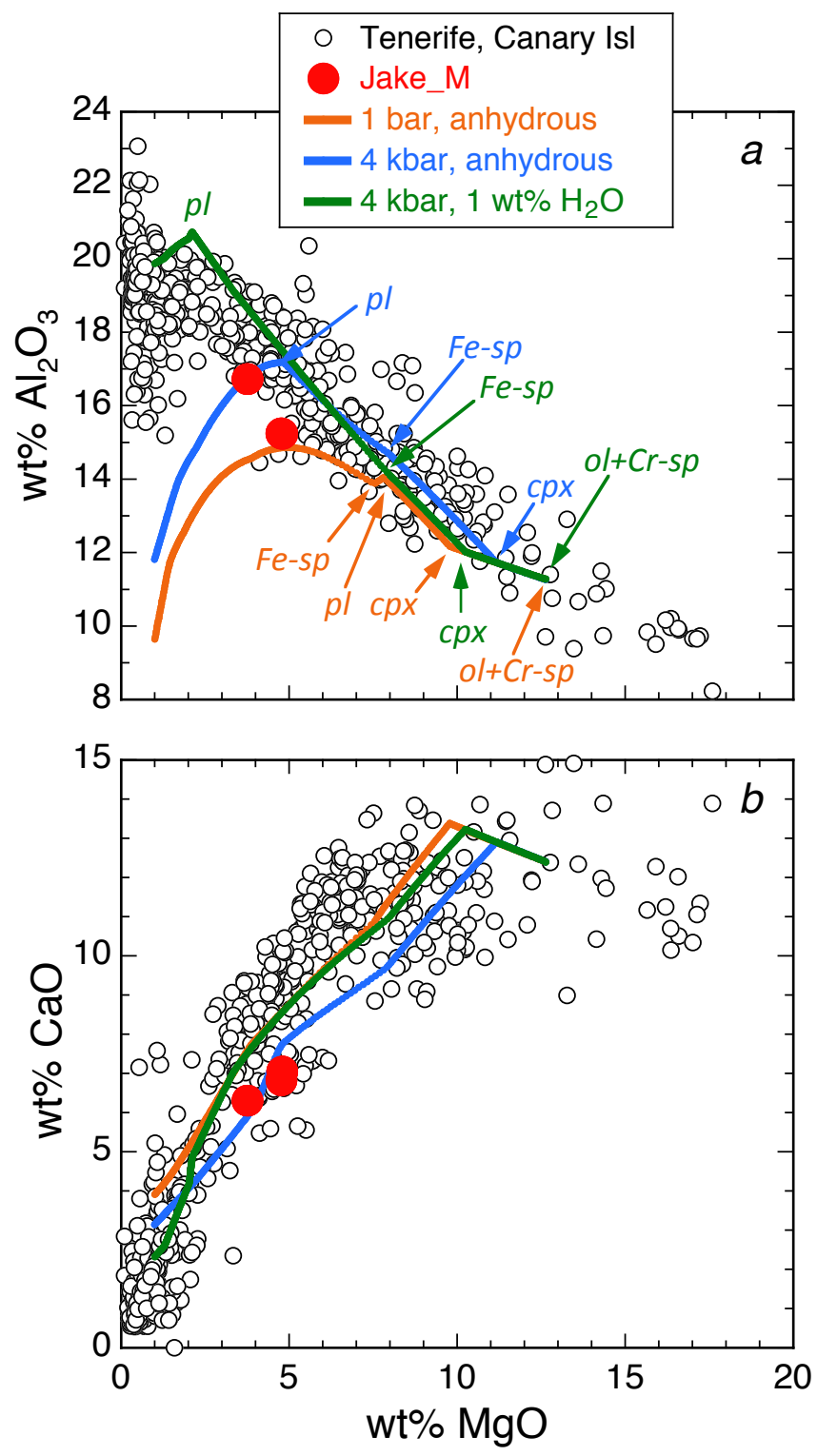

Fig. 4. 
Table 1. Composition and CIPW norms of Jake_M

\begin{tabular}{|c|c|c|c|c|c|c|c|}
\hline $\mathrm{wt} \%$ & JM1 & JM2 & JM2n & Average & Norm & $0 \mathrm{Fe}^{3+}$ & $0.15 \mathrm{Fe}^{3+}$ \\
\hline $\mathrm{SiO}_{2}$ & $50.7(6)$ & $49.3(9)$ & $48.9(5)$ & $51.6(9)$ & $\mathrm{P} 1$ & 32.3 & 34.4 \\
\hline $\mathrm{TiO}_{2}$ & $0.50(3)$ & $0.65(6)$ & $0.73(3)$ & $0.65(12)$ & Or & 12.5 & 12.5 \\
\hline $\mathrm{Al}_{2} \mathrm{O}_{3}$ & $16.1(5)$ & $14.6(7)$ & $14.6(2)$ & $15.7(9)$ & $\mathrm{Ne}$ & 17.4 & 16.2 \\
\hline $\mathrm{Cr}_{2} \mathrm{O}_{3}$ & $0.03(1)$ & $0.09(3)$ & $0.04(1)$ & $0.04(1)$ & Cpx & 20.0 & 19.8 \\
\hline $\mathrm{FeO}$ & $9.44(7)$ & $10.61(11)$ & $10.94(9)$ & $10.8(8)$ & $\mathrm{Ol}$ & 14.9 & 11.6 \\
\hline $\mathrm{MnO}$ & $0.14(1)$ & $0.17(2)$ & $0.21(1)$ & $0.18(4)$ & Ilm & 1.2 & 1.2 \\
\hline $\mathrm{MgO}$ & $3.6(4)$ & $4.6(7)$ & $4.60(12)$ & $4.4(6)$ & $\mathrm{Mt}$ & & 2.6 \\
\hline $\mathrm{CaO}$ & $6.09(7)$ & $6.54(11)$ & $6.78(8)$ & $6.7(4)$ & Ap & 1.6 & 1.6 \\
\hline $\mathrm{Na}_{2} \mathrm{O}$ & $7.1(3)$ & $6.6(5)$ & $5.59(14)$ & $7.0(3)$ & Chr & 0.06 & 0.06 \\
\hline $\mathrm{K}_{2} \mathrm{O}$ & $2.22(4)$ & $2.01(6)$ & $1.89(3)$ & $2.12(17)$ & $\%$ An & 15.2 & 14.2 \\
\hline $\mathrm{P}_{2} \mathrm{O}_{5}$ & $0.50(7)$ & $0.60(12)$ & $0.85(4)$ & $0.68(19)$ & $\mathrm{Mg} \#$ ol & 43.0 & 49.7 \\
\hline $\mathrm{SO}_{3}$ & $2.46(9)$ & $3.05(16)$ & $2.81(8)$ & & $\mathrm{Mg \#}$ & 43.0 & 49.7 \\
\hline $\mathrm{Cl}$ & $0.88(3)$ & $1.03(5)$ & $0.95(3)$ & & $(\mathrm{Mg} \#)^{\mathrm{ol}}$ & 68.0 & 71.6 \\
\hline Total & 99.80 & 99.80 & 99.90 & & & & \\
\hline Ni (ppm) & $22(17)$ & n.d. & $59(17)$ & & & & \\
\hline $\mathrm{Zn}(\mathrm{ppm})$ & $216(13)$ & $341(25)$ & $318(15)$ & & & & \\
\hline $\mathrm{Br}(\mathrm{ppm})$ & $88(8)$ & $94(11)$ & $107(7)$ & & & & \\
\hline Temp & $-3^{\circ} \mathrm{C}$ & $-2{ }^{\circ} \mathrm{C}$ & $-55^{\circ} \mathrm{C}$ & & & & \\
\hline Duration & $30 \mathrm{~min}$ & $12 \mathrm{~min}$ & $30 \mathrm{~min}$ & & & & \\
\hline
\end{tabular}

1 and 2 after JM indicate the two locations analyzed on the rock (see Fig. 1), 2n indicates the nighttime analysis on spot 2. Values in parentheses for JM1, JM2, and JM2n are assessments of $2 \sigma$ uncertainty based on counting statistics and data reduction in terms of the least units cited, i.e., $50.7(6)=50.7 \pm 0.6$; for further details see (2); n.d. $=$ not detected. The average represents the unweighted mean of the three compositions each normalized to $100 \%$ excluding $\mathrm{SO}_{3}, \mathrm{Cl}$, and trace elements; values in parentheses are the standard deviations. Norm $=$ normative minerals in wt. \%; the column labeled $0 \mathrm{Fe}^{3+}$ shows the calculated CIPW norm assuming that all $\mathrm{Fe}$ in the average bulk composition is $\mathrm{Fe}^{2+}$; the column labeled $0.15 \mathrm{Fe}^{3+}$ shows the calculated CIPW norm assuming $\mathrm{Fe}^{3+} /($ total $\mathrm{Fe})=0.15$; normative constituents: $\mathrm{Pl}=$ plagioclase (sum of normative anorthite and albite); $\mathrm{Or}=$ orthoclase; $\mathrm{Ne}=$ nepheline; $\mathrm{Cpx}=$ sum of normative diopside and hedenbergite; $\mathrm{Ol}=$ sum of normative forsterite and fayalite; $\mathrm{Ilm}=$ ilmenite; $\mathrm{Mt}=$ magnetite; $\mathrm{Ap}=$ apatite; $\mathrm{Chr}=$ chromite; $\% \mathrm{An}=100 \times \mathrm{Ca} /(\mathrm{Ca}+\mathrm{Na})_{\text {molar }}$ in the normative plagioclase; $\mathrm{Mg \#}$ ol and $\mathrm{Mg} \# \mathrm{cpx}=100 \times \mathrm{Mg} /(\mathrm{Mg}+\mathrm{Fe})_{\text {molar }}$ in normative olivine and high-Ca pyroxene, respectively; $(\mathrm{Mg} \#)^{\mathrm{ol}}=100 \times \mathrm{Mg} /(\mathrm{Mg}+\mathrm{Fe})_{\text {molar }}$ of the liquidus olivine calculated using an ol-liq $\mathrm{K}_{\mathrm{D}, \mathrm{Fe}{ }^{2+} \mathrm{Mg}}$ of $0.34(80,81)$. 


\title{
Supplementary Materials for
}

\section{The Petrochemistry of Jake_M: A Martian Mugearite}

\author{
E.M. Stolper ${ }^{1}$, M.B. Baker ${ }^{1}$, M.E. Newcombe ${ }^{1}$, M.E. Schmidt ${ }^{2}$, A.H. Treiman ${ }^{3}$, A. Cousin ${ }^{4,5}$, M.D. Dyar ${ }^{6}$, M.R. Fisk ${ }^{7}$, \\ R. Gellert ${ }^{8}$, P.L. King ${ }^{9}$, L. Leshin ${ }^{10}$, S. Maurice ${ }^{5}$, S.M. McLennan ${ }^{11}$, M.E. Minitti ${ }^{12}$, G. Perrett ${ }^{8}$, S. Rowland ${ }^{13}$, V. \\ Sautter $^{14}$, R.C. Wiens ${ }^{4}$, and the MSL Science Team. \\ correspondence to: ems@gps.caltech.edu
}

Includes:

Materials and Methods

Supplementary Text

Figs. S1 to S24 


\section{Supplementary Text}

Here we present supporting materials for the article: The Petrochemistry of Jake_M: A Martian Mugearite. In particular, we provide a more complete discussion and supporting figures (S1-S4) for the LIBS analyses. We also compare Jake_M (JM) to terrestrial igneous rocks and show the close compositional resemblance of JM to terrestrial mugearites and phonotephrites (Figs. S5, S6). We compare the composition of JM to the compositions of terrestrial lavas in terms of $\mathrm{TiO}_{2}$ vs. $\mathrm{MgO}$ (Fig. S7) and $\mathrm{Fe} / \mathrm{Mn}$ vs. $\mathrm{MgO}$ (Fig. S8). Data from $(10,75,76)$ are also used to demonstrate how the $\mathrm{SO}_{3}$ and $\mathrm{Cl}$ contents of "unbrushed" or "as is" rocks analyzed by the Mars Exploration Rovers (MERs) compare to the sulfur and chlorine contents of the "unbrushed" JM analyses (Fig. S9). We also compare unbrushed and physically abraded compositions from the same outcrops (both normalized to $100 \mathrm{wt}$ \% on a $\mathrm{SO}_{3}$ - and $\mathrm{Cl}$-free basis) analyzed by the Spirit rover to the three normalized JM analyses (Fig. S10) to demonstrate that, for a given rock/outcrop, the major element spread in the unbrushed and abraded analyses, once renormalized, is comparable to the spread in the three JM analyses. Additionally, we provide a more detailed discussion of the MELTS calculations as well as a complete set of oxide- $\mathrm{MgO}$ variation diagrams (for $\mathrm{SiO}_{2}, \mathrm{TiO}_{2}, \mathrm{Al}_{2} \mathrm{O}_{3}, \mathrm{FeO} *, \mathrm{CaO}, \mathrm{Na}_{2} \mathrm{O}, \mathrm{K}_{2} \mathrm{O}$, and $\mathrm{P}_{2} \mathrm{O}_{5}$ ) showing the Tenerife Island lavas, JM, and selected MELTS fractionation paths (Fig. S11). A contoured misfit map (Fig. S12) shows the extent to which MELTS calculations at different pressures and with varying initial water contents match the overall fractionation trend of the Tenerife lavas. A similar set of figures shows MELTS fractional crystallization calculations (in oxide- $\mathrm{MgO}$ space) and misfit contour maps where the starting compositions were various known martian rocks (surface rocks from Gusev Crater, and the NWA 7034 meteorite), both with and without arbitrarily increased $\mathrm{Na}_{2} \mathrm{O}$ and $\mathrm{K}_{2} \mathrm{O}$ contents (Figs. S13-S24). The purpose of these calculations was to test whether known martian rock compositions could be viable parental liquids for JM. At the end of the Supplement, we list all MSL science team members and their institutional affiliations.

We note that in two previously presented abstracts of oral presentations that discussed the petrogenesis of JM $(82,83)$, the JM composition was compared to lavas from St. Helena, and not those from Tenerife. These two abstracts were based on a preliminary APXS data reduction of the raw JM analyses. Following a re-calibration of the APXS data, the composition of JM changed slightly and although the average of the new and old analyses overlap at $2 \sigma$, the St. Helena fractionation trend was not as good a match to the revised JM composition as it had been to the previous composition. For this reason, the compositions of St. Helena lavas have been replaced in this work by lavas from Tenerife Island. Nevertheless, it is important to stress that both terrestrial suites are alkaline and 
that the most successful MELTS calculations for both suites require moderate pressures and water contents.

\section{Materials and Methods}

Three APXS analyses of JM were obtained on two unbrushed areas $\sim 1.7 \mathrm{~cm}$ in diameter (JM1 and JM2) and separated by $\sim 7 \mathrm{~cm}$ (Fig. 1): JM1 was analyzed once during the day and JM2 was analyzed twice (at night and during the day). Results of the three analyses are listed in Table 1. The surface of JM was not brushed or abraded prior to analysis, so the APXS analyses include surface-correlated contributions, including adhering dust that likely contributes to the observed $\mathrm{S}$ and $\mathrm{Cl}$. Note that $\mathrm{Na}$ and $\mathrm{Mg}$ would be the major elements most affected in the APXS analyses by surface-correlated components since most emitted X-rays for $\mathrm{Na}$ and $\mathrm{Mg}$ originate in the outer $\sim 2$ to $3 \mu \mathrm{m}$ of the target (71, 84). However, experience with the MERs indicates that the characteristics of rock compositions are typically not obscured by surface components, and the levels of S in JM are lower than in most unbrushed analyses from the Exploration rovers (see The effect of surface components on Jake M's composition below), so the level of surface contamination and alteration are likely relatively minor (85). Moreover, successive LIBS shots on a single location gave no evidence of a surface coating or crust, but suggested instead a thin dust layer that was penetrated within 1-2 laser shots (3). Individual LIBS shots involved a spot size of $\sim 0.45 \mathrm{~mm}$ and a penetration depth of $\sim 0.5 \mu \mathrm{m}(86,87)$. Although the differences between the JM1 and JM2n analyses (the two long-duration analyses; Table 1) are small in an absolute sense, none of the concentrations except $\mathrm{Cr}_{2} \mathrm{O}_{3}$ overlap at the $2 \sigma$ level. This suggests heterogeneity on a $\mathrm{cm}$ scale - not unsurprising in a polymineralic igneous rock - and consistent with the observed variations between the LIBS analyses (albeit on a different length scale).

\section{ChemCam Analyses}

Fourteen locations were analyzed by ChemCam $(86,87)$ on JM with two sets of measurements $(3,88)$ : a 5-point line-scan with points separated by $\sim 6 \mathrm{~mm}$ on sol 45 while the target was at a distance of $3.8 \mathrm{~m}$, and a $3 \times 3$ raster (total of 9 LIBS points separated by $7 \mathrm{~mm}$ horizontally and $\sim 10 \mathrm{~mm}$ vertically) on sol 48 while the target was at a distance of $3.2 \mathrm{~m}$ (Figs. 1, S1). Thirty laser shots [spot size around 420-440 $\mu \mathrm{m}$; (89)] were directed at each analysis location, each providing a spectrum at successive depths to a maximum depth of $\sim 15 \mu \mathrm{m}$ inside the rock (87). The 420 spectra obtained from the fourteen LIBS analysis locations show that JM is heterogeneous at scales $>\sim 0.5 \mathrm{~mm}$ (and likely smaller), with the thirty spectra from each analysis location defining a separate compositional cluster in multi-dimensional component space. Four distinct end-member compositions were determined by subjecting 392 spectra (the first two spectra at each analysis location were excluded since they are most affected by surface dust) to an 
independent component analysis (ICA) algorithm. ICA involves a linear transformation that minimizes the statistical dependence between components, allowing spectra to be compared in the phase space of the most strongly varying components $(90,91)$. Different components can represent the spectral signature of a single element. Plots displaying ICA results show the correlation coefficients of the represented elements in arbitrary units. Figure S2 shows the Ti component versus the Ca component obtained from ICA. Most of the 28 spectra from each analysis location cluster together showing that for these elements the composition does not vary significantly with depth. We observe two main end members corresponding to analysis locations 1 and 2 (labeled JM_1 and JM_2 in Fig. S2). JM_2 is strongly associated with Ti, whereas JM_1 shows the lowest Ca. The other two end members are also labeled in Fig. S2: JM_10 is enriched in alkali elements (Fig. S3), whereas JM_14 shows higher Ca.

Figure S3 presents the four end members in the ultra-violet (UV) and part of the visible and near infrared (VNIR) spectral ranges. For this figure, the spectra from each analysis location were averaged over depth, which is justified in most cases given the similarity of most analysis points. Ti line intensities are low in JM_1 and JM_10. JM_1 and JM_2 (in red and green, respectively) also show weak Ca lines compared to JM_10 and JM_14 (in blue and black, respectively). JM_1 and JM_14 show stronger Mg signals than JM_2. This location (JM_2) shows almost no $\mathrm{Mg}, \mathrm{Al}$, and $\mathrm{Ca}$, and is interpreted to be a mixture that includes Fe-Ti oxide(s). JM_10 is enriched in Al and alkalis relative to JM_2 and JM_14. Preliminary elemental compositions in wt. \% were obtained via the partial-leastsquare (PLS) technique discussed by Lasue et al. (92); these compositions are consistent with three major types of minerals: plagioclase, pyroxene, and olivine. PLS also shows that JM-2 does not contain a significant fraction of these three phases - its higher Fe and $\mathrm{Ti}$ are consistent with a substantial fraction of Fe-Ti oxide(s) in the analyzed volumes of each laser shot.

While most of the JM analysis locations are homogeneous with depth, a comparison of the thirty successive spectra at each analysis location shows that some locations exhibit significant heterogeneity with increasing depth. The location showing the greatest heterogeneity with depth is JM_14. Figure S4a shows that successive spectra at this location have increasing $\mathrm{MgO}$ and $\mathrm{CaO}$ along a linear trend. The first two shots (Fig. $\mathrm{S} 4 \mathrm{a}$ ) are contaminated by dust, and then the trend (shots 3-30) suggests a mixture of groundmass (?) and plagioclase and high-Ca pyroxene with the proportion of pyroxene increasing with depth. The presence of groundmass is suggested by CIPW normative components such as orthoclase, pyroxene, magnetite and ilmenite in the composition from shot number 4. A CIPW norm calculation of the $30^{\text {th }}$ laser shot composition contains $>50 \%$ diopside + hedenbergite but the analysis is potentially consistent, within uncertainties, with other Ca-rich pyroxene compositions. Figure S4b shows the same 
location for other elements, indicating that they are decreasing in a manner consistent with progressive profiling into a region that is dominated by a high-Ca pyroxene grain but with other contributions to the spectra. This result indicates that JM contains mineral grains that are at least nearly as large as the laser beam diameter. Other locations generally show less variation with depth, although JM_4 initially shows a composition enriched in $\mathrm{CaO}$ and $\mathrm{MgO}$, which becomes richer in alkalis at greater depth. This trend suggests that in this case, first a pyroxene was sampled, and then the fine-grained matrix.

\section{Further Compositional Comparisons of Jake_M to Terrestrial Lavas}

Figures S5 and S6 compare the three JM analyses (normalized to $100 \%$ minus $\mathrm{SO}_{3}, \mathrm{Cl}$, and trace elements) to rock compositions culled from the Georoc database that had been labeled either as mugearites or phonotephrites. With the exception of $\mathrm{TiO}_{2}-\mathrm{MgO}$ and $\mathrm{Na}_{2} \mathrm{O}-\mathrm{MgO}$, the JM compositions plot broadly near the centers of the remaining oxide$\mathrm{MgO}$ mugearite fields (Fig. S5). For $\mathrm{TiO}_{2}$ and $\mathrm{Na}_{2} \mathrm{O}$, JM lies near/on the lower and upper boundaries of the range of mugearite compositions, respectively. Similarly, the JM compositions lie at the extreme ranges of $\mathrm{Na}_{2} \mathrm{O}$ (upper bound) and $\mathrm{TiO}_{2}$ (lower bound) of rocks called phonotephrites (Fig. S6). But unlike the mugearites, JM's $\mathrm{K}_{2} \mathrm{O}$ content is much lower than typical phonotephrites. It is largely for these reasons that, although JM plots in the phonotephrite field in the total alkali-silica diagram in Fig. 2 (although near the phonotephrite/mugearite boundary), we prefer to refer to it as a mugearite, since it has a stronger overall affinity to terrestrial rocks that have been given this designation.

As noted in the main text, martian rocks are depleted in $\mathrm{TiO}_{2}$ relative to alkaline lavas from the island of Tenerife. However, Fig. S7 shows that, although they are low, the $\mathrm{TiO}_{2}$ contents of JM, basaltic shergotittes (martian meteorites) and martian rocks analyzed by the Mars Exploration Rovers, are not outside of the range of both terrestrial alkaline lavas and terrestrial tholeiites. In Fig. S7a, the JM compositions plot at the lower end, but nevertheless within the range of $\mathrm{TiO}_{2}$ contents in alkaline lavas with similar $\mathrm{MgO}$ and $\mathrm{SiO}_{2}$ contents. Likewise, JM, basaltic shergotittes, and Mars surface rocks are not outside of the $\mathrm{TiO}_{2}-\mathrm{MgO}$ field defined by terrestrial tholeiites (Fig. S7b).

Although bulk rock Fe/Mn ratios have historically been one of the criteria used to distinguish martian from terrestrial rocks, (e.g., 29, 30), Fig. S8 shows that the longduration nighttime analysis of $\mathrm{JM}$ has $\mathrm{Fe} / \mathrm{Mn}$ and $\mathrm{MgO}$ values that place it on the trend of Tenerife lavas in Fe/Mn-MgO space. High-precision Fe/Mn measurements $(93,94)$ of Hawaiian and Icelandic lavas with $\mathrm{MgO}$ contents of $\sim 7-28$ wt. \% have values between $\sim 58$ and 70; these values are largely independent of $\mathrm{MgO}$ and are substantially above the $\mathrm{JM}$ value of 53. Fe/Mn values of Tenerife lavas with $>\sim 7-8 \mathrm{wt} . \% \mathrm{MgO}$, although displaying greater variation ( $\sim 90 \%$ of the lavas with $>8$ wt. $\% \mathrm{MgO}$ have Fe/Mn of 60 $80)$, nevertheless overlap the high-precision measurements on Hawaiian and Icelandic 
basalts (greater scatter in Fe/Mn among the Tenerife rocks largely reflects lower precision of the $\mathrm{MnO}$ measurements). However, at lower magnesium contents $(<\sim 7-8$ wt. $\% \mathrm{MgO}), \mathrm{Fe} / \mathrm{Mn}$ values in the Tenerife lavas are positively correlated with $\mathrm{MgO}$ and drop dramatically reaching values as low as $10-15$ at $\mathrm{MgO}<1 \mathrm{wt}$. \%. This drop in $\mathrm{Fe} / \mathrm{Mn}$ reflects the appearance and fractionation of titanomagnetite ( \pm ilmenite $)$ at $\mathrm{MgO}$ contents $<\sim 7-8$ wt. $\%$ and is consistent with the MELTS models in which Fe-rich spinel appears in the liquid-line-of-descent at $\sim-8$ wt. \% MgO (Fig. 4, S11). Although not plotted, we note that lavas from St. Helena show a similar monotonic decrease in Fe/Mn with decreasing magnesium content once bulk rock $\mathrm{MgO}$ values fall below $\sim 7-8$ wt. \%. Note that the martian rocks plotted in Fig. S8 have Fe/Mn values that are essentially independent of $\mathrm{MgO}$ content ( 4-22 wt. \%) and thus for $\mathrm{MgO}$ concentrations $>\sim 6-7 \mathrm{wt}$. $\%, \mathrm{Fe} / \mathrm{Mn}$ values $(\sim 30-45)$ are substantially below the terrestrial ratios. However, because $\mathrm{Fe} / \mathrm{Mn}$ values are not positively correlated with $\mathrm{MgO}$ at low $\mathrm{MgO}$ contents, more evolved (i.e., less magnesian) martian rocks intersect the Tenerife trend, suggesting that $\mathrm{Fe} / \mathrm{Mn}$ is not a robust discriminant for evolved martian and terrestrial lavas.

\section{The Effect of Surface Components on Jake_M's Composition}

As discussed in the main text and in the Materials and Methods section above, the surface of Jake_M was not cleaned (i.e., mechanically brushed or physically abraded) prior to the three APXS analyses and thus a major fraction of the $\mathrm{S}$ and $\mathrm{Cl}$ in the analyses may reflect a surface component such as dust. Figure $\mathrm{S} 9$ compares $\mathrm{SO}_{3}$ and $\mathrm{Cl}$ contents in $\mathrm{JM}$ with those from rocks analyzed by the MERs. With respect to $\mathrm{S}$, the JM concentrations are lower than in most of the martian rock analyses collected from undisturbed (i.e., "as is") surfaces; in fact only a few rocks have lower S contents (e.g., Backstay, Irvine, Esperanza, and Humboldt Peak). $\mathrm{Cl}$ contents in the analyses of JM are roughly at the mid-point of the range of $\mathrm{Cl}$ concentrations in "as is" rock analyses $(\sim 0.4-1.6 \mathrm{wt} . \% \mathrm{Cl})$. Figure 10 shows that the spread in $\mathrm{SiO}_{2}, \mathrm{Al}_{2} \mathrm{O}_{3}, \mathrm{FeO} *, \mathrm{CaO}$ and $\mathrm{MgO}$ concentrations among the three normalized JM analyses is comparable to the spread observed in analyses of "as is" $v s$. abraded rock/outcrop surfaces once each analysis had been normalized on $\mathrm{S} \mathrm{SO}_{3}$ - and $\mathrm{Cl}$-free basis. This suggests that if we had analyses of $\mathrm{JM}$ from an abraded surface, they would not be sufficiently different from the compositions in Table 1 (once all had been renormalized without $\mathrm{S}$ and $\mathrm{Cl}$ ) to substantively change any of the conclusions of this study.

\section{MELTS Modeling of Liquid-lines-of-descent: Tenerife}

AlphaMELTS $1.2(39,40)$ was used to model fractional crystallization of a primitive Tenerife composition (all in wt. \%: $\mathrm{SiO}_{2} 44.231 ; \mathrm{TiO}_{2}$ 3.186; $\mathrm{Al}_{2} \mathrm{O}_{3}$ 11.317; $\mathrm{Cr}_{2} \mathrm{O}_{3}$ 0.098; FeO* 12.431; $\mathrm{MnO} 0.181 ; \mathrm{MgO} 12.672 ; \mathrm{CaO} 12.430 ; \mathrm{Na}_{2} \mathrm{O} 2.253 ; \mathrm{K}_{2} \mathrm{O} 0.801 ; \mathrm{P}_{2} \mathrm{O}_{5}$ 0.401 ), over a range of pressures ( 1 bar and 1, 2, 3, 4, and 6 kbar) and starting water concentrations $(0,0.1,0.5,1,2$, and $3 \mathrm{wt} . \%)$. The effect of oxygen fugacity $\left(f \mathrm{O}_{2}\right)$ on the 
liquid-lines-of-descent was also explored; however, a fixed $f \mathrm{O}_{2}$ of QFM+1 is shown in Figs. S11 and S12. This $\mathrm{fO}_{2}$ is consistent with estimates from Fe-Ti oxides in Tenerife volcanics (38); under more oxidizing or reducing conditions Fe-rich spinel would appear earlier or later in the calculated liquid-line-of-descent. For each fractional crystallization calculation, the oxides were plotted against $\mathrm{MgO}$ and cubic spline functions were fit to the discrete model points. The Tenerife lavas and a subset of MELTS calculations are shown in Fig. S11. For each of the 36 MELTS calculations, a misfit parameter was calculated by summing the absolute values of the differences between the MELTS curves in $\mathrm{SiO}_{2^{-}}, \mathrm{Al}_{2} \mathrm{O}_{3^{-}}, \mathrm{FeO}^{*}$, and $\mathrm{CaO}-\mathrm{MgO}$ space and the Tenerife lava compositions; i.e., for each Tenerife lava, the $\mathrm{MgO}$ concentration was used to calculate an $\mathrm{SiO}_{2}, \mathrm{Al}_{2} \mathrm{O}_{3}$, $\mathrm{FeO}^{*}$, and $\mathrm{CaO}$ content based on cubic spline fits to a given MELTS calculation and the absolute value of these differences were summed for all of the lavas with $\mathrm{MgO}$ contents between 1 and 12.685 wt. \%. The sum of the differences was then divided by the number of Tenerife data points in this composition range (445). Some of the calculated liquidlines-of-descent at pressures $>1 \mathrm{kbar}$ and water concentrations $<2 \mathrm{wt}$. $\%$ became saturated in orthopyroxene at low $\mathrm{MgO}$ concentrations $(\mathrm{MgO}<2.5$ wt. \%).

Orthopyroxene is not expected in evolved alkaline magmas, (e.g., 16) and has not been observed in the Tenerife lavas (e.g., 95), so the crystallization of this phase was suppressed for the calculations shown in Figs. S11 and S12 [we note that MELTS is known to overstabilize orthopyroxene and thus its presence in these calculated evolved liquid compositions is likely an artifact (96)].

Figure S12 shows a contour plot of misfit over the tested range of pressures and water concentrations. The best fit over this range of pressures and water concentrations is in the middle of the darkest blue region at a pressure of $4 \mathrm{kbar}$ and a starting water concentration of 1 wt. \%. As illustrated by the $\mathrm{MgO}$ variation diagrams in Fig. S11, a good match to the Tenerife data requires the suppression of plagioclase crystallization such that the $\mathrm{Al}_{2} \mathrm{O}_{3}$ concentrations in the most evolved melts can be enriched to $20 \mathrm{wt}$. $\%$. Although the "best-fit" requires elevated pressure and water contents, as discussed in the main text, the suppression of plagioclase can be achieved by increasing the pressure of crystallization either with or without added water (increasing pressure and water content is more effective than pressure alone).

MELTS Modeling of Liquid-lines-of-descent: Martian Starting Liquid Compositions We explored the possibility that JM might represent a residual liquid from fractional crystallization of known martian rock compositions. We tried a variety of starting liquid compositions, including the shergottite EETA 79001A (9), NWA 7034 (74), and four compositions measured by the Spirit rover in Gusev crater: Adirondack, Humphrey, Humboldt Peak, and Backstay. For these starting compositions, we again used MELTS to calculate liquid-lines-of-descent over a range of pressures (1 bar and 1, 2, 3, and 4 kbar) 
and starting water concentrations $(0,0.1,0.5,1,2$, and $3 \mathrm{wt} . \%)$. We tried calculations over a range of $f \mathrm{O}_{2}$ conditions from $\mathrm{QFM}-1$ to $\mathrm{QFM}+3(6,7,97)$. However, all of the results shown in Figs. S13-S24 were calculated at QFM-1. The misfit between the calculated liquid-lines-of-descent and JM was computed using a similar method to that described above for Tenerife, the only difference being that the calculated concentrations of $\mathrm{SiO}_{2}, \mathrm{Al}_{2} \mathrm{O}_{3}, \mathrm{FeO}^{*}$, and $\mathrm{CaO}$ were this time compared to the three analyses of $\mathrm{JM}$ instead of the large Tenerife dataset. The results of the Backstay, NWA 7034, and Humboldt Peak calculations are discussed below.

Although none of the martian compositions considered in this study have high enough concentrations of alkalis to be viable parental liquids for JM (Figs. S13, S17, and S21), fractional crystallization of Backstay is able to match the concentrations of $\mathrm{SiO}_{2}, \mathrm{Al}_{2} \mathrm{O}_{3}$, $\mathrm{FeO}^{*}$, and $\mathrm{CaO}$ in JM reasonably well (Fig. S13). A contoured misfit plot using Backstay as the starting composition (Fig. S14) shows that the best-fit conditions are $4 \mathrm{kbar}$ and 3 wt. \% water in the starting composition. These conditions yield a best-fit match to JM that is comparable to the best-fit to JM achieved by starting with the primitive Tenerife composition (again considering only $\mathrm{SiO}_{2}, \mathrm{Al}_{2} \mathrm{O}_{3}, \mathrm{FeO}^{*}$, and $\mathrm{CaO}$ ). However, all of the melts comprising the best-fit liquid-line-of-descent calculated using Backstay are hyperthene normative (i.e., normative nepheline $=0$ ), in striking contrast to the $\sim 16-17$ wt. \% normative nepheline in the JM bulk composition (Table 1).

Fractional crystallization of NWA 7034 and Humboldt Peak give poorer fits to JM (in terms of $\mathrm{SiO}_{2}, \mathrm{Al}_{2} \mathrm{O}_{3}, \mathrm{FeO}^{*}$, and $\mathrm{CaO}$ ) than Backstay, with misfits ranging from 7.5-12 for NWA 7034 (Fig. S18) and 10.5-12 for Humboldt Peak (Fig. S22). However, unlike Backstay, NWA 7034 and Humboldt Peak produced fractionated model liquids in the compositional region of JM ( 4.4 wt. \% MgO) that are nepheline normative, although the calculated abundances of normative nepheline ( $<1 \mathrm{wt} . \%$, NWA 7034; $\sim 6 \mathrm{wt} . \%$ Humboldt Peak) are substantially less than that calculated for JM ( 16-17 wt. \%). In addition to having insufficient alkalis, both NWA 7034 and Humboldt Peak have concentrations of $\mathrm{Al}_{2} \mathrm{O}_{3}$ that are too low and concentrations of $\mathrm{FeO} *$ that are too high for either of these starting compositions to be parental to JM under the conditions considered in this study.

In order to assess whether a known martian composition enriched in alkalis could provide a viable parent for JM, we re-calculated the liquid-lines-of-descent from Backstay, NWA 7034, and Humboldt Peak with arbitrarily increased concentrations of $\mathrm{Na}_{2} \mathrm{O}$ and $\mathrm{K}_{2} \mathrm{O}$. The addition of extra alkalis had the effect of decreasing the $\mathrm{Al}_{2} \mathrm{O}_{3}$ and $\mathrm{SiO}_{2}$ concentrations of the residual liquids at a given $\mathrm{MgO}$ concentration, which increased the combined misfit for $\mathrm{SiO}_{2}, \mathrm{Al}_{2} \mathrm{O}_{3}, \mathrm{FeO}^{*}$, and $\mathrm{CaO}$ between the calculated liquid-lines-ofdescent and JM (Figs. S16, S20, and S24). The best-fit conditions for the Backstay 
starting composition shifted to a higher pressure and a lower water concentration as a result of increasing the alkali concentration of the melt. This could reflect the role of $\mathrm{Na}_{2} \mathrm{O}$ and $\mathrm{K}_{2} \mathrm{O}$ as network modifiers in silicate liquids (98).

In conclusion, of the martian starting compositions considered in this study, fractional crystallization of Backstay provides the best match to the $\mathrm{SiO}_{2}, \mathrm{Al}_{2} \mathrm{O}_{3}, \mathrm{FeO}$, and $\mathrm{CaO}$ concentrations in JM. However, concentrations of $\mathrm{K}_{2} \mathrm{O}$ and $\mathrm{Na}_{2} \mathrm{O}$ for all previously analyzed martian rocks, including Backstay, are too low to explain the alkali-rich nature of JM. A Backstay-like melt arbitrarily enriched in alkalis could on fractionation produce a melt similar to JM in most elements via fractional crystallization. The best-fit crystallization conditions are at pressures of $3 \mathrm{kbar}$ or higher for all starting melt compositions. 


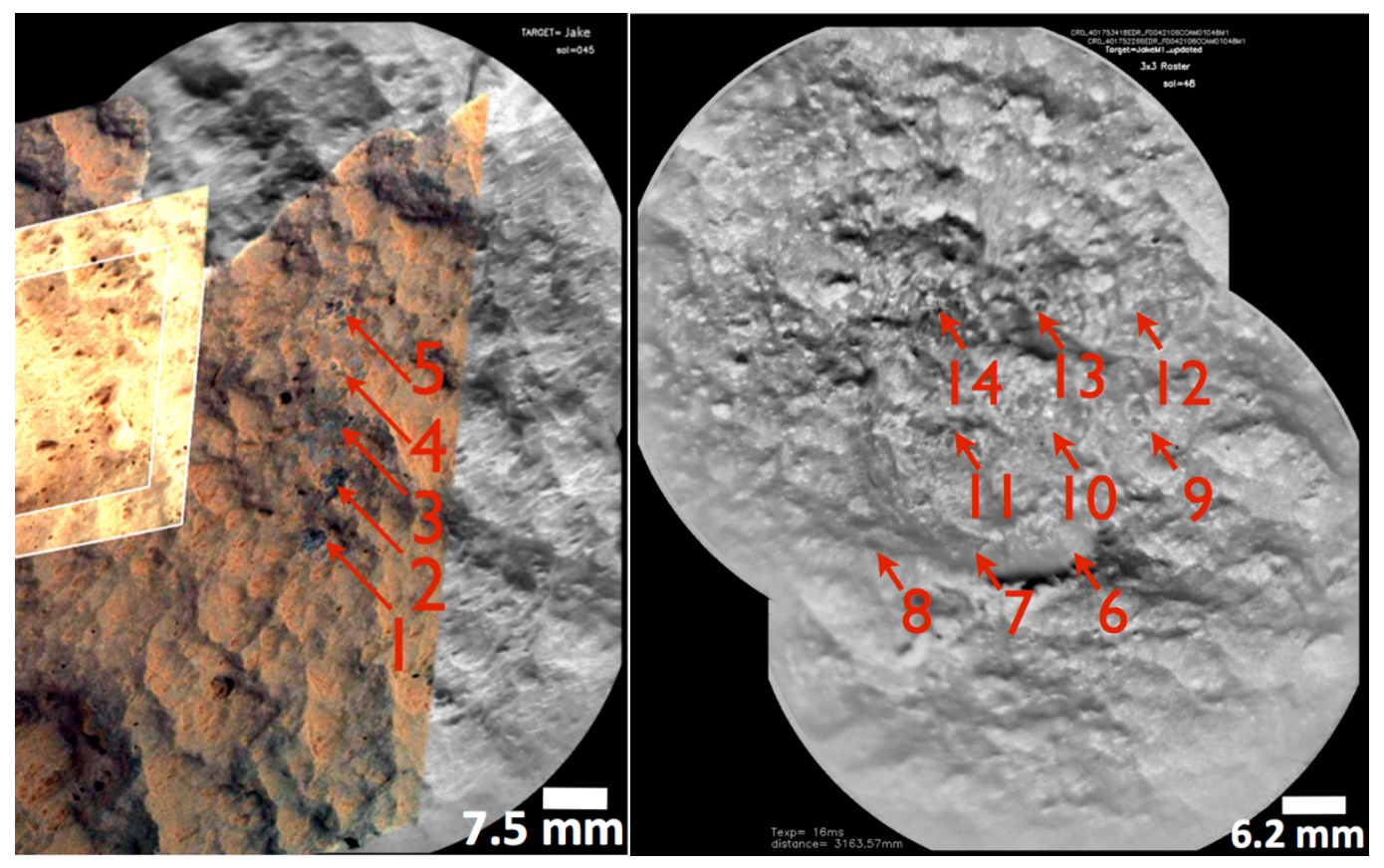

Fig. S1.

RMI mosaics of the 2 rasters performed on Jake_M. The mosaic on the left is coupled with Mahli colors. Credit : NASA/JPL-Caltech/ LANL/IRAP/MSSS/IAS/LTP- Nantes. 


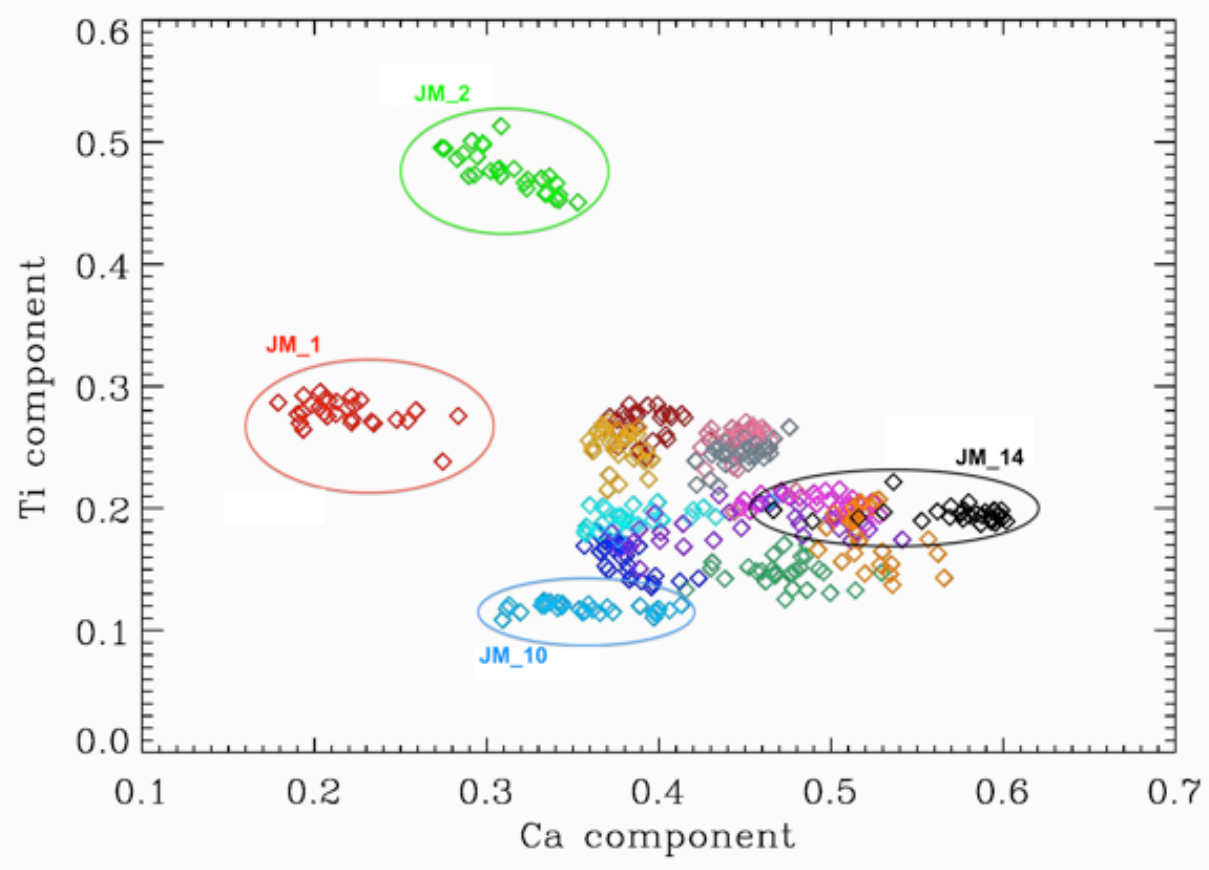

Fig. S2.

ICA (91) plot showing Ti component vs. Ca component for all the 392 spectra obtained on Jake_M (dust spectra removed). Observations at locations 1, 2, 10, and 14 represent compositional end-members. Units along the axes give relative separation of a given ICA component. 


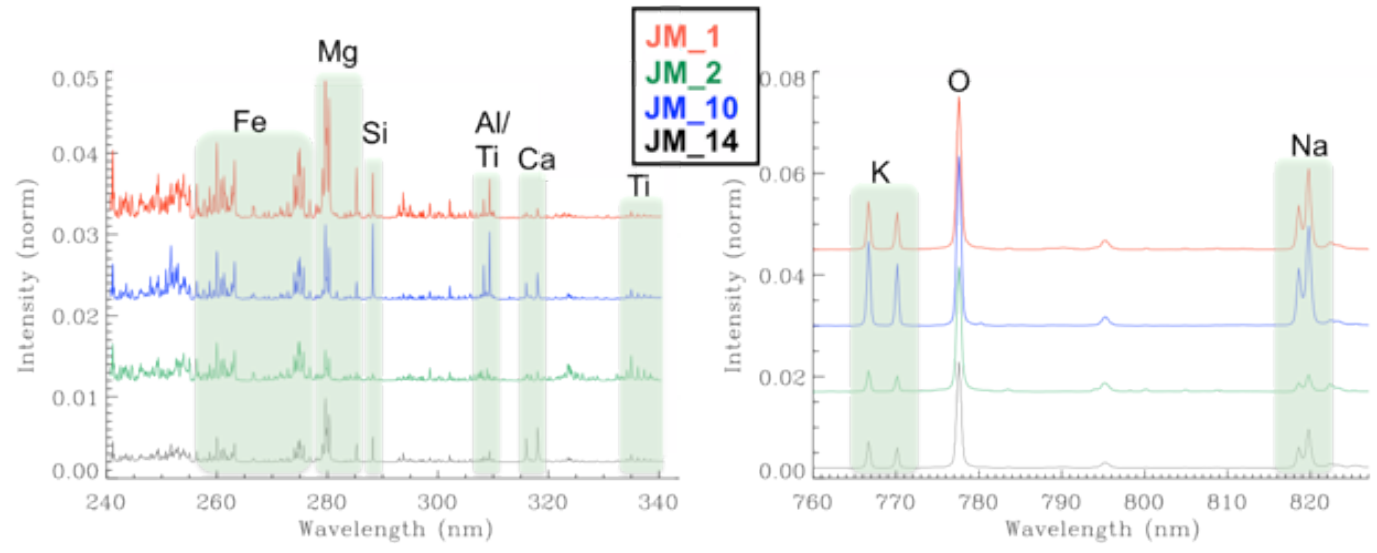

Fig. S3.

Spectra averaged over depth for the four analysis locations that are show end-member compositions from Jake_M. Left panel: UV range; Right panel: Part of the VNIR range showing the $\mathrm{K}$ and $\mathrm{Na}$ lines. 


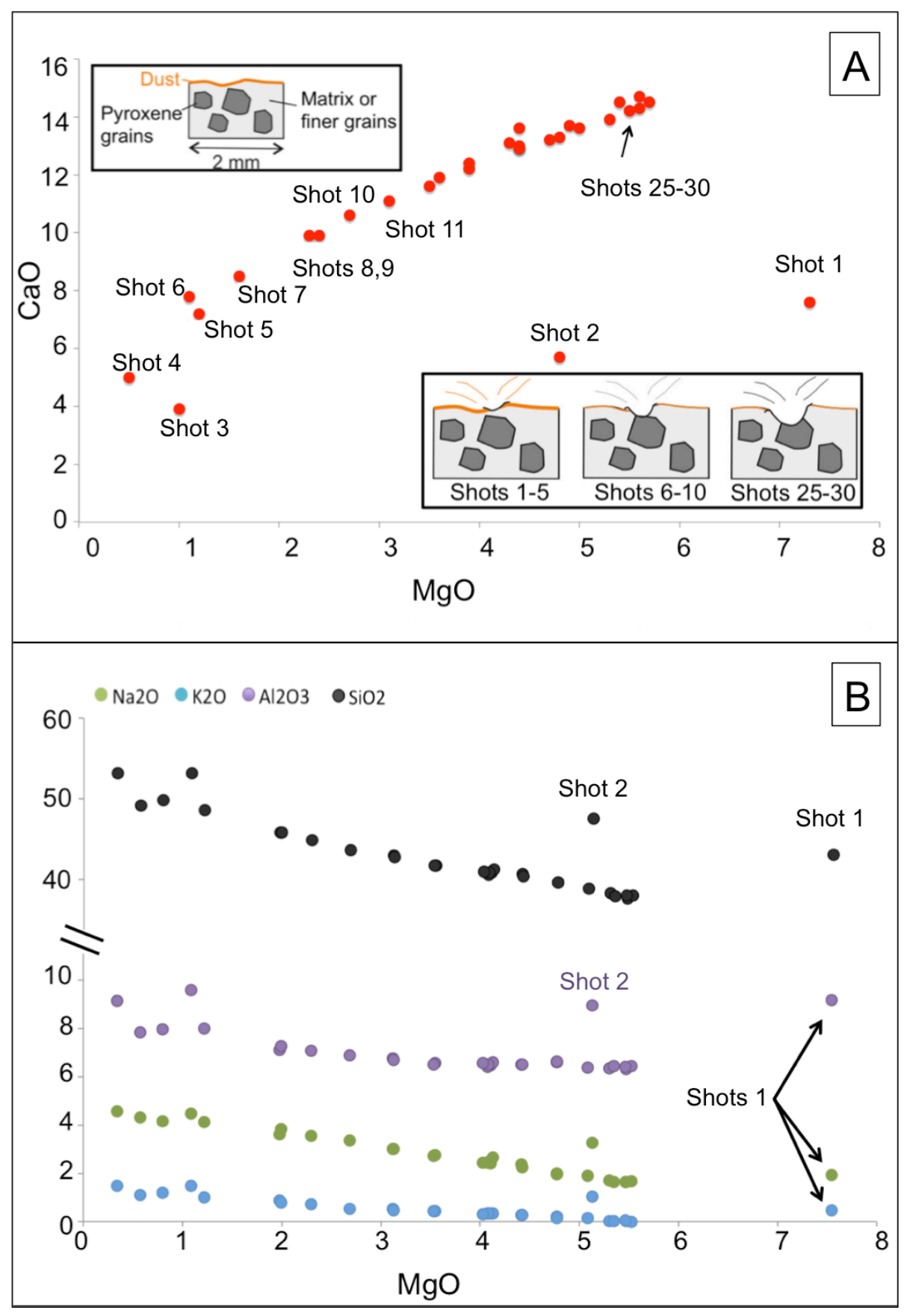

\section{Fig. S4.}

(A) $\mathrm{CaO}$ vs. $\mathrm{MgO}$ determined by PLS for ChemCam location 14 on Jake_M. The first two shots show the effect of surface dust; shots 3-30 suggest a mixture dominated by plagioclase and a high-Ca pyroxene with the proportion of pyroxene increasing with depth. (B) $\mathrm{SiO}_{2}, \mathrm{Al}_{2} \mathrm{O}_{3}, \mathrm{~K}_{2} \mathrm{O}$, and $\mathrm{Na}_{2} \mathrm{O} v s . \mathrm{MgO}$ in wt. \% determined by PLS for ChemCam location 14 on Jake_M. The first two shots show the effect of surface dust. All these elements are decreasing while $\mathrm{Mg}$ increases, which is consistent with an interpretation of a Ca-rich pyroxene at depth. 

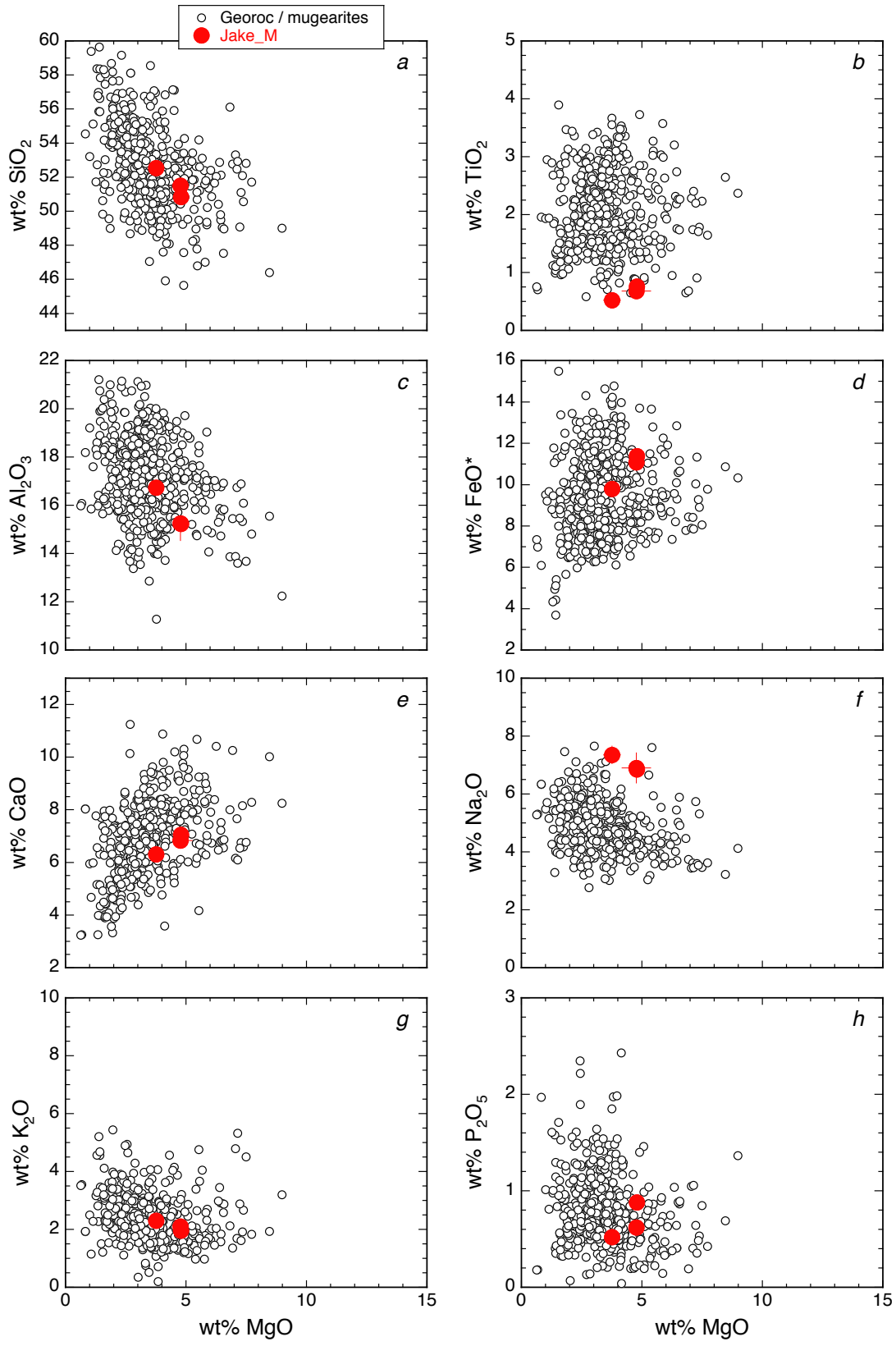

Fig. S5.

Comparison of the three Jake_M analyses (Table 1) to terrestrial rocks labeled mugearites in the Georoc database (25); all analyses normalized to $100 \%$ on a $\mathrm{H}_{2} \mathrm{O}-, \mathrm{CO}_{2^{-}}, \mathrm{S}-$, and Cl-free basis. (a) $\mathrm{SiO}_{2}-\mathrm{MgO}$, (b) $\mathrm{TiO}_{2}-\mathrm{MgO}$, (c) $\mathrm{Al}_{2} \mathrm{O}_{3}-\mathrm{MgO}$, (d) $\mathrm{FeO} *-\mathrm{MgO}$, (e) CaO-MgO, (f) $\mathrm{Na}_{2} \mathrm{O}-\mathrm{MgO}$, (g) $\mathrm{K}_{2} \mathrm{O}-\mathrm{MgO}$, (h) $\mathrm{P}_{2} \mathrm{O}_{5}-\mathrm{MgO} ; \mathrm{FeO}^{*}=$ all $\mathrm{Fe}$ as $\mathrm{FeO}$. 

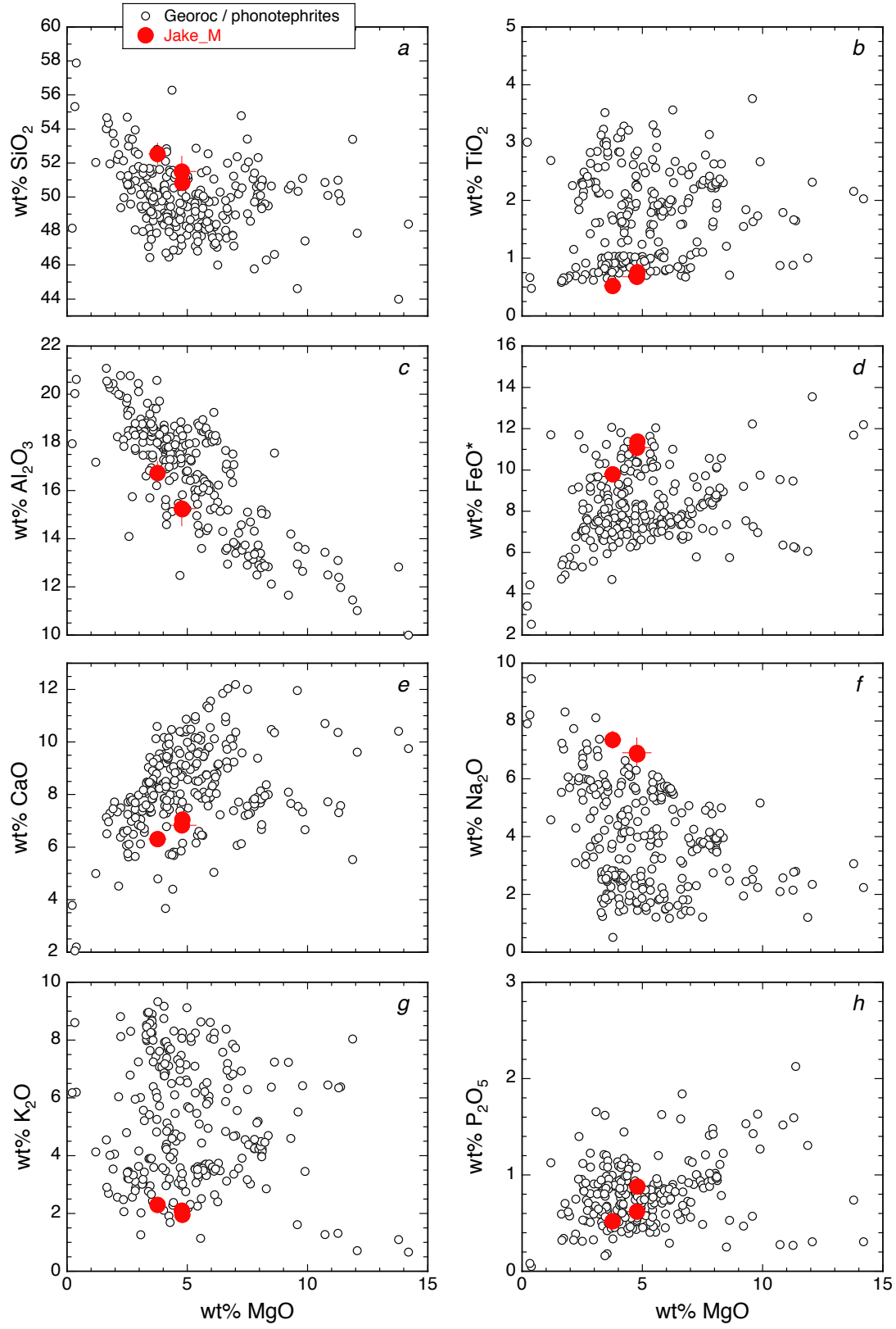

Fig. S6.

Comparison of the three Jake_M analyses (Table 1) to terrestrial rocks labeled phonotephrites in the Georoc database (25); all analyses normalized to $100 \%$ on a $\mathrm{H}_{2} \mathrm{O}-, \mathrm{CO}_{2^{-}}$, S-, and Cl-free basis. (a) $\mathrm{SiO}_{2}-\mathrm{MgO}$, (b) $\mathrm{TiO}_{2}-\mathrm{MgO}$, (c) $\mathrm{Al}_{2} \mathrm{O}_{3}-\mathrm{MgO}$, (d) $\mathrm{FeO} *-\mathrm{MgO}$, (e) $\mathrm{CaO}-\mathrm{MgO}$, (f) $\mathrm{Na}_{2} \mathrm{O}-$ $\mathrm{MgO}$, (g) $\mathrm{K}_{2} \mathrm{O}-\mathrm{MgO}$, (h) $\mathrm{P}_{2} \mathrm{O}_{5}-\mathrm{MgO} ; \mathrm{FeO}^{*}=$ all $\mathrm{Fe}$ as $\mathrm{FeO}$. 

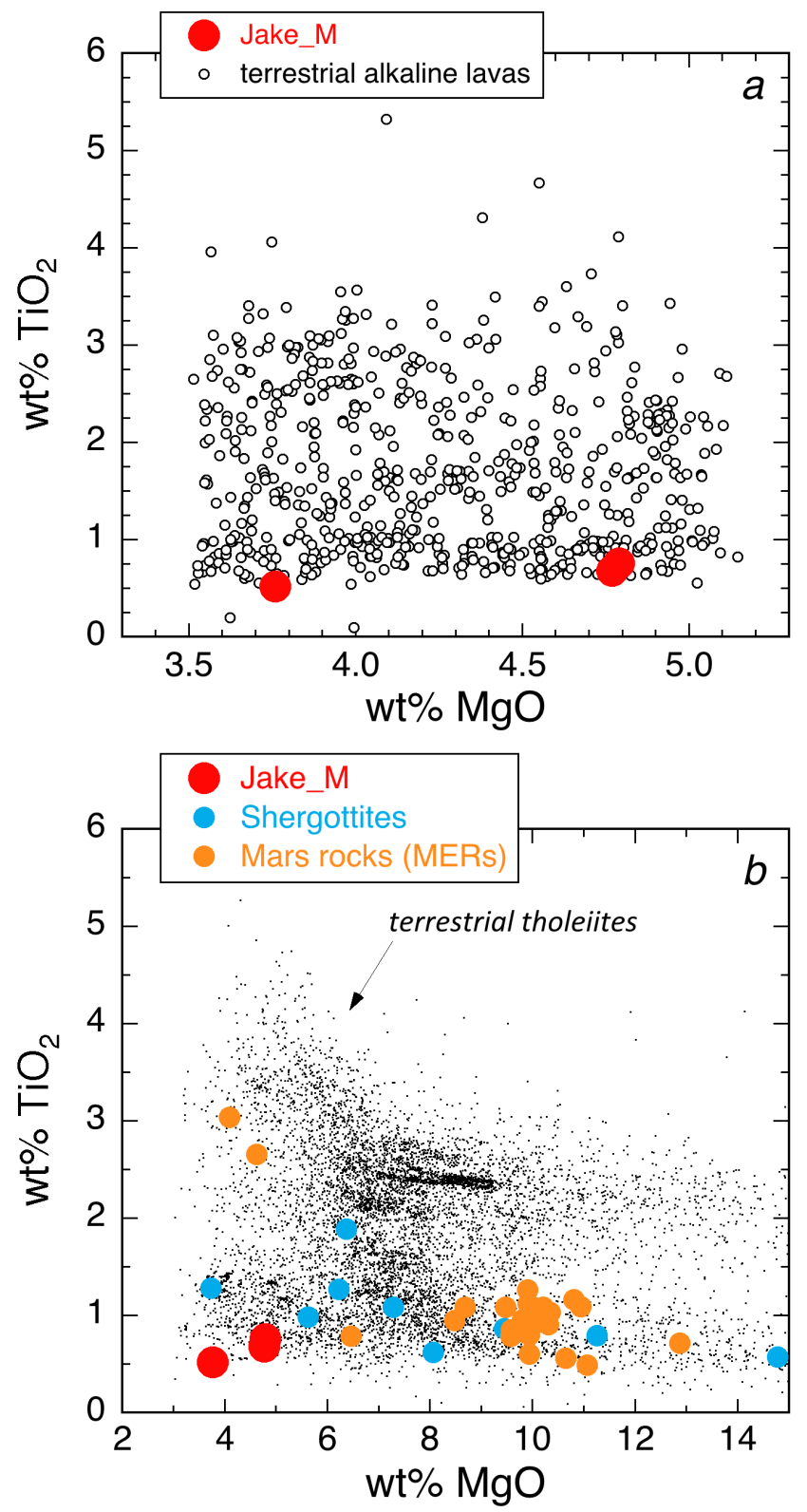

Fig. S7.

(a) $\mathrm{TiO}_{2}$ vs. $\mathrm{MgO}$ comparison between terrestrial alkaline rocks (25) [those lying above the alkaline-subalkaline boundary (23) in $\mathrm{Na}_{2} \mathrm{O}+\mathrm{K}_{2} \mathrm{O} v s$. $\mathrm{SiO}_{2}$ space] with 50-55 wt. \% $\mathrm{SiO}_{2}$ and 3.55 wt. $\% \mathrm{MgO}$ and Jake_M (Table 1). (b) $\mathrm{TiO}_{2} v s$. MgO comparison between terrestrial tholeiitic rocks (i.e., compositions that plot below the alkaline-subalkaline boundary) with 47-53 wt. \% $\mathrm{SiO}_{2}$ and 3-15 wt. \% MgO (25) and Jake M (Table 1), shergottites (9), and martian rocks analyzed by the Mars Exploration Rovers $(10,75-77)$. The two high $\mathrm{TiO}_{2}$ martian rocks are Wishstone and Champagne (10). All analyses in (a) and (b) have been normalized to $100 \mathrm{wt}$ \% on a volatile-free basis with all $\mathrm{Fe}$ as $\mathrm{FeO}$; terrestrial lavas were culled from the Georoc database (25) prior to normalization. 


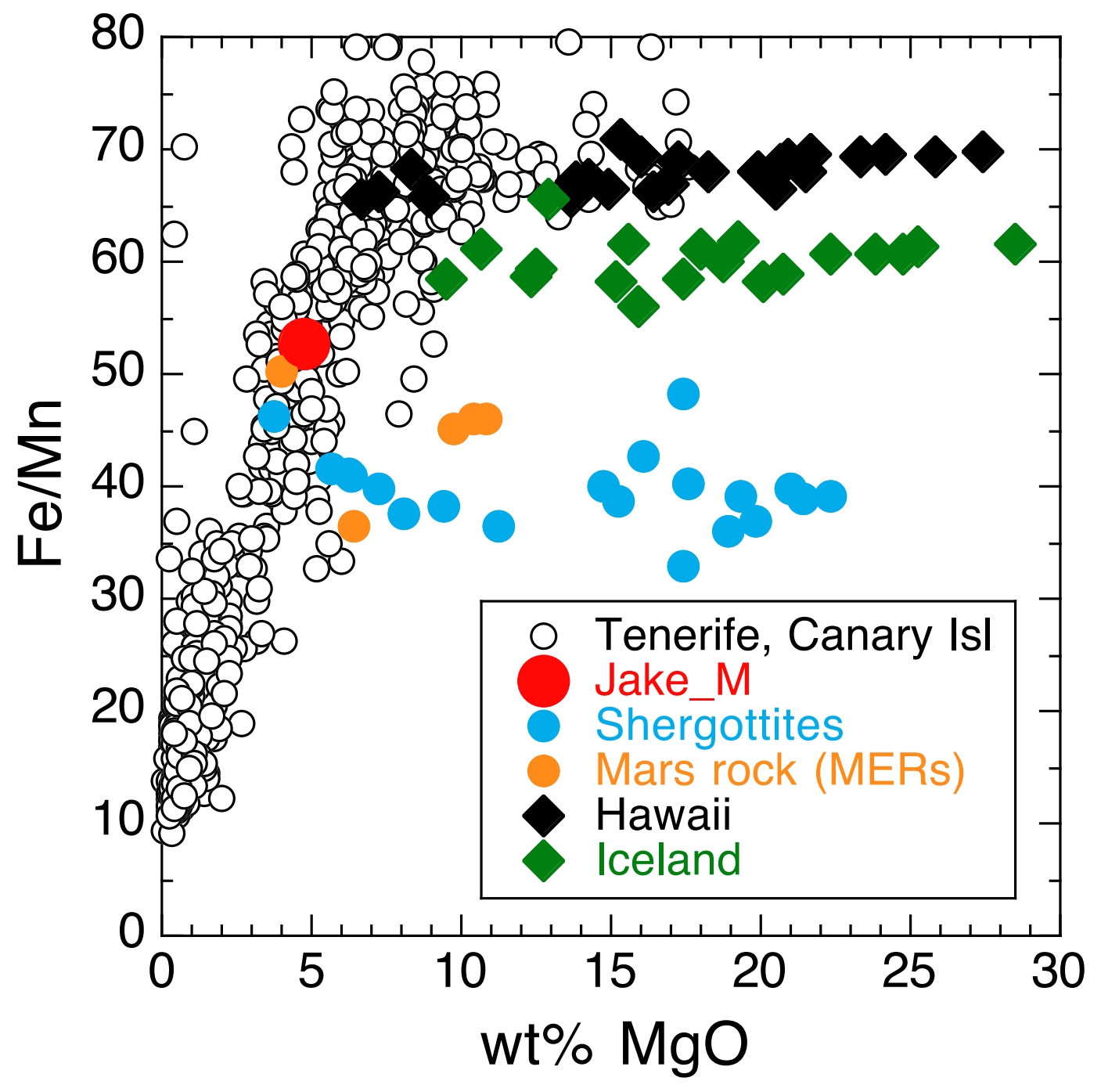

Fig. S8.

Fe/Mn (by weight) vs. MgO for Tenerife lavas (25), Jake_M (JM2n, Table 1), shergottites (9, 73), "abraded" Mars surface rock compositions analyzed by the Mars Exploration Rovers $(10,76)$ and high-precision Fe/Mn measurements on Hawaiian and Icelandic basalts (93, 94). The 13 Tenerife lavas with $\mathrm{Fe} / \mathrm{Mn}>80$ are not plotted and most likely represent analytical errors (high $\mathrm{Fe} / \mathrm{Mn}$ correlates with low, i.e., $\leq 0.1$ wt. $\%, \mathrm{MnO}$ values). One-sigma errors for the Hawaiian and Icelandic lavas are smaller than the size of the symbols. 


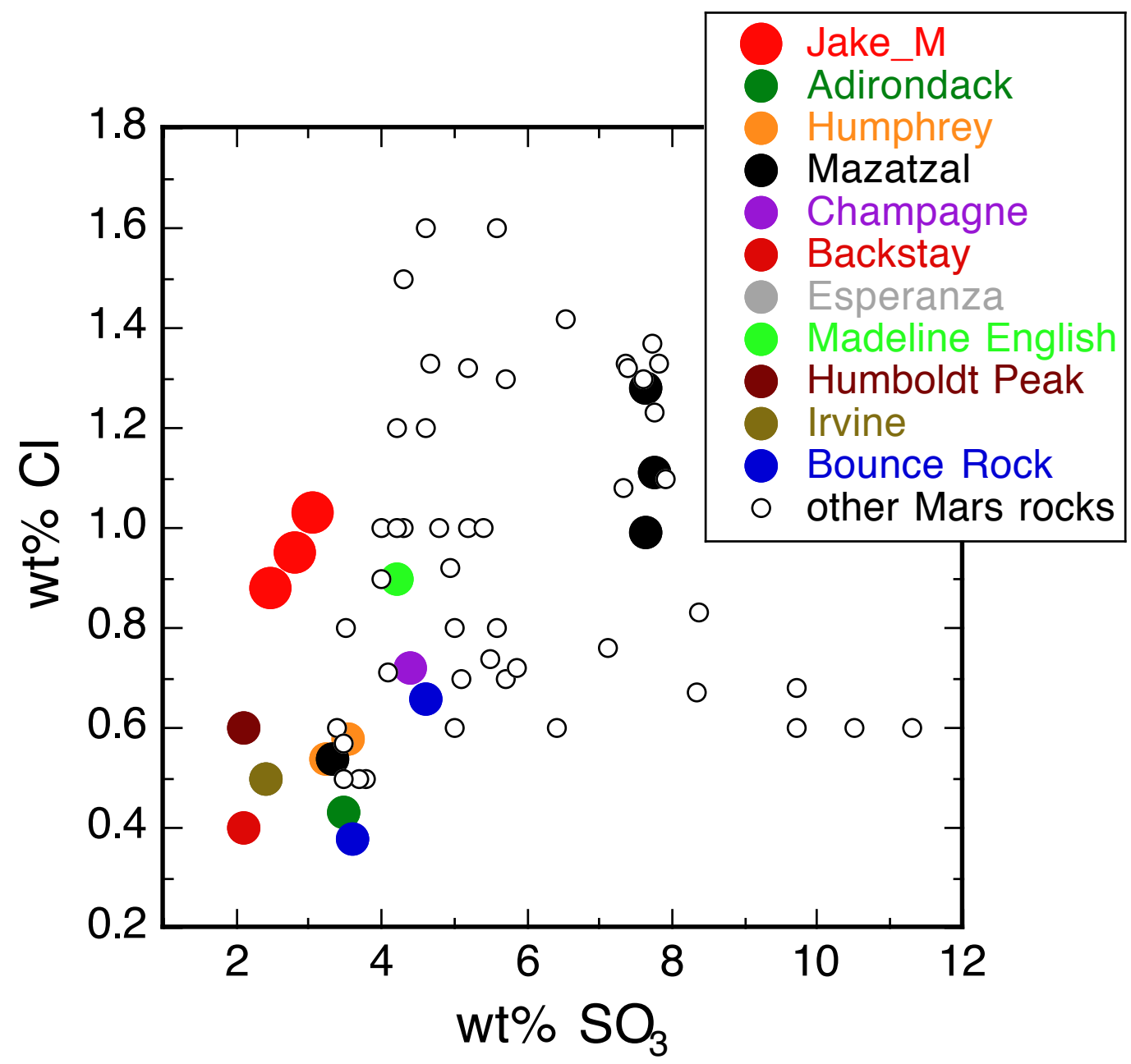

Fig. S9.

$\mathrm{SO}_{3}$ vs. $\mathrm{Cl}$ (both in wt. \%) in unbrushed and unabraded (i.e., "as is") rocks analyzed by the MERs $(10,75,76)$ and in Jake_M (Table 1); note that Esperanza plots beneath Irvine. 

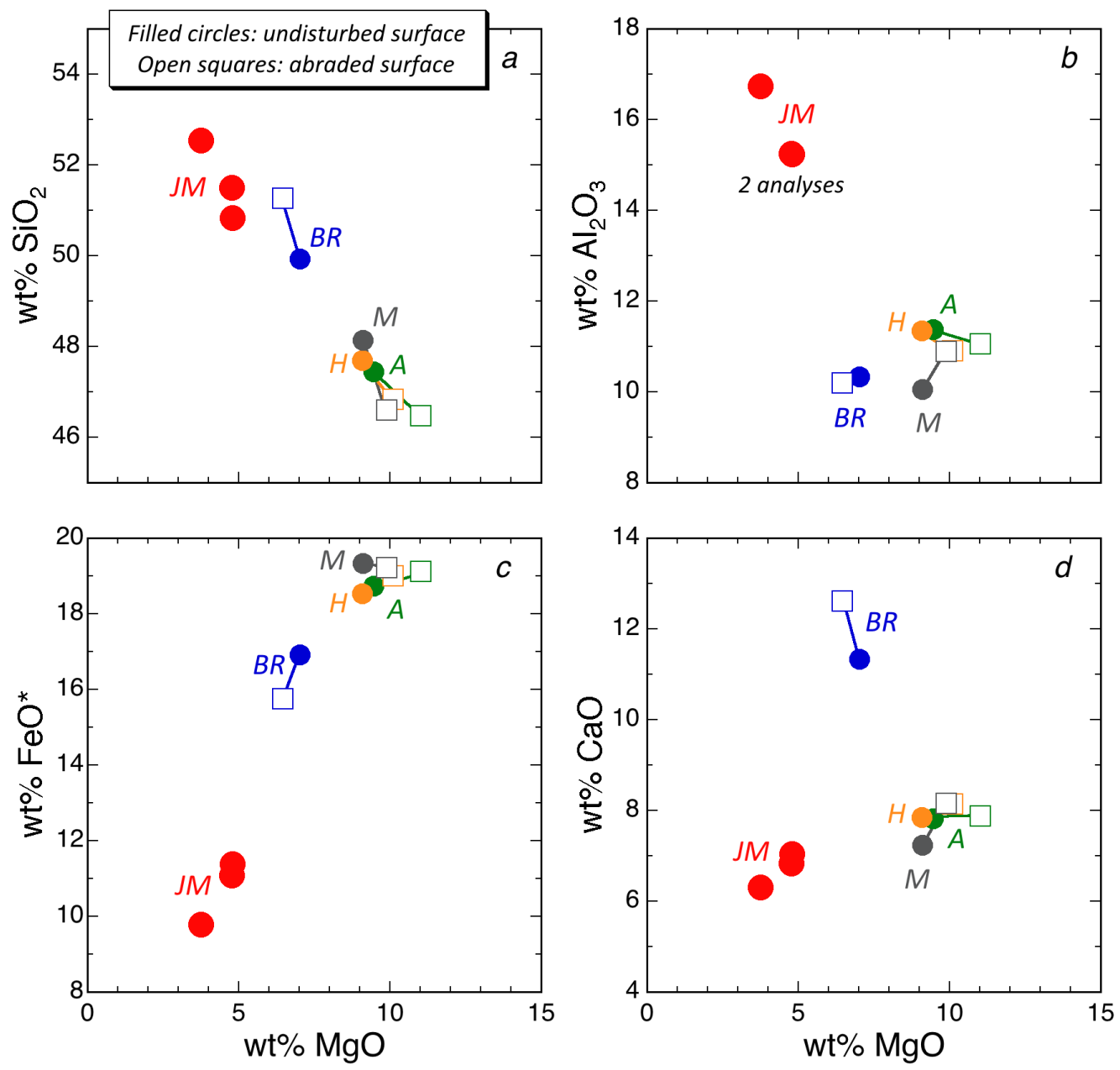

Fig. S10.

Oxide-MgO (all in wt. \%) in JM (large filled circles; Table 1) and in unbrushed and unabraded, i.e., "as is" rock analyses (smaller filled circles) and physically abraded rock analyses (open squares) by the MERs $(10,76)$. All analyses have been normalized to $100 \mathrm{wt} . \%$ on a $\mathrm{SO}_{3}$ - and $\mathrm{Cl}$-free basis; tie lines connect "as is" and abraded analyses of the same rock/outcrop. Abbreviations: $\mathrm{JM}=$ Jake_M; $\mathrm{BR}=$ Bounce Rock; $\mathrm{M}=$ Mazatzal; $\mathrm{H}=$ Humphrey; $\mathrm{A}=$ Adirondack. In the case of Mazatzal and Humphrey, multiple analyses have been averaged after being normalized. (a) $\mathrm{SiO}_{2}-\mathrm{MgO}$; (b) $\mathrm{Al}_{2} \mathrm{O}_{3}-\mathrm{MgO}$; (c) $\mathrm{FeO}^{*}-\mathrm{MgO}$, where $\mathrm{FeO}^{*}=$ all $\mathrm{Fe}$ as $\mathrm{FeO}$; (d) $\mathrm{CaO}-\mathrm{MgO}$. 

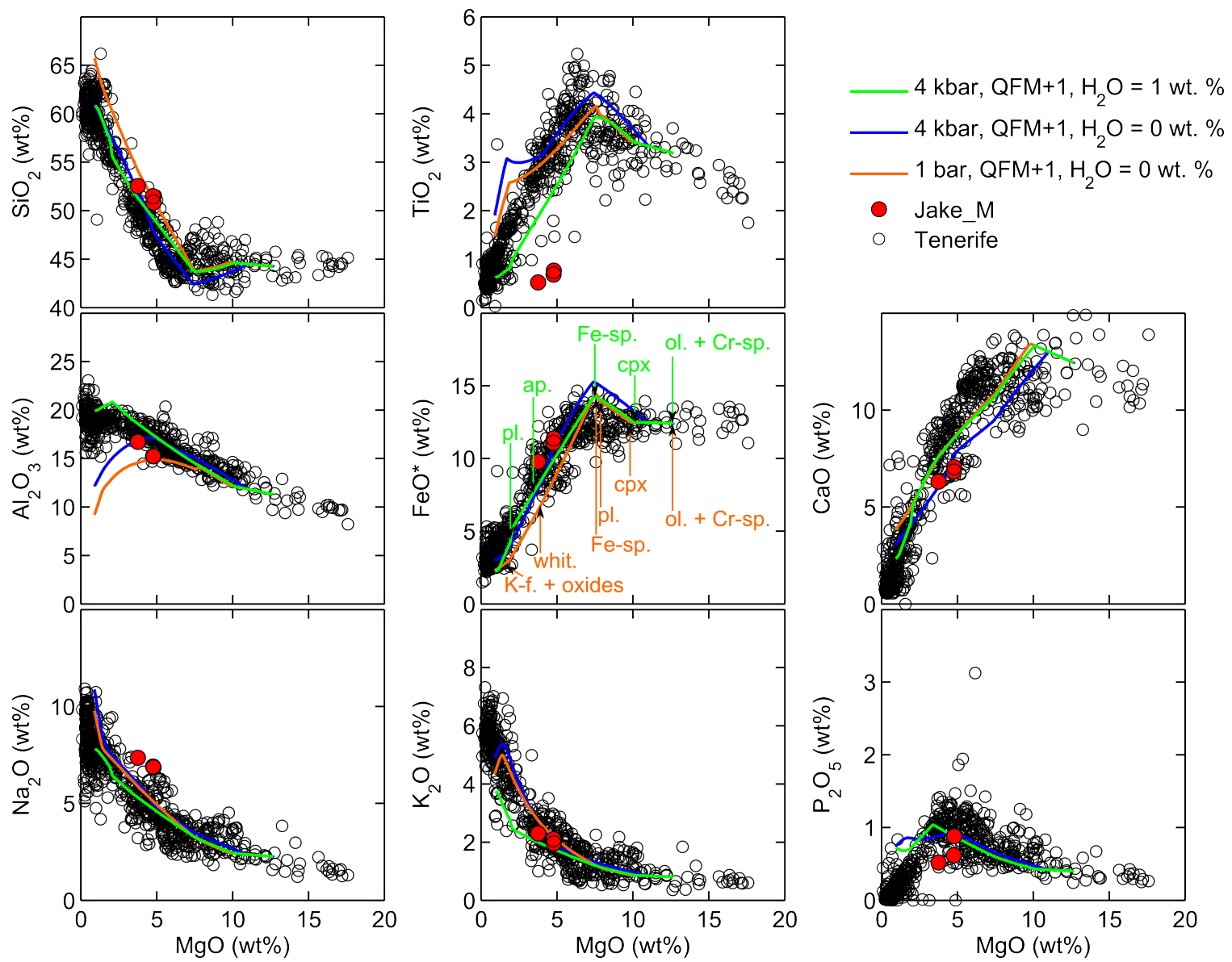

\section{Fig. S11.}

Oxide- $\mathrm{MgO}$ variation diagrams showing the compositions of Tenerife lavas (25), Jake_M (Table 1 ), and the results of selected MELTS fractional crystallization calculations. The best-fit MELTS calculation (4 kbar, QFM $+1, \mathrm{H}_{2} \mathrm{O}=1 \mathrm{wt} . \%$ ) is plotted in green (Fig. S12 shows how the mismatch between a given MELTS calculation and the Tenerife lavas varies as a function of pressure and initial water content). For comparison, the calculation at $4 \mathrm{kbar}, \mathrm{QFM}+1$ and $0 \mathrm{wt}$. $\%$ water is shown in blue and the calculation at $1 \mathrm{bar}, \mathrm{QFM}+1$ and $0 \mathrm{wt} . \%$ water is shown in orange. Colored arrows indicate the entry of phases in the calculated fractional crystallization sequence: ol. = olivine; $\mathrm{cpx}=$ clinopyroxene; pl. = plagioclase; Fe-sp. = Fe-rich spinel; K-f. = Kfeldspar; whit. $=$ whitlockite; ap. $=$ apatite; oxides $=$ ilmenite. 


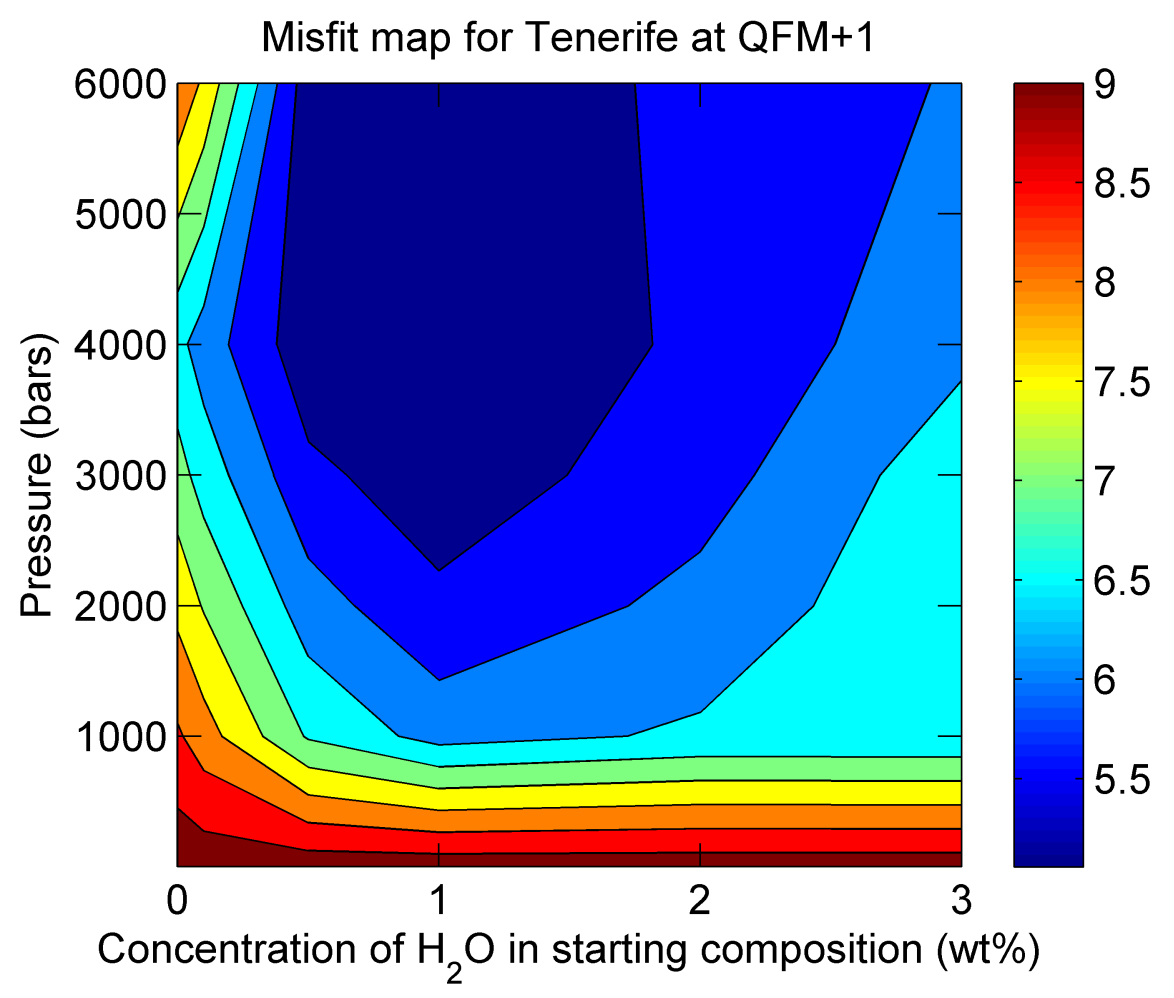

Fig. S12.

Contour plot of misfit between Tenerife data and MELTS fractional crystallization calculations. Calculations performed at QFM+1, at pressures of 1, 1000, 2000, 3000, 4000 and 6000 bars, and water concentrations of $0,0.1,0.5,1,2$ and $3 \mathrm{wt}$. \%. For each of the 36 MELTS calculations, the misfit was calculated by summing the absolute values of the differences between the MELTS curves in $\mathrm{SiO}_{2^{-}}, \mathrm{Al}_{2} \mathrm{O}_{3^{-}}, \mathrm{FeO}^{*}$-, and $\mathrm{CaO}-\mathrm{MgO}$ space and Tenerife lava compositions with $\mathrm{MgO}$ contents between 1 and 12.685 wt. \%. The sum of the differences was then divided by the number of Tenerife data points (445) within this $\mathrm{MgO}$ concentration range. Note that this misfit parameter does not directly compare with the ones that follow (in Figs. S14, S16, S18, S20, S22, and S24), which are calculated against the three measured Jake_M compositions rather than the whole Tenerife suite. Colored vertical scale bar indicates the degree of misfit; red = large (i.e., worse fit to the Tenerife data) and blue $=$ small (i.e., better fit to the Tenerife data) . 


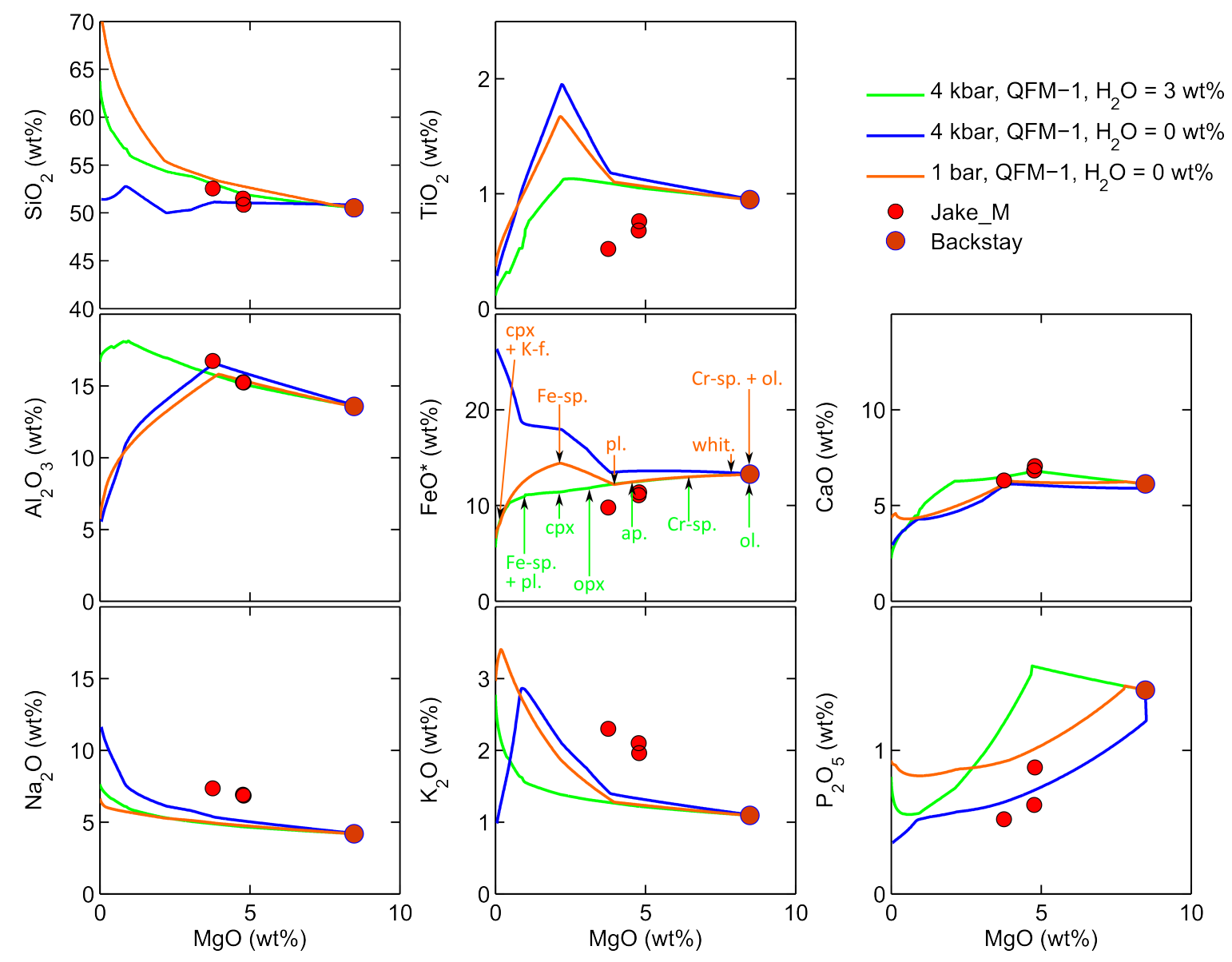

Fig. S13.

$\mathrm{MgO}$ variation diagrams for Backstay, Jake_M, and MELTS fractional crystallization calculations at QFM-1. The best-fit calculation (4 kbar and $3 \mathrm{wt}$. \% water) is plotted in green. For comparison, the calculation at $4 \mathrm{kbar}$ and $0 \mathrm{wt}$. \% water is shown in blue, and the calculation at 1 bar and $0 \mathrm{wt} . \%$ water is shown in orange. Colored arrows indicate the entry of phases in the calculated fractional crystallization sequence: ol. $=$ olivine; $\mathrm{Cr}$-sp. $=\mathrm{Cr}$-spinel; whit. $=$ whitlockite; ap. = apatite; $\mathrm{pl} .=$ plagioclase; $\mathrm{opx}=$ orthopyroxene; $\mathrm{cpx}=$ clinopyroxene; Fe-sp. $=$ Fe-rich spinel; K-f. = K-feldspar. 


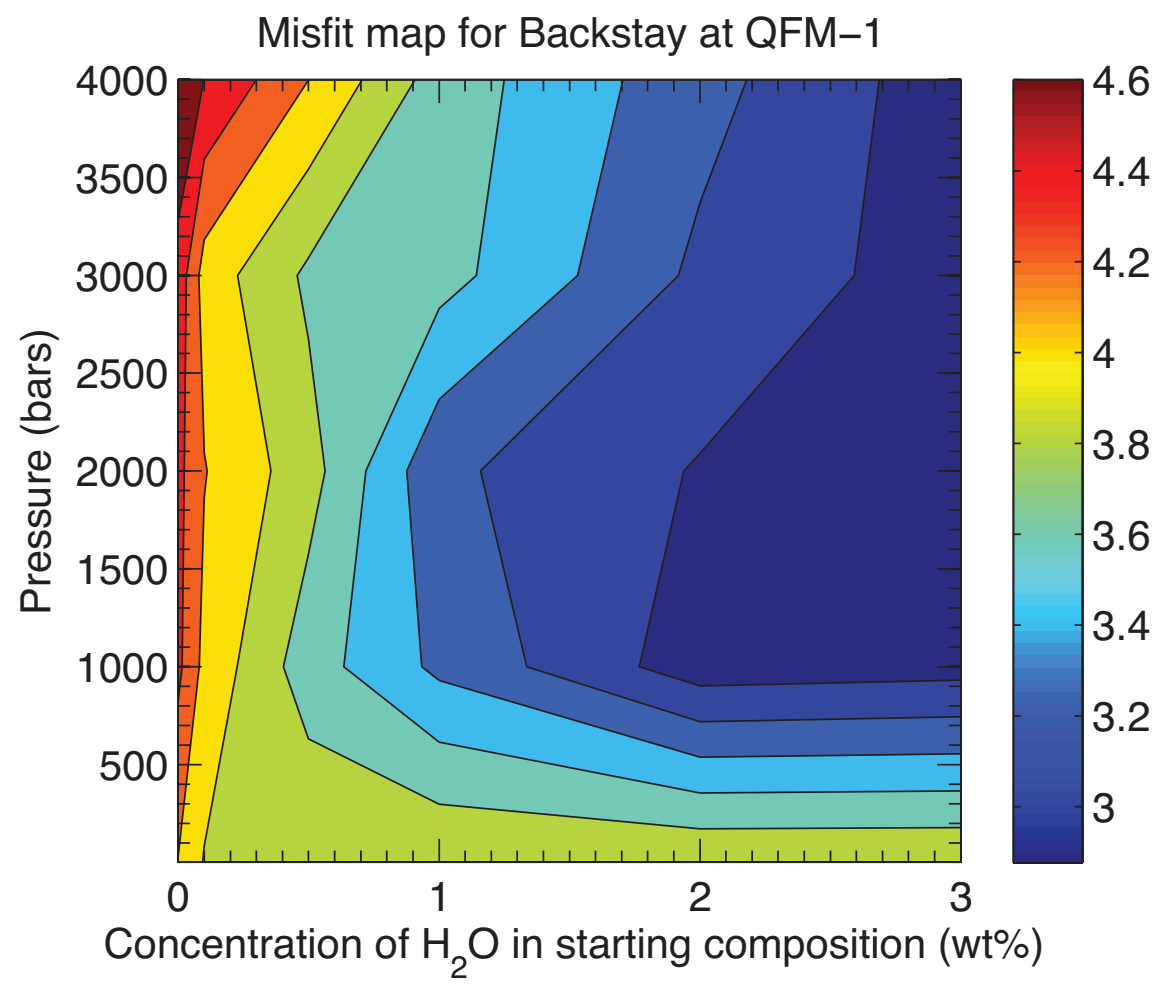

Fig. S14.

Contour plot of misfit between Jake_M and MELTS fractional crystallization calculations at QFM-1 using Backstay as the starting composition. Calculations performed at pressures of 1, $1000,2000,3000$ and 4000 bars, and water concentrations of 0, 0.1, 0.5, 1, 2 and 3 wt. \%. For each of the 30 MELTS calculations, the misfit was calculated by summing the differences between the MELTS curves in $\mathrm{SiO}_{2-}, \mathrm{Al}_{2} \mathrm{O}_{3^{-}}, \mathrm{FeO}^{*}$-, and $\mathrm{CaO}-\mathrm{MgO}$ space and the three measured Jake_M compositions. The sum of the differences was then divided by three. Note that the misfit in this figure and subsequent figures is not directly comparable to the misfit plotted in Fig. S12, which is calculated against the whole Tenerife suite rather than Jake_M. Colored vertical scale bar indicates the degree of misfit; red = large (i.e., worse fit to Jake_M) and blue = small (i.e., better fit to Jake_M). 

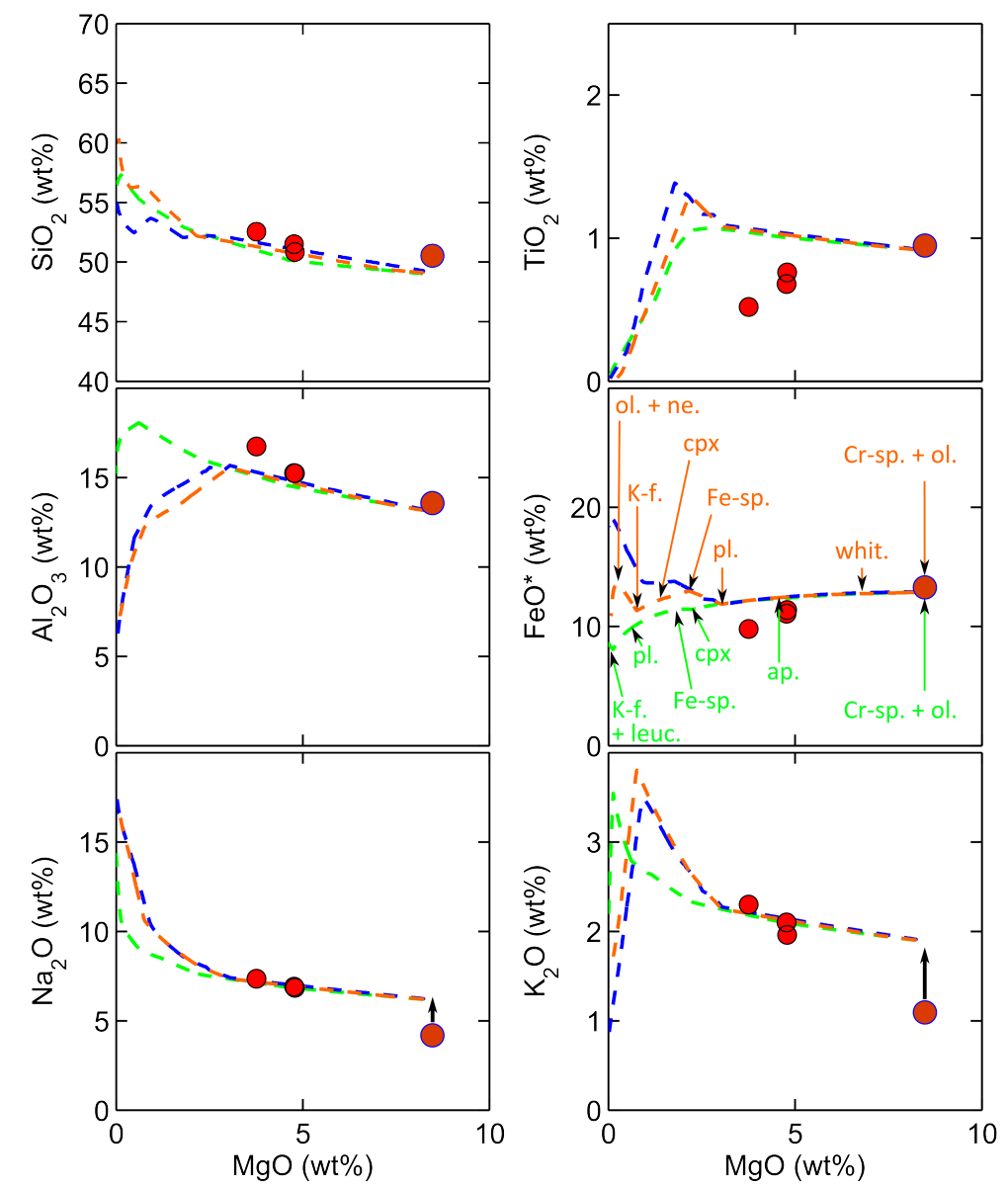

$$
\begin{aligned}
& ---4 \text { kbar, QFM-1, } \mathrm{H}_{2} \mathrm{O}=3 \mathrm{wt} \% \\
& ---4 \text { kbar, QFM-1, } \mathrm{H}_{2} \mathrm{O}=0 \mathrm{wt} \% \\
& ---1 \text { bar, QFM-1, } \mathrm{H}_{2} \mathrm{O}=0 \mathrm{wt} \% \\
& \text { Jake_M } \\
& \text { Backstay }
\end{aligned}
$$

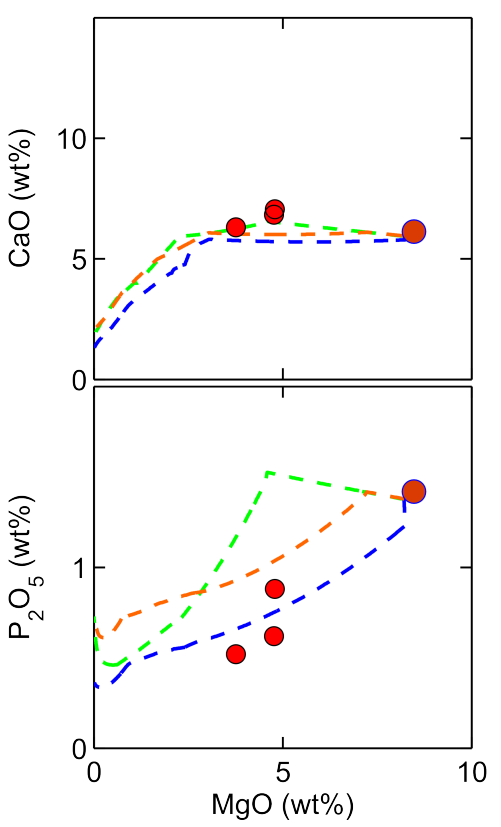

Fig. S15.

$\mathrm{MgO}$ variation diagrams for Backstay (with added $\mathrm{Na}_{2} \mathrm{O}$ and $\mathrm{K}_{2} \mathrm{O}$ so as to match the alkali content of Jake_M), Jake_M, and MELTS fractional crystallization calculations at QFM-1. The best-fit calculation ( $4 \mathrm{kbar}$ and $3 \mathrm{wt}$. \% water) is plotted in green (note that for the modified and unmodified Backstay composition, the best-fit models occur at the extremes of our investigated pressures and water contents and thus may not represent true minima in pressure- $\mathrm{H}_{2} \mathrm{O}$ space). For comparison, the calculation at $4 \mathrm{kbar}$ and $0 \mathrm{wt}$. \% water is shown in blue, and the calculation at 1 bar and $0 \mathrm{wt} . \%$ water is shown in orange. Colored arrows indicate the entry of phases in the calculated fractional crystallization sequence: $\mathrm{ol}$. $=$ olivine; $\mathrm{Cr}$-sp. $=\mathrm{Cr}$-spinel; whit. $=$ whitlockite; ap. $=$ apatite; Fe-sp. $=$ Fe-rich spinel; $\mathrm{cpx}=$ clinopyroxene; K-f. $=$ K-feldspar; leuc. $=$ leucite. Note that renormalization to $100 \mathrm{wt}$ \% following the addition of alkalis to the Backstay starting composition causes a small decrease in the concentrations of all of the other elements, such that the starting point for the MELTS fractional crystallization calculations is offset from Backstay in all panels. Black arrows in the $\mathrm{Na}_{2} \mathrm{O}$ and $\mathrm{K}_{2} \mathrm{O}$ variation diagrams emphasize the amount by which Backstay has been enriched in alkalis to create this new starting composition. 


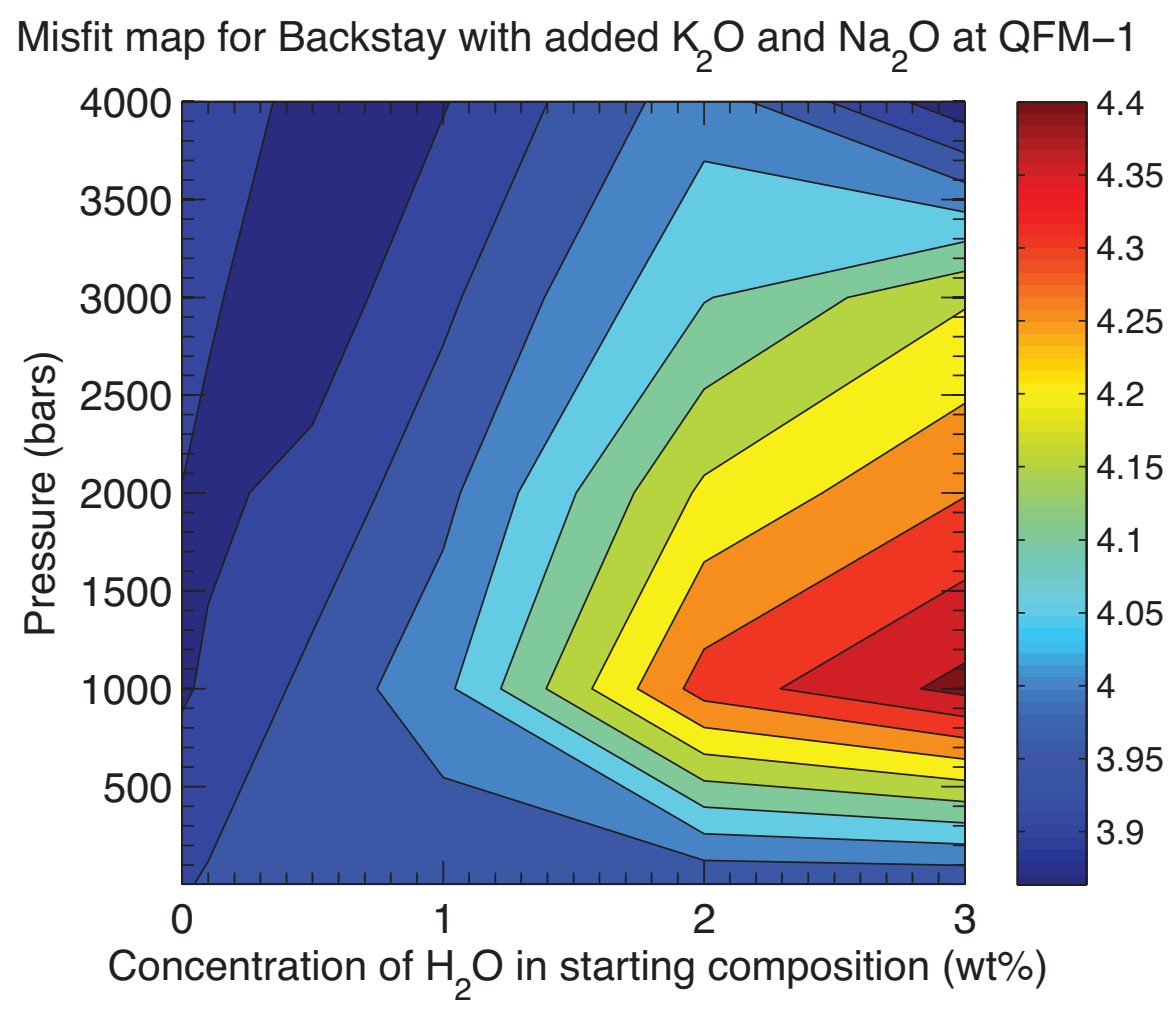

Fig. S16.

Contour plot of misfit between MELTS fractional crystallization calculations at QFM-1, starting with a Backstay composition with added $\mathrm{Na}_{2} \mathrm{O}$ and $\mathrm{K}_{2} \mathrm{O}$. Calculations performed at pressures of $1,1000,2000,3000$ and 4000 bars, and water concentrations of $0,0.1,0.5,1,2$ and $3 \mathrm{wt}$ \%. For each of the 30 MELTS calculations, the misfit was calculated by summing the differences between the MELTS curves in $\mathrm{SiO}_{2-}, \mathrm{Al}_{2} \mathrm{O}_{3^{-}}, \mathrm{FeO}^{*}$, and $\mathrm{CaO}-\mathrm{MgO}$ space and the three measured Jake_M compositions. The sum of the differences was then divided by three. Note that the misfit in this figure and subsequent figures is not directly comparable to the misfit plotted in Fig. S12, which is calculated against the whole Tenerife suite rather than Jake_M. Colored vertical scale bar indicates the degree of misfit; red = large (i.e., worse fit to Jake_M) and blue = small (i.e., better fit to Jake_M). 

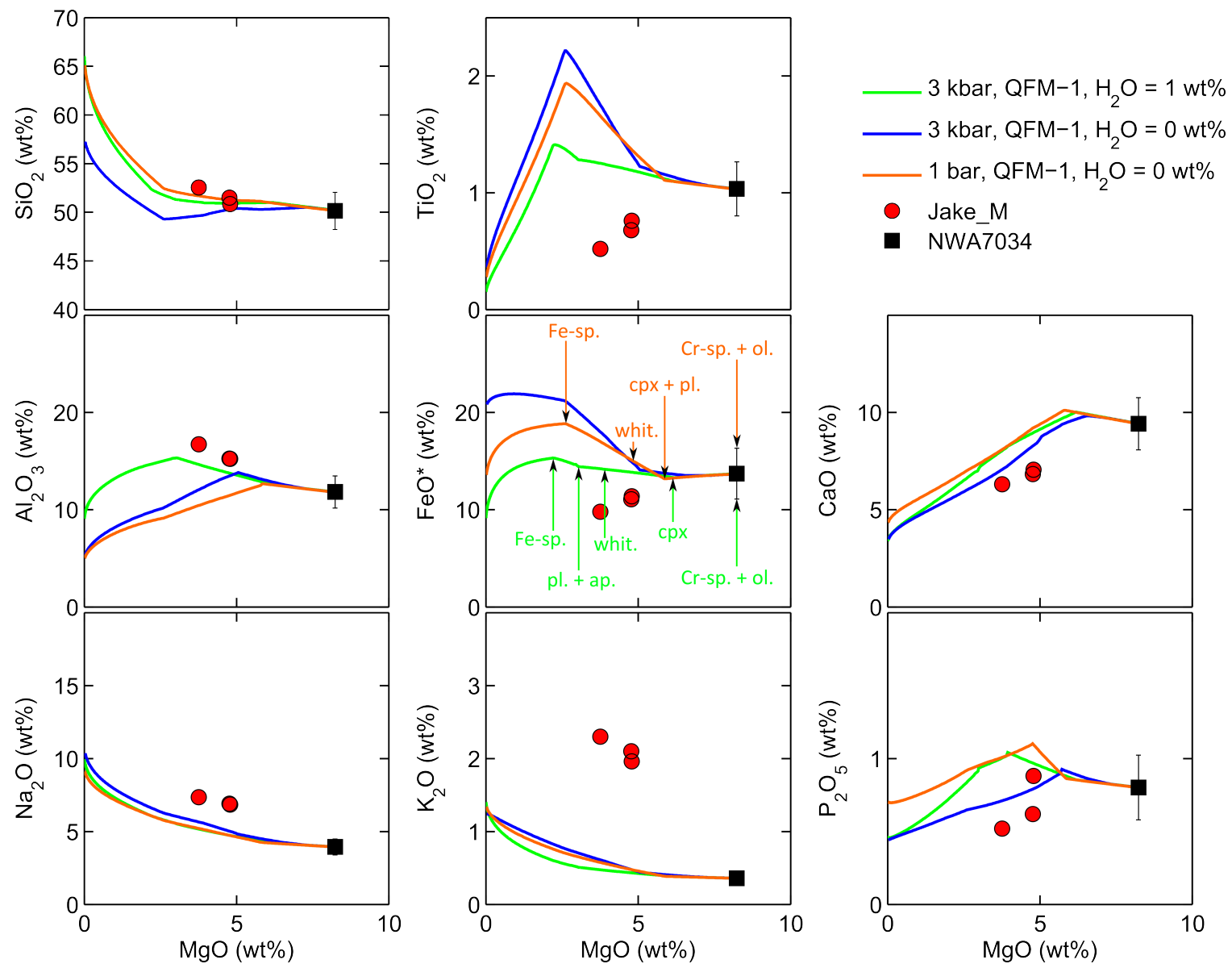

Fig. S17.

$\mathrm{MgO}$ variation diagrams for NWA 7034, Jake_M, and MELTS fractional crystallization calculations at QFM-1. The best-fit calculation (3 kbar and $1 \mathrm{wt}$. \% water) is plotted in green. For comparison, the calculation at $3 \mathrm{kbar}$ and $0 \mathrm{wt}$. \% water is shown in blue, and the calculation at $1 \mathrm{bar}$ and $0 \mathrm{wt} . \%$ water is shown in orange. Colored arrows indicate the entry of phases in the calculated fractional crystallization sequence: ol. $=$ olivine; $\mathrm{Cr}$-sp. $=\mathrm{Cr}$-spinel; $\mathrm{cpx}=$ clinopyroxene; pl. = plagioclase; whit. $=$ whitlockite; ap. $=$ apatite $;$ Fe-sp. $=$ Fe-rich spinel. Error bars on the composition of NWA 7034 are one standard deviation of 225 microprobe analyses of plumose groundmass (74). 


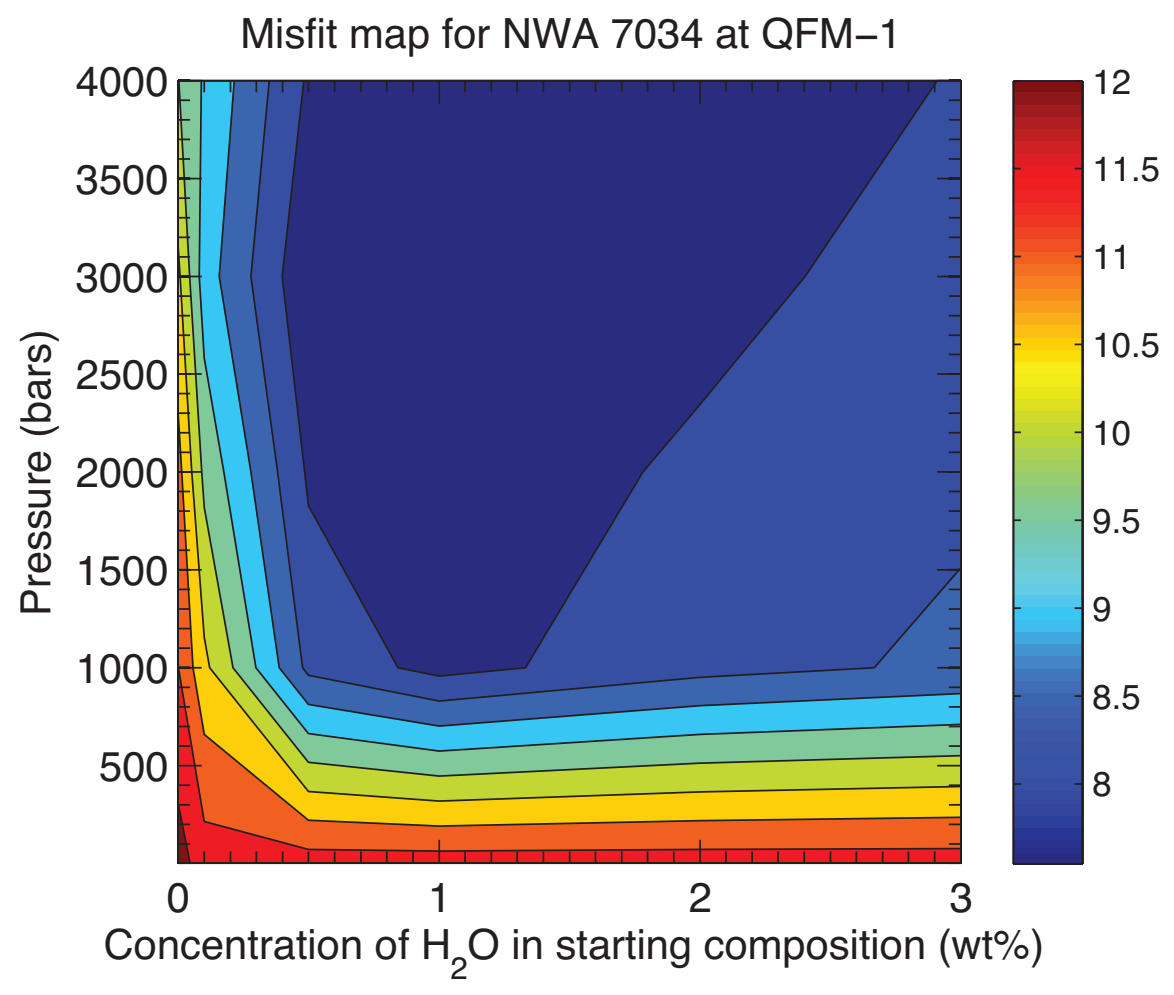

\section{Fig. S18.}

Contour plot of misfit between Jake_M and MELTS fractional crystallization calculations at QFM-1 using NWA 7034 as the starting composition. Calculations performed at pressures of 1, 1000, 2000, 3000 and 4000 bars, and water concentrations of 0, 0.1, 0.5, 1, 2 and 3 wt. \%. For each of the 30 MELTS calculations, the misfit was calculated by summing the differences between the MELTS curves in $\mathrm{SiO}_{2^{-}}, \mathrm{Al}_{2} \mathrm{O}_{3^{-}}, \mathrm{FeO}^{*}$-, and $\mathrm{CaO}-\mathrm{MgO}$ space and the three measured Jake_M compositions. The sum of the differences was then divided by three. Note that the misfit in this figure and subsequent figures is not directly comparable to the misfit plotted in Fig. S12, which is calculated against the whole Tenerife suite rather than Jake_M. Colored vertical scale bar indicates the degree of misfit; red = large (i.e., worse fit to Jake_M) and blue = small (i.e., better fit to Jake_M). 

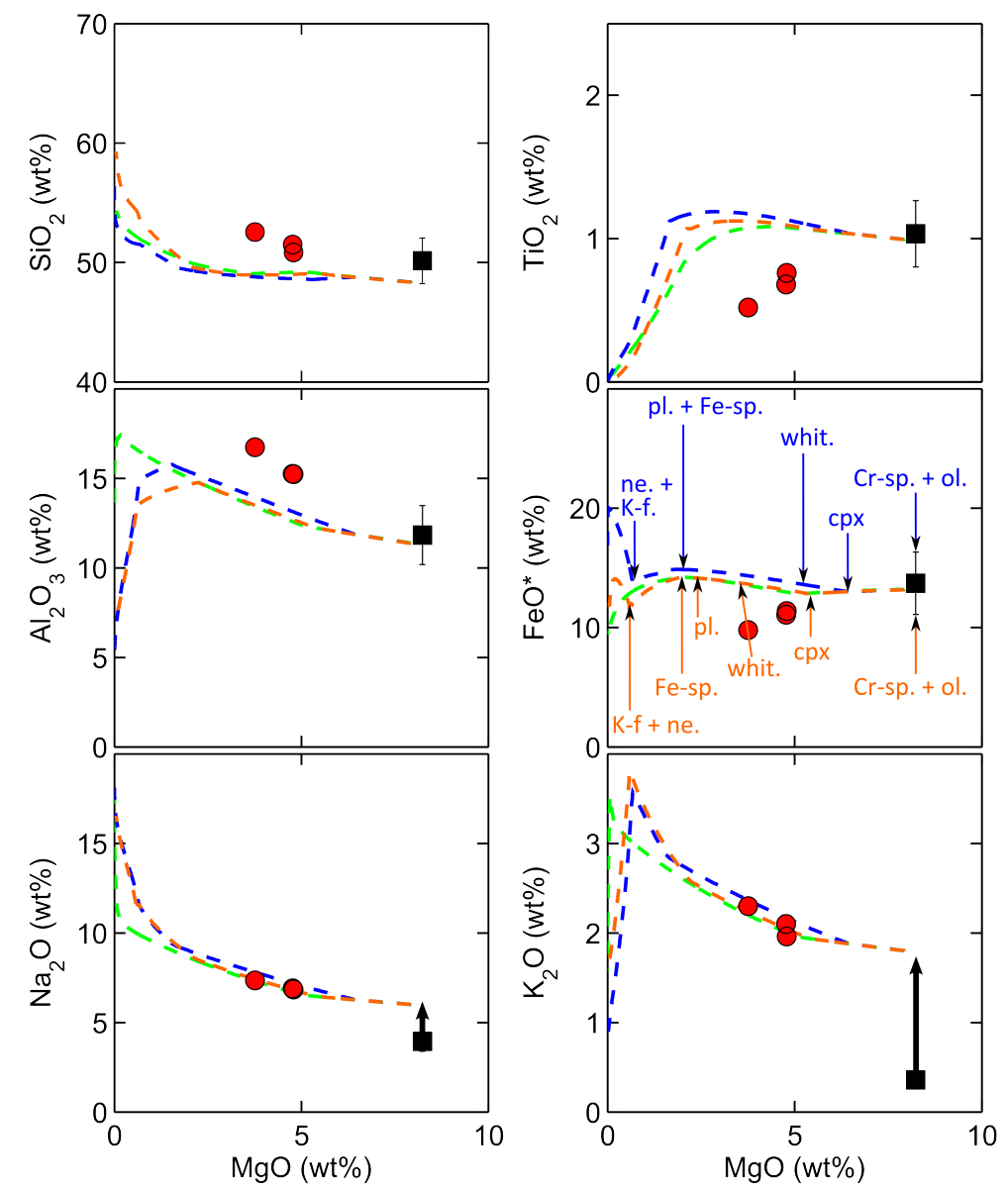

$$
\begin{aligned}
& ---4 \text { kbar, QFM-1, } \mathrm{H}_{2} \mathrm{O}=3 \mathrm{wt} \% \\
& ---4 \mathrm{kbar}, \mathrm{QFM}-1, \mathrm{H}_{2} \mathrm{O}=0 \mathrm{wt} \% \\
& ---1 \text { bar, QFM-1, } \mathrm{H}_{2} \mathrm{O}=0 \mathrm{wt} \% \\
& \text { - Jake_M } \\
& \text { - NWA7034 }
\end{aligned}
$$

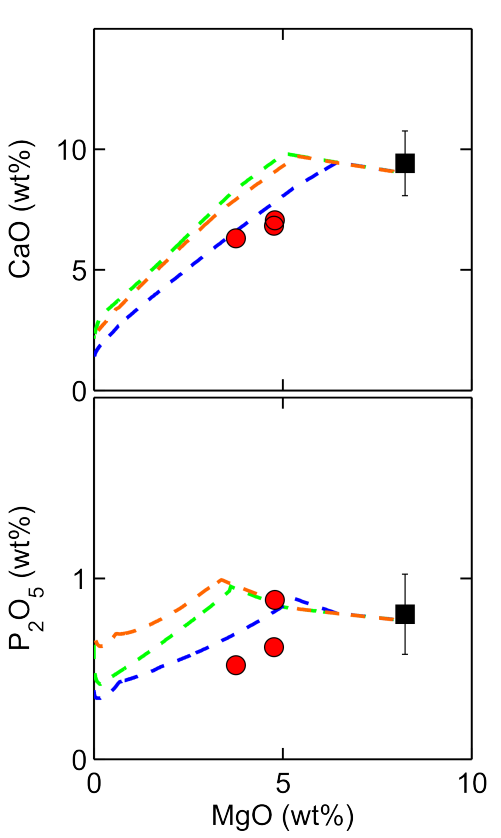

Fig. S19.

$\mathrm{MgO}$ variation diagrams for NWA 7034 (with added $\mathrm{Na}_{2} \mathrm{O}$ and $\mathrm{K}_{2} \mathrm{O}$ so as to match the alkali content of Jake_M), Jake_M, and MELTS fractional crystallization calculations at QFM-1. The best-fit calculation ( $4 \mathrm{kbar}$ and $0 \mathrm{wt}$ \% water) is plotted in blue and represents the minimum with respect to the investigated region of pressure- $\mathrm{H}_{2} \mathrm{O}$ space. For comparison, the calculation at 4 kbar and $3 \mathrm{wt} . \%$ water is shown in green, and the calculation at 1 bar and $0 \mathrm{wt}$. \% water is shown in orange. Colored arrows indicate the entry of phases in the calculated fractional crystallization sequence: ol. $=$ olivine; $\mathrm{Cr}$-sp. $=\mathrm{Cr}$-spinel; $\mathrm{cpx}=$ clinopyroxene; whit. $=$ whitlockite; $\mathrm{pl} .=$ plagioclase; ap. = apatite; Fe-sp. = Fe-rich spinel; K-f. = K-feldspar; ne. = nepheline. Note that renormalization to $100 \mathrm{wt}$. \% following the addition of alkalis to the NWA 7034 starting composition causes a small decrease in the concentrations of all of the other elements, such that the starting point for the MELTS fractional crystallization calculations is offset from NWA 7034 in all panels. Black arrows in the $\mathrm{Na}_{2} \mathrm{O}$ and $\mathrm{K}_{2} \mathrm{O}$ variation diagrams emphasize the amount by which NWA 7034 has been enriched in alkalis to create this new starting composition. Error bars on the composition of NWA 7034 are one standard deviation of 225 microprobe analyses of plumose groundmass (74). 


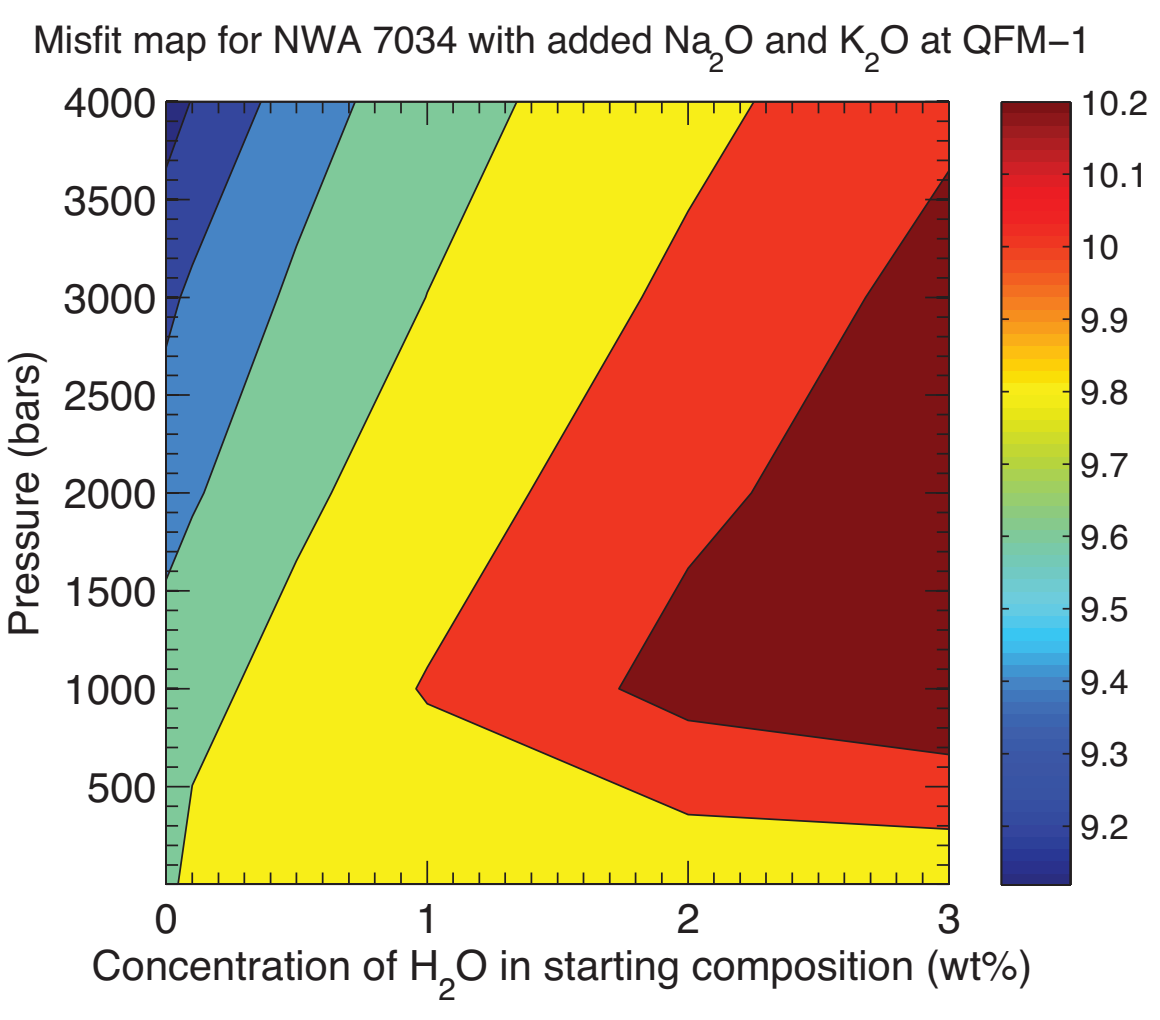

Fig. S20.

Contour plot of misfit between Jake_M and MELTS fractional crystallization calculations at QFM-1 using NWA 7034 with added $\mathrm{Na}_{2} \mathrm{O}$ and $\mathrm{K}_{2} \mathrm{O}$ as the starting composition. Calculations performed at pressures of 1, 1000, 2000, 3000 and 4000 bars, and water concentrations of $0,0.1$, $0.5,1,2$ and 3 wt. \%. For each of the 30 MELTS calculations, the misfit was calculated by summing the differences between the MELTS curves in $\mathrm{SiO}_{2^{-}}, \mathrm{Al}_{2} \mathrm{O}_{3^{-}}, \mathrm{FeO}^{*}$-, and $\mathrm{CaO}-\mathrm{MgO}$ space and the three measured Jake_M compositions. The sum of the differences was then divided by three. Note that the misfit in this figure and subsequent figures is not directly comparable to the misfit plotted in Fig. S12, which is calculated against the whole Tenerife suite rather than Jake_M. Colored vertical scale bar indicates the degree of misfit; red = large (i.e., worse fit to Jake_M) and blue = small (i.e., better fit to Jake_M). 

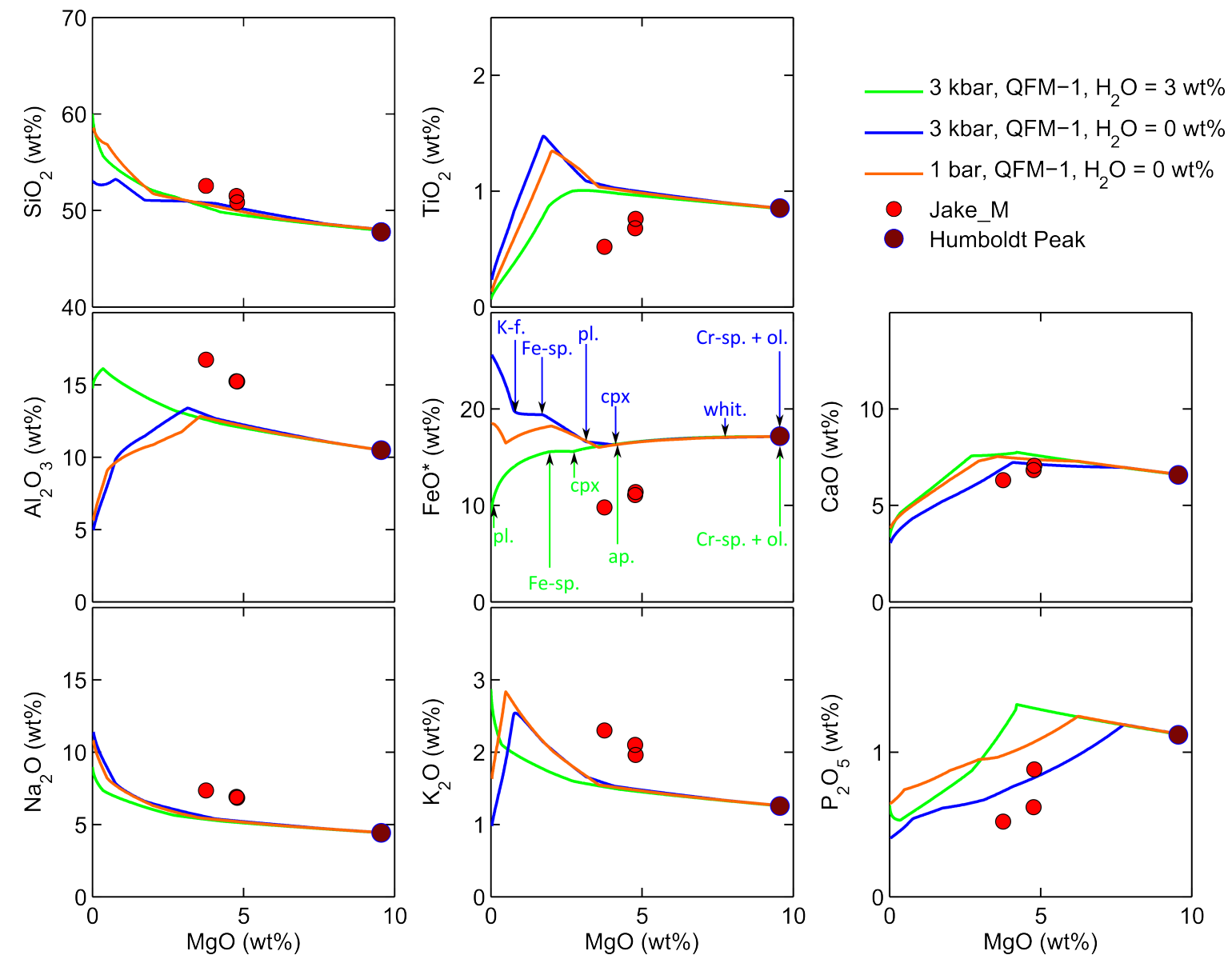

Fig. S21.

$\mathrm{MgO}$ variation diagrams for Humboldt Peak, Jake_M, and MELTS fractional crystallization calculations at QFM-1. The best-fit calculation (3 kbar and $0 \mathrm{wt}$. \% water) is plotted in blue. For comparison, the calculation at $3 \mathrm{kbar}$ and $3 \mathrm{wt} . \%$ water is shown in green, and the calculation at $1 \mathrm{bar}$ and $0 \mathrm{wt} . \%$ water is shown in orange. Colored arrows indicate the entry of phases in the calculated fractional crystallization sequence ol. $=$ olivine; $\mathrm{Cr}$-sp. $=\mathrm{Cr}$-spinel; whit $=$ whitlockite; ap. $=$ apatite; pl. = plagioclase; $\mathrm{cpx}=$ clinopyroxene; Fe-sp. $=$ Fe-rich spinel; K-f. $=$ K-feldspar. 


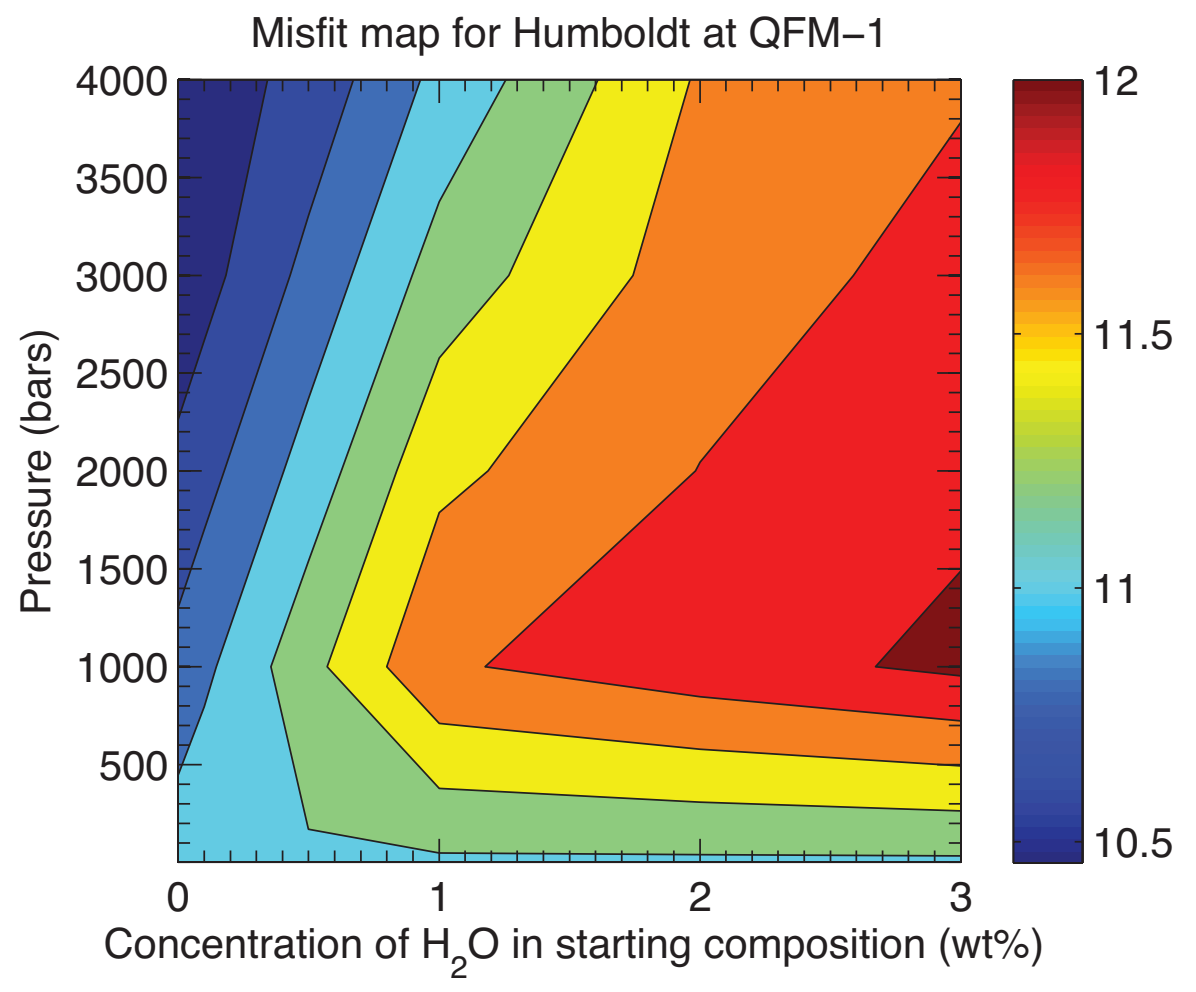

Fig. S22.

Contour plot of misfit between Jake_M and MELTS fractional crystallization calculations at QFM-1 using Humboldt Peak as the starting composition. Calculations performed at pressures of $1,1000,2000,3000$ and 4000 bars, and water concentrations of $0,0.1,0.5,1,2$ and 3 wt. \%. For each of the 30 MELTS calculations, the misfit was calculated by summing the differences between the MELTS curves in $\mathrm{SiO}_{2^{-}}, \mathrm{Al}_{2} \mathrm{O}_{3^{-}}, \mathrm{FeO}^{*}$-, and $\mathrm{CaO}-\mathrm{MgO}$ space and the three measured Jake_M compositions. The sum of the differences was then divided by three. Note that the misfit in this figure and subsequent figures is not directly comparable to the misfit plotted in Fig. S12, which is calculated against the whole Tenerife suite rather than Jake_M. Colored vertical scale bar indicates the degree of misfit; red = large (i.e., worse fit to Jake_M) and blue = small (i.e., better fit to Jake_M). 

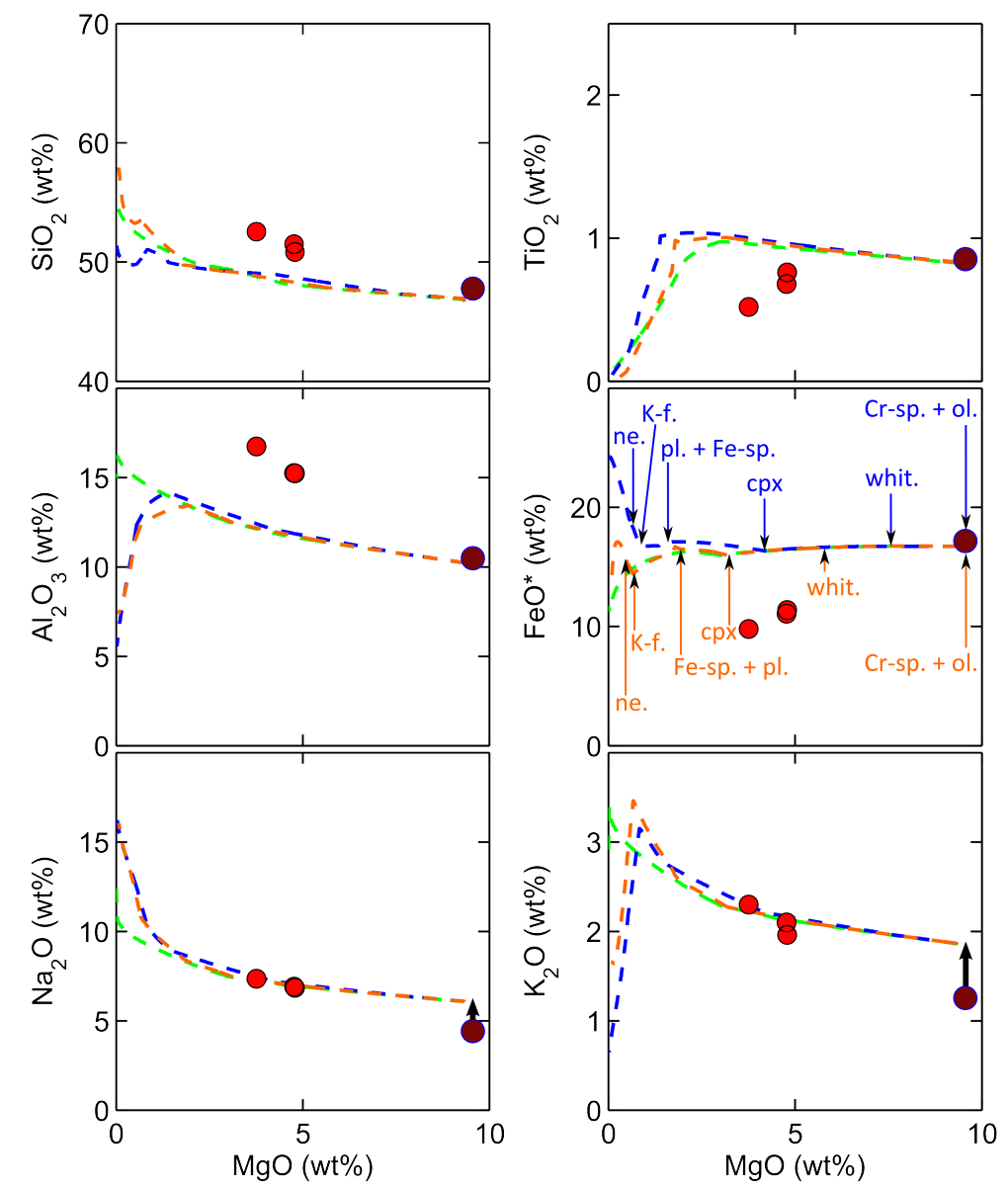

$$
\begin{aligned}
& ---4 \text { kbar, QFM-1, } \mathrm{H}_{2} \mathrm{O}=3 \mathrm{wt} \% \\
& ---4 \mathrm{kbar}, \mathrm{QFM}-1, \mathrm{H}_{2} \mathrm{O}=0 \mathrm{wt} \% \\
& ---1 \text { bar, QFM-1, } \mathrm{H}_{2} \mathrm{O}=0 \mathrm{wt} \% \\
& \text { Jake_M } \\
& \text { Humboldt Peak }
\end{aligned}
$$

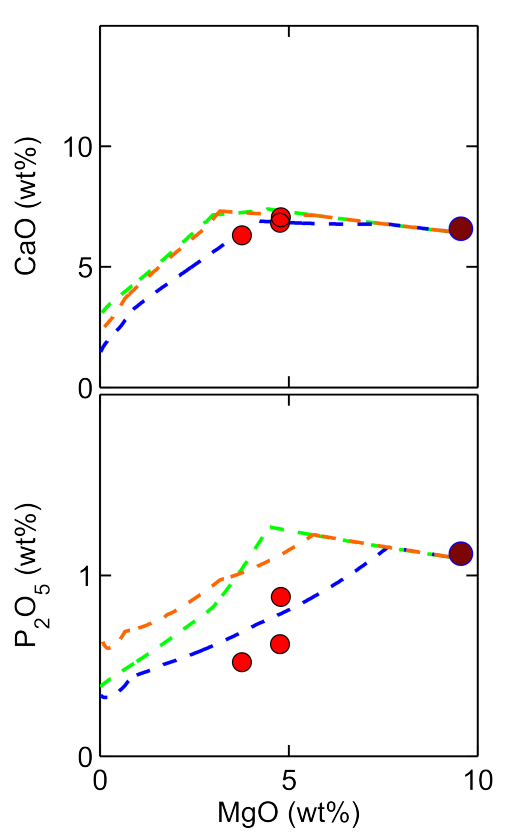

Fig. S23.

$\mathrm{MgO}$ variation diagrams for Humboldt Peak (with added $\mathrm{Na}_{2} \mathrm{O}$ and $\mathrm{K}_{2} \mathrm{O}$ so as to match the alkali content of Jake_M), Jake_M, and MELTS fractional crystallization calculations at QFM-1. The best-fit calculation ( $4 \mathrm{kbar}$ and $0 \mathrm{wt}$. \% water) is plotted in blue. For comparison, the calculation at $4 \mathrm{kbar}$ and $3 \mathrm{wt}$. \% water is shown in green, and the calculation at $1 \mathrm{bar}$ and $0 \mathrm{wt}$. \% water is shown in orange. Colored arrows indicate the entry of phases in the calculated fractional crystallization sequence: ol. = olivine; $\mathrm{Cr}$-sp. $=\mathrm{Cr}$-spinel; whit. $=$ whitlockite; ap. $=$ apatite; $\mathrm{cpx}=$ clinopyroxene; pl. = plagioclase; Fe-sp. $=$ Fe-rich spinel; opx = orthopyroxene; ne. = nepheline; K-f. = K-feldspar. Note that renormalization to $100 \mathrm{wt}$. $\%$ following the addition of alkalis to the Humboldt Peak starting composition causes a small decrease in the concentrations of all of the other elements, such that the starting point for the MELTS fractional crystallization calculations is offset from Humboldt Peak in all panels. Black arrows in the $\mathrm{Na}_{2} \mathrm{O}$ and $\mathrm{K}_{2} \mathrm{O}$ variation diagrams emphasize the amount by which Humboldt Peak has been enriched in alkalis to create this new starting composition. 


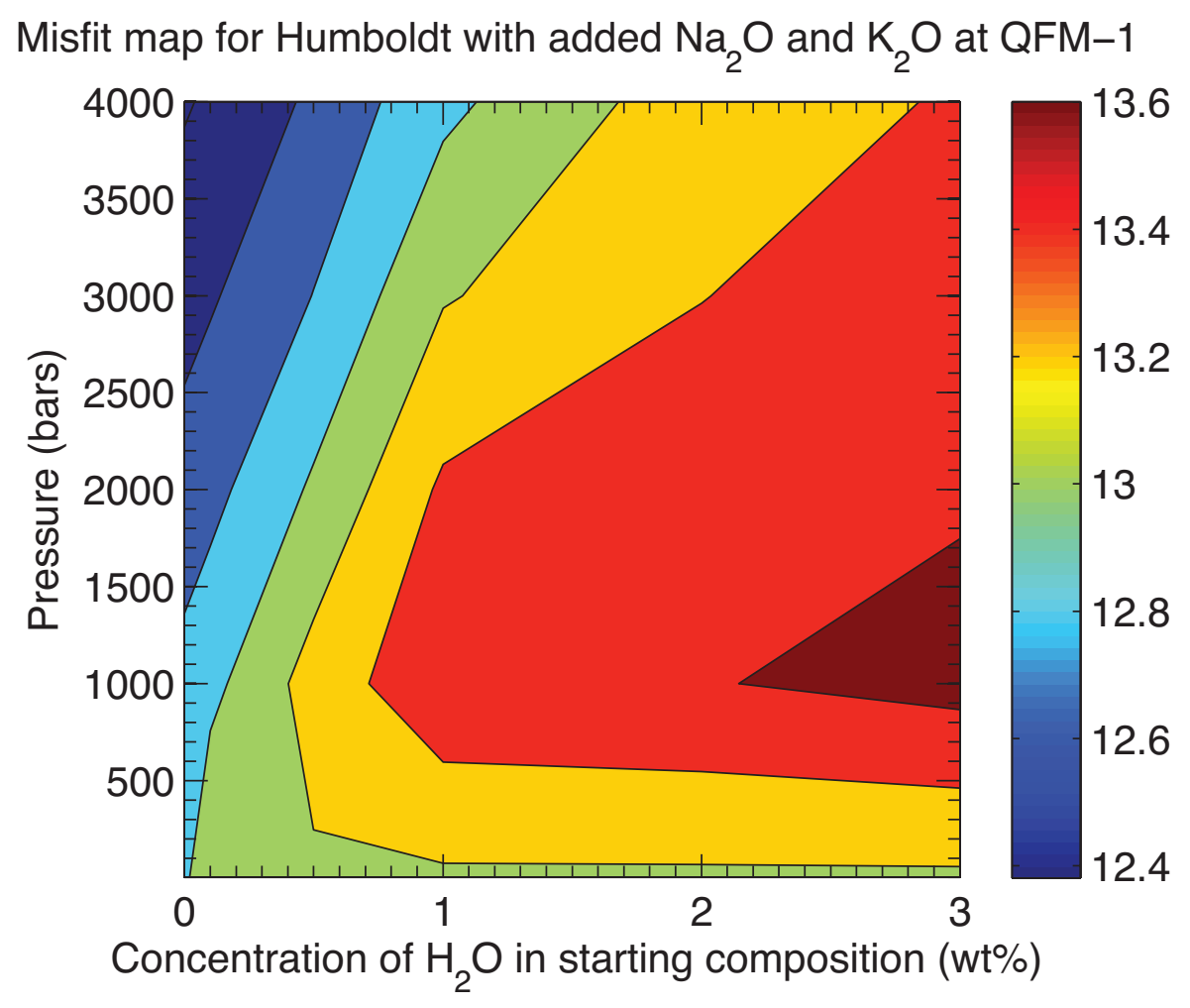

Fig. S24.

Contour plot of misfit between Jake_M and MELTS fractional crystallization calculations at QFM-1 using Humboldt Peak with added $\mathrm{Na}_{2} \mathrm{O}$ and $\mathrm{K}_{2} \mathrm{O}$ as the starting composition. Calculations performed at pressures of 1, 1000, 2000, 3000 and 4000 bars, and water concentrations of $0,0.1,0.5,1,2$ and 3 wt. \%. For each of the 30 MELTS calculations, the misfit was calculated by summing the differences between the MELTS curves in $\mathrm{SiO}_{2^{-}}, \mathrm{Al}_{2} \mathrm{O}_{3^{-}}, \mathrm{FeO}^{*}$, and $\mathrm{CaO}-\mathrm{MgO}$ space and the three measured Jake_M compositions. The sum of the differences was then divided by three. Note that the misfit in this figure and subsequent figures is not directly comparable to the misfit plotted in Fig. S12, which is calculated against the whole Tenerife suite rather than Jake_M. Colored vertical scale bar indicates the degree of misfit; red = large (i.e., worse fit to Jake_M) and blue = small (i.e., better fit to Jake_M). 
Mars Science Laboratory (MSL) Science Team

Aalto University

Osku Kemppinen

Applied Physics Laboratory (APL) at Johns Hopkins University

Nathan Bridges, Jeffrey R. Johnson, Michelle Minitti

Applied Research Associates, Inc. (ARA)

David Cremers

Arizona State University (ASU)

James F. Bell III, Lauren Edgar, Jack Farmer, Austin Godber, Meenakshi Wadhwa, Danika Wellington

Ashima Research

Ian McEwan, Claire Newman, Mark Richardson

ATOS Origin

Antoine Charpentier, Laurent Peret

Australian National University (ANU)

Penelope King

Bay Area Environmental Research Institute (BAER)

Jennifer Blank

Big Head Endian LLC

Gerald Weigle

Brock University

Mariek Schmidt

Brown University

Shuai Li, Ralph Milliken, Kevin Robertson, Vivian Sun

California Institute of Technology (Caltech)

Michael Baker, Christopher Edwards, Bethany Ehlmann, Kenneth Farley, Jennifer Griffes, John Grotzinger, Hayden Miller, Megan Newcombe, Cedric Pilorget, Melissa Rice, Kirsten Siebach, Katie Stack, Edward Stolper

Canadian Space Agency (CSA)

Claude Brunet, Victoria Hipkin, Richard Léveillé, Geneviève Marchand, Pablo Sobrón Sánchez

\section{Capgemini France}

Laurent Favot

Carnegie Institution of Washington

George Cody, Andrew Steele

Carnegie Mellon University

Lorenzo Flückiger, David Lees, Ara Nefian

Catholic University of America

Mildred Martin

Centre National de la Recherche Scientifique (CNRS)

Marc Gailhanou, Frances Westall, Guy Israël

Centre National d'Etudes Spatiales (CNES)

Christophe Agard, Julien Baroukh, Christophe Donny, Alain Gaboriaud, Philippe Guillemot, Vivian Lafaille, Eric Lorigny, Alexis Paillet, René Pérez, Muriel Saccoccio, Charles Yana

Centro de Astrobiología (CAB) 
Carlos Armiens-Aparicio, Javier Caride Rodríguez, Isaías Carrasco Blázquez, Felipe Gómez Gómez, Javier GómezElvira, Sebastian Hettrich, Alain Lepinette Malvitte, Mercedes Marín Jiménez, Jesús Martínez-Frías, Javier MartínSoler, F. Javier Martín-Torres, Antonio Molina Jurado, Luis Mora-Sotomayor, Guillermo Muñoz Caro, Sara Navarro López, Verónica Peinado-González, Jorge Pla-García, José Antonio Rodriguez Manfredi, Julio José Romeral-Planelló, Sara Alejandra Sans Fuentes, Eduardo Sebastian Martinez, Josefina Torres Redondo, Roser Urqui-O'Callaghan, MaríaPaz Zorzano Mier

Chesapeake Energy

Steve Chipera

Commissariat à l'Énergie Atomique et aux Énergies Alternatives (CEA)

Jean-Luc Lacour, Patrick Mauchien, Jean-Baptiste Sirven

Concordia College

Heidi Manning

Cornell University

Alberto Fairén, Alexander Hayes, Jonathan Joseph, Steven Squyres, Robert Sullivan, Peter Thomas

CS Systemes d'Information

Audrey Dupont

Delaware State University

Angela Lundberg, Noureddine Melikechi, Alissa Mezzacappa

Denver Museum of Nature \& Science

Julia DeMarines, David Grinspoon

Deutsches Zentrum für Luft- und Raumfahrt (DLR)

Günther Reitz

eINFORMe Inc. (at NASA GSFC)

Benito Prats

Finnish Meteorological Institute

Evgeny Atlaskin, Maria Genzer, Ari-Matti Harri, Harri Haukka, Henrik Kahanpää, Janne Kauhanen, Osku Kemppinen, Mark Paton, Jouni Polkko, Walter Schmidt, Tero Siili

GeoRessources

Cécile Fabre

Georgia Institute of Technology

James Wray, Mary Beth Wilhelm

Géosciences Environnement Toulouse (GET)

Franck Poitrasson

Global Science \& Technology, Inc.

Kiran Patel

Honeybee Robotics

Stephen Gorevan, Stephen Indyk, Gale Paulsen

Imperial College

Sanjeev Gupta

Indiana University Bloomington

David Bish, Juergen Schieber

Institut d'Astrophysique Spatiale (IAS)

Brigitte Gondet, Yves Langevin 
Institut de Chimie des Milieux et Matériaux de Poitier (IC2MP)

Claude Geffroy

Institut de Recherche en Astrophysique et Planétologie (IRAP), Université de Toulouse

David Baratoux, Gilles Berger, Alain Cros, Claude d'Uston, Olivier Forni, Olivier Gasnault, Jérémie Lasue, Qiu-Mei

Lee, Sylvestre Maurice, Pierre-Yves Meslin, Etienne Pallier, Yann Parot, Patrick Pinet, Susanne Schröder, Mike Toplis

Institut des Sciences de la Terre (ISTerre)

Éric Lewin

inXitu

Will Brunner

Jackson State University

Ezat Heydari

Jacobs Technology

Cherie Achilles, Dorothy Oehler, Brad Sutter

Laboratoire Atmosphères, Milieux, Observations Spatiales (LATMOS)

Michel Cabane, David Coscia, Guy Israël, Cyril Szopa, Samuel Teinturier

Laboratoire de Géologié de Lyon : Terre, Planète, Environnement (LGL-TPE)

Gilles Dromart

Laboratoire de Minéralogie et Cosmochimie du Muséum (LMCM)

François Robert, Violaine Sautter

Laboratoire de Planétologie et Géodynamique de Nantes (LPGN)

Stéphane Le Mouélic, Nicolas Mangold, Marion Nachon

Laboratoire Génie des Procédés et Matériaux (LGPM)

Arnaud Buch

Laboratoire Interuniversitaire des Systèmes Atmosphériques (LISA)

Fabien Stalport, Patrice Coll, Pascaline François, François Raulin

Lightstorm Entertainment Inc.

James Cameron

Los Alamos National Lab (LANL)

Sam Clegg, Agnès Cousin, Dorothea DeLapp, Robert Dingler, Ryan Steele Jackson, Stephen Johnstone, Nina Lanza, Cynthia Little, Tony Nelson, Roger C. Wiens, Richard B. Williams

Lunar and Planetary Institute (LPI)

Laurel Kirkland, Allan Treiman

Malin Space Science Systems (MSSS)

Burt Baker, Bruce Cantor, Michael Caplinger, Scott Davis, Brian Duston, Kenneth Edgett, Donald Fay, Craig Hardgrove, David Harker, Paul Herrera, Elsa Jensen, Megan R. Kennedy, Gillian Krezoski, Daniel Krysak, Leslie Lipkaman, Michael Malin, Elaina McCartney, Sean McNair, Brian Nixon, Liliya Posiolova, Michael Ravine, Andrew Salamon, Lee Saper, Kevin Stoiber, Kimberley Supulver, Jason Van Beek, Tessa Van Beek, Robert Zimdar

Massachusetts Institute of Technology (MIT)

Katherine Louise French, Karl Iagnemma, Kristen Miller, Roger Summons

Max Planck Institute for Solar System Research

Fred Goesmann, Walter Goetz, Stubbe Hviid

Microtel 
Micah Johnson, Matthew Lefavor, Eric Lyness

Mount Holyoke College

Elly Breves, M. Darby Dyar, Caleb Fassett

NASA Ames

David F. Blake, Thomas Bristow, David DesMarais, Laurence Edwards, Robert Haberle, Tori Hoehler, Jeff

Hollingsworth, Melinda Kahre, Leslie Keely, Christopher McKay, Mary Beth Wilhelm

NASA Goddard Space Flight Center (GSFC)

Lora Bleacher, William Brinckerhoff, David Choi, Pamela Conrad, Jason P. Dworkin, Jennifer Eigenbrode, Melissa Floyd, Caroline Freissinet, James Garvin, Daniel Glavin, Daniel Harpold, Paul Mahaffy, David K. Martin, Amy McAdam, Alexander Pavlov, Eric Raaen, Michael D. Smith, Jennifer Stern, Florence Tan, Melissa Trainer

NASA Headquarters

Michael Meyer, Arik Posner, Mary Voytek

NASA Jet Propulsion Laboratory (JPL)

Robert C, Anderson, Andrew Aubrey, Luther W. Beegle, Alberto Behar, Diana Blaney, David Brinza, Fred Calef, Lance Christensen, Joy Crisp, Lauren DeFlores, Bethany Ehlmann, Jason Feldman, Sabrina Feldman, Gregory Flesch, Joel Hurowitz, Insoo Jun, Didier Keymeulen, Justin Maki, Michael Mischna, John Michael Morookian, Timothy

Parker, Betina Pavri, Marcel Schoppers, Aaron Sengstacken, John J. Simmonds, Nicole Spanovich, Manuel de la Torre Juarez, Ashwin Vasavada, Christopher R. Webster, Albert Yen

NASA Johnson Space Center (JSC)

Paul Douglas Archer, Francis Cucinotta, John H. Jones, Douglas Ming, Richard V. Morris, Paul Niles, Elizabeth Rampe

Nolan Engineering

Thomas Nolan

Oregon State University

Martin Fisk

Piezo Energy Technologies

Leon Radziemski

Planetary Science Institute

Bruce Barraclough, Steve Bender, Daniel Berman, Eldar Noe Dobrea, Robert Tokar, David Vaniman, Rebecca M. E. Williams, Aileen Yingst

Princeton University

Kevin Lewis

Rensselaer Polytechnic Institute (RPI)

Laurie Leshin

Retired

Timothy Cleghorn, Wesley Huntress, Gérard Manhès

Salish Kootenai College

Judy Hudgins, Timothy Olson, Noel Stewart

Search for Extraterrestrial Intelligence Institute (SETI I)

Philippe Sarrazin

Smithsonian Institution

John Grant, Edward Vicenzi, Sharon A. Wilson

Southwest Research Institute (SwRI)

Mark Bullock, Bent Ehresmann, Victoria Hamilton, Donald Hassler, Joseph Peterson, Scot Rafkin, Cary Zeitlin 
Space Research Institute

Fedor Fedosov, Dmitry Golovin, Natalya Karpushkina, Alexander Kozyrev, Maxim Litvak, Alexey Malakhov, Igor Mitrofanov, Maxim Mokrousov, Sergey Nikiforov, Vasily Prokhorov, Anton Sanin, Vladislav Tretyakov, Alexey

Varenikov, Andrey Vostrukhin, Ruslan Kuzmin

Space Science Institute (SSI)

Benton Clark, Michael Wolff

State University of New York (SUNY) Stony Brook

Scott McLennan

Swiss Space Office

Oliver Botta

TechSource

Darrell Drake

Texas A\&M

Keri Bean, Mark Lemmon

The Open University

Susanne P. Schwenzer

United States Geological Survey (USGS) Flagstaff

Ryan B. Anderson, Kenneth Herkenhoff, Ella Mae Lee, Robert Sucharski

Universidad de Alcalá

Miguel Ángel de Pablo Hernández, Juan José Blanco Ávalos, Miguel Ramos

Universities Space Research Association (USRA)

Andrea Jones, Myung-Hee Kim, Charles Malespin, Ianik Plante

University College London (UCL)

Jan-Peter Muller

University Nacional Autónoma de México (UNAM)

Rafael Navarro-González

University of Alabama

Ryan Ewing

University of Arizona

William Boynton, Robert Downs, Mike Fitzgibbon, Karl Harshman, Shaunna Morrison

University of California Berkeley

William Dietrich, Onno Kortmann, Marisa Palucis

University of California Davis

Dawn Y. Sumner, Amy Williams

University of California San Diego

Günter Lugmair

University of California San Francisco

Michael A. Wilson

University of California Santa Cruz

David Rubin

University of Colorado Boulder

Bruce Jakosky 
University of Copenhagen

Tonci Balic-Zunic, Jens Frydenvang, Jaqueline Kløvgaard Jensen, Kjartan Kinch, Asmus Koefoed, Morten Bo Madsen, Susan Louise Svane Stipp

University of Guelph

Nick Boyd, John L. Campbell, Ralf Gellert, Glynis Perrett, Irina Pradler, Scott VanBommel

University of Hawai'i at Manoa

Samantha Jacob, Tobias Owen, Scott Rowland

University of Helsinki

Evgeny Atlaskin, Hannu Savijärvi

University of Kiel

Eckart Boehm, Stephan Böttcher, Sönke Burmeister, Jingnan Guo, Jan Köhler, César Martín García, Reinhold MuellerMellin, Robert Wimmer-Schweingruber

University of Leicester

John C. Bridges

University of Maryland

Timothy McConnochie

University of Maryland Baltimore County

Mehdi Benna, Heather Franz

University of Maryland College Park

Hannah Bower, Anna Brunner

University of Massachusetts

Hannah Blau, Thomas Boucher, Marco Carmosino

University of Michigan Ann Arbor

Sushil Atreya, Harvey Elliott, Douglas Halleaux, Nilton Rennó, Michael Wong

University of Minnesota

Robert Pepin

University of New Brunswick

Beverley Elliott, John Spray, Lucy Thompson

University of New Mexico

Suzanne Gordon, Horton Newsom, Ann Ollila, Joshua Williams

University of Queensland

Paulo Vasconcelos

University of Saskatchewan

Jennifer Bentz

University of Southern California (USC)

Kenneth Nealson, Radu Popa

University of Tennessee Knoxville

Linda C. Kah, Jeffrey Moersch, Christopher Tate

University of Texas at Austin

Mackenzie Day, Gary Kocurek

University of Washington Seattle

Bernard Hallet, Ronald Sletten 
University of Western Ontario

Raymond Francis, Emily McCullough

University of Winnipeg

Ed Cloutis

\section{Utrecht University}

Inge Loes ten Kate

Vernadsky Institute

Ruslan Kuzmin

Washington University in St. Louis (WUSTL)

Raymond Arvidson, Abigail Fraeman, Daniel Scholes, Susan Slavney, Thomas Stein, Jennifer Ward

Western University

Jeffrey Berger

York University

John E. Moores 


\section{References}

1. J. P. Grotzinger et al., Mars Science Laboratory: First 100 sols of geologic and geochemical exploration from Bradbury Landing to Glenelg. $44^{\text {th }}$ Lunar and Planetary Science Conference, 1259 (2013).

2. R. Gellert et al., Initial MSL APXS activities and observations at Gale Crater, Mars. $44^{\text {th }}$ Lunar and Planetary Science Conference, 1432 (2013).

3. A. Cousin et al., ChemCam analysis of Jake Matijevic, Gale Crater. $44^{\text {th }}$ Lunar and Planetary Science Conference, 1409 (2013).

4. M. E. Minitti et al., Mars Hand Lens Imager (MAHLI) observations of rocks at Curiosity's field site. $44^{\text {th }}$ Lunar and Planetary Science Conference, 2186 (2013).

5. W. Cross, J. P. Iddings, L. V. Pirsson, H. S. Washington, Quantitative Classification of Igneous Rocks. (University of Chicago Press, 1903), pp. 286.

6. M. Wadhwa, Redox conditions on small bodies, the Moon and Mars. Reviews in Mineralogy and Geochemistry 68, 493 (2008).

7. J. Tuff, J. Wade, B. J. Wood, Volcanism on Mars controlled by early oxidation of the upper mantle. Nature 498, 342 (2013).

8. J. M. Rhodes, Geochemical stratigraphy of lava flows sampled by the Hawaiian Scientific Drilling Project. Journal of Geophysical Research 101, 11 (1996).

9. C. Meyer, The Martian meteorite compendium. (http://curator.jsc.nasa.gov/antmet/mmc/index.cfm), (2012).

10. R. Gellert et al., Alpha particle X-ray spectrometer (APXS): Results from Gusev crater and calibration report. Journal of Geophysical Research 111, E02S05 (2006).

11. H. Wänke, J. Brückner, G. Dreibus, R. Rieder, I. Ryabchikov, Chemical composition of rocks and soils at the Pathfinder site. Space Science Reviews 96, 317 (2001).

12. C. N. Foley, T. E. Economou, R. N. Clayton, W. Dietrich, Calibration of the Mars Pathfinder alpha proton Xray spectrometer. Journal of Geophysical Research 108, 8095 (2003).

13. A. Harker, The Tertiary Igneous Rocks of Skye. Memoirs of the Geological Survey of the United Kingdom (Glascow, 1904), pp. 481.

14. I. D. Muir, C. E. Tilley, Mugearites and their place in alkali igneous rock series. Journal of Geology 69, 186 (1961).

15. I. S. E. Carmichael, F. J. Turner, J. Verhoogen, Igneous Petrology. (McGraw-Hill, 1974), pp. 739.

16. M. Wilson, Igneous Petrogenesis. (Unwin Hyman, London, 1989), pp. 466.

17. R. V. Morris et al., Iron mineralogy and aqueous alteration from Husband Hill through Home Plate at Gusev Crater, Mars: results from the Mössbauer instrument on the Spirit Mars Exploration Rover. Journal of Geophysical Research 113, E12S42 (2008).

18. V. Sautter, A. Jambon, O. Boudouma, Cl-amphibole in the nakhlite MIL 03346: Evidence for sediment contamination in a Martian meteorite. Earth and Planetary Science Letters 252, 45 (2006).

19. J. M. D. Day, L. A. Taylor, C. Floss, H. Y. McSween Jr., Petrology and chemistry of ML 03346 and its significance in understanding the petrogenesis of nakhlites on Mars. Meteoritics and Planetary Science 41, $581(2006)$.

20. A. H. Treiman, The parent magma of the Nakhla (SNC) meteorite, inferred from magmatic inclusions. Geochimica et Cosmochimica Acta 57, 4753 (1993).

21. H. Y. McSween Jr., G. J. Taylor, M. B. Wyatt, Elemental composition of the Martian crust. Science 324, 736 (2009).

22. A. S. Yen et al., Nickel on Mars: Constraints on meteoritic material at the surface. Journal of Geophysical Research 111, E12S11 (2006).

23. T. N. Irvine, W. R. A. Baragar, A guide to the chemical classification of the common volcanic rocks. Canadian Journal of Earth Sciences 8, 523 (1971).

24. T. Usui, H. Y. McSween Jr., B. C. Clark III, Petrogenesis of high-phosphorus Wishstone Class rocks in Gusev Crater, Mars. Journal of Geophysical Research 113, E12S44 (2008).

25. Georoc database, (http://georoc.mpch-mainz.gwdg.de/georoc/).

26. H. Y. McSween Jr., What have we learned about Mars from SNC meteorites. Meteoritics 29, 757 (1994).

27. A. Ruzicka, G. A. Synder, L. A. Taylor, Comparative geochemistry of basalts from the Moon, Earth, HED asteroid, and Mars: Implications for the origin of the Moon. Geochimica et Cosmochimica Acta 65, 979 (2001).

28. J. Filiberto, Similarities between the Shergottites and terrestrial ferropicrites. Icarus 197, 52 (2008).

29. E. Stolper, H. Y. McSween Jr., J. F. Hays, A petrologic model of the relationships among achondritic meteorites. Geochimica et Cosmochimica Acta 43, 589 (1979). 
30. H. Wänke, G. Dreibus, Chemical composition and accretion history of terrestrial planets. Philosophical Transactions of the Royal Society of London A 325, 545 (1988).

31. J. Karner, J. J. Papike, C. K. Shearer, Olivine from planetary basalts: Chemical signatures that indicate planetary parentage and those that record igneous setting and process. American Mineralogist 88, 806 (2003).

32. J. Karner, J. J. Papike, C. K. Shearer, Comparative planetary mineralogy: Pyroxene major- and minorelement chemistry and partitioning of vanadium between pyroxene and melt in planetary basalts. American Mineralogist 91, 1574 (2006).

33. A. Lacroix, Les lavas à haüyne d'Auvergne et leurs enclaves homoeogènes. Comptes Rendus CLXIV, 581 (1917)

34. J. Andújar, F. Costa, J. Martí, J. A. Wolff, M. R. Carroll, Experimental constraints on pre-eruptive conditions of phonolitic magma from caldera-forming El Abrigo eruption, Tenerife (Canary Islands). Chemical Geology 257, 173 (2008).

35. J. F. G. Wilkinson, R. A. Binns, Hawaiite of high pressure origin from northeastern New South Wales. Nature 222, 553 (1969).

36. A. J. Stolz, Garnet websterites and associated ultramamfic inclusions from a nepheline mugearite in the Walcha area, New South Wales, Australia. Mineralogical Magazine 48, 167 (1984).

37. D. H. Green, A. D. Edgar, P. Beasley, E. Kiss, N. G. Ware, Upper mantle source for some hawaiites, mugearites and benmoreites. Contributions to Mineralogy and Petrology 48, 33 (1974).

38. G. J. Ablay, M. R. Carroll, M. R. Palmer, J. Martí, R. S. J. Sparks, Basanite-phonolite lineages of the TeidePico volcanic complex, Tenerife, Canaray Islands. Journal of Petrology 39, 905 (1998).

39. P. M. Smith, P. D. Asimow, Adiabat_1ph: A new public front-end to the MELTS, pMELTS, and pHMELTS models. Geochemistry, Geophysics, Geosystems 6, Q02004 (2005).

40. M. S. Ghiorso, R. O. Sack, Chemical mass transfer in magmatic processes. IV. A revised and internally consistent thermodynamic model for the interpolation and extrapolation of liquid-solid equilibria. Contributions to Mineralogy and Petrology 119, 197 (1995).

41. H. S. Yoder, C. E. Tilley, Origin of basaltic magmas: An experimental study of natural and synthetic rock systems. Journal of Petrology 3, 342 (1962).

42. D. C. Presnall et al., Liquidus phase relations on the join diopside-forsterite-anorthite from 1-atm to $20 \mathrm{kbar}$ : Their bearing on the generation and crystallization of basaltic magma. Contributions to Mineralogy and Petrology 66, 203 (1978).

43. D. H. Eggler, Water-saturated and undersaturated melting relations in a Paricutin andesite and an estimate of water content in the natural magma. Contributions to Mineralogy and Petrology 34, 261 (1972).

44. P. J. Wyllie, Magmas and volatile components. American Mineralogist 64, 469 (1979).

45. G. J. Ablay, G. G. J. Ernst, J. Marti, R. S. J. Sparks, The $\sim 2 k a$ subplinian eruption of Montana Blanca, Tenerife. Bulletin of Volcanology 57, 337 (1995).

46. C. Beier, K. M. Haase, T. H. Hansteen, Magma evolution of the Sete Cidades volcano, São Miguel, Azores. Journal of Petrology 47, 1375 (2006).

47. J. C. Dann, A. H. Holzheid, T. L. Grove, H. Y. McSween Jr., Phase equilibria of the Shergotty meteorite: Constraints on pre-eruptive water contents of martian magmas and fractional crystallization under hydrous conditions. Meteoritics and Planetary Science 36, 793 (2001).

48. H. Nekvasil, J. Filiberto, F. M. McCubbin, D. H. Lindsley, Alkalic parental magmas for chassignites? Meteoritics and Planetary Science 42, 979 (2007).

49. M. C. Johnson, M. J. Rutherford, P. C. Hess, Chassigny petrogenesis: Melt compositions, intersive parameters, and water contents of Martian (?) magmas. Geochimica et Cosmochimica Acta 55, 349 (1991).

50. F. M. McCubbin et al., Hydrous magmatism on Mars: A source of water for the surface and subsurface during the Amazonian. Earth and Planetary Science Letters 292, 132 (2010).

51. J. Filiberto, A. H. Treiman, Martian magmas contained abundant chlorine, but little water. Geology 37, 1087 (2009).

52. D. R. Baker, M. Alletti, Fluid saturation and volatile partitioning between melts and hydrous fluids in crustal magmatic systems: The contribution of experimental measurements and solubility models. Earth-Science Reviews 114, 298 (2012).

53. M. R. Carroll, J. D. Webster, Solubilities of sulfur, noble gases, nitrogen, chlorine, and fluorine in magmas. Reviews in Mineralogy 30, 231 (1994).

54. P. J. Wyllie, O. F. Tuttle, Experimental investigations of silicate systems containing two volatile components. Part III. The effects of $\mathrm{SO}_{3}, \mathrm{P}_{2} \mathrm{O}_{5}, \mathrm{HCl}$, and $\mathrm{Li}_{2} \mathrm{O}$, in addition to $\mathrm{H}_{2} \mathrm{O}$, on the melting temperatures of albite and granite. American Journal of Science 262, 930 (1964).

55. A. D. Edgar, in Alkaline Igneous Rocks, J. G. Fitton, B. G. J. Upton, Eds. (Geological Society of London, 1987), pp. 29-52.

56. D. H. Green, T. J. Falloon, W. R. Taylor, in Magmatic Processes: Physiochemical Principles, B. O. Mysen, Ed. (The Geochemical Society, 1987), pp. 139-154.

57. R. Dasgupta, M. M. Hirschmann, Partial melting experiments of peridotite $+\mathrm{CO}_{2}$ at $3 \mathrm{GPa}$ and genesis of alkalic ocean island basalts. Journal of Petrology 48, 2093 (2007). 
58. F. E. Lloyd, D. K. Bailey, Light element metasomatism of the continental mantle: The evidence and the consequences. Physics and Chemistry of the Earth 9, 389 (1975).

59. M. Menzies, V. Rama Murthy, Mantle metasomatism as a precursor to the genesis of alkaline magmasisotopic evidence. American Journal of Science 280-A, 622 (1980).

60. S. Pilet, M. B. Baker, E. M. Stolper, Metasomatized lithosphere and the origin of alkaline lavas. Science 320, 916 (2008).

61. S. Keshav, G. H. Gudfinnsson, G. Sen, Y. W. Fei, High-pressure melting experiments on garnet clinopyroxenite and the alkalic to tholeiitic transition in ocean-island basalts. Earth and Planetary Science Letters 223, 365 (2004).

62. T. Kogiso, M. M. Hirschmann, D. J. Frost, High-pressure partial melting of garnet pyroxenite: possible mafic lithologies in the source of ocean island basalts. Earth and Planetary Science Letters 216, 603 (2003).

63. M. E. Schmidt, T. J. McCoy, The evolution of a heterogeneous Martian mantle: Clues from K, P, Ti, Cr, and $\mathrm{Ni}$ variations in Gusev basalts and shergottite meteorites. Earth and Planetary Science Letters 296, 67 (2010).

64. H. Y. McSween Jr. et al., Alkaline volcanic rocks from the Columbia Hills, Gusev crater, Mars. Journal of Geophysical Research 111, E09S91 (2006).

65. G. Dreibus, H. Wänke, Volatiles on Earth and Mars: A comparison. Icarus 71, 225 (1987).

66. G. J. Taylor et al., Bulk composition and early differentiation of Mars. Journal of Geophysical Research 111, E03S10 (2006).

67. K. Lodders, B. Fegley Jr., An oxygen isotope model for the composition of Mars. Icarus 126, 373 (1997).

68. S. M. McLennan, Large-ion lithophile element fractionation during the early differentiation of Mars and the composition of the Martian primitive mantle. Meteoritics and Planetary Science 38, 895 (2003).

69. A. H. Treiman, Chemical compositions of martian basalts (shergottites): Some inferences on basalt formation, mantle metasomatism, and differentiation in Mars. Meteoritics and Planetary Science 38, 1849 (2003).

70. J. D. Winter, An Introduction to Igneous and Metamorphic Petrology. (Prentice Hall, 2010), pp. 702.

71. M. E. Schmidt et al., APXS of first rocks encountered by Curiosity in Gale Crater: Geochemical diversity and volatile element (K and Zn) enrichment. 44th Lunar and Planetary Science Conference, 1278 (2013). R. W. Le Maitre, Ed., Igneous Rocks: A Classification and Glossary of Terms, (Cambridge University Press, ed. $\left.2^{\text {nd }}, 2002\right)$, pp. 236.

73. H. Chennaoui Aoudjehane et al., Tissint martian meteorite: a fresh look at the interior, surface, and atmosphere of Mars. Science 338, 785 (2012).

74. C. B. Agee et al., Unique meteorite from early Amazonian Mars: Water-rich basaltic breccia Northwest Africa 7034. Science 339, 780 (2013).

75. D. W. Ming et al., Geochemical properties of rocks and soils in Gusev crater, Mars: Results of the Alpha particle X-ray spectrometer from Cumberland Ridge to Home Plate. Journal of Geophysical Research 113, E12S39 (2008).

76. R. Rieder et al., Chemistry of rocks and soils at Meridiani Planum from the Alpha Particle X-ray Spectrometer. Science 306, 1746 (2004).

77. S. W. Squyres et al., Pyroclastic activity at Home Plate in Gusev Crater, Mars. Science 316, 738 (2007).

78. R. H. Hewins et al., Northwest Africa 7533, an impact breccia from Mars. 44th Lunar and Planetary Science Conference, 2385 (2013).

79. M. Humayun, B. Zanda, R. H. Hewins, C. Göpel, Composition of Northwest Africa 7533: Implications for the origin of martian soils and crust. $44^{\text {th }}$ Lunar and Planetary Science Conference, 1429 (2013).

80. A. K. Matzen, M. B. Baker, J. R. Beckett, E. M. Stolper, Fe-Mg partitioning between olivine and highmagnesian melts and the nature of Hawaiian parental liquids. Journal of Petrology 52, 1243 (2011).

81. J. Filiberto, R. Dasgupta, $\mathrm{Fe}^{+2}-\mathrm{Mg}$ partitioning between olivine and basaltic melts: Applications to genesis of olivine-phyric Shergottites and conditions of melting in the Martian interior. Earth and Planetary Science Letters 304, 527 (2011).

82. E. M. Stolper et al., The petrochemistry of Jake_M: A martian mugearite. $44^{\text {th }}$ Lunar and Planetary Science Conference, 1685 (2013).

83. E. M. Stolper et al., The petrochemistry of Jake_M: A martian mugearite. Mineralogical Magazine 77, 2269 (2013).

84. J. Brückner et al., in The Martian Surface: Composition, Mineralogy, and Physical Properties, J. F. Bell III, Ed. (Cambridge University Press, Cambridge, 2008), pp. 58-102.

85. J. A. Hurowitz et al., In situ and experimental evidence for acidic weathering of rocks and soils on Mars. Journal of Geophysical Research 111, E02S19 (2006).

86. S. Maurice et al., The ChemCam instrument suite on the Mars Science Laboratory (MSL) rover: Science objectives, and mast unit description. Space Science Reviews 170, 95 (2012).

87. R. C. Wiens et al., The ChemCam instrument suite on the Mars Science Laboratory (MSL) rover: Body unit and combined system tests. Space Science Reviews 170, 167 (2012). 
88. E. Lewin et al., Modal mineralogy of igneous rocks with ChemCam at Gale crater. $44^{\text {th }}$ Lunar and Planetary Science Conference, 3102 (2013).

89. S. Maurice et al., Laser Induced Spectroscopy (LIBS) spot size stand-off distances with ChemCam. $43^{\text {rd }}$ Lunar and Planetary Science Conference, 2899 (2012).

90. P. Comon, Independent component analysis, a new concept? Signal Processing 36, 287 (1994).

91. O. Forni et al., Component separation of OMEGA spectra with ICA. $36^{\text {th }}$ Lunar and Planetary Science Conference, 1623 (2005).

92. J. Lasue et al., Partial least squares sensitivity analysis and improvements for ChemCam LIBS data anlysis on Mars. $44^{\text {th }}$ Lunar and Planetary Science Conference, 2230 (2013).

93. L. Qin, M. Humayun, The Fe/Mn ratio in MORB and OIB determined by ICP-MS. Geochimica et Cosmochimica Acta 72, 1660 (2008).

94. M. Humayun, L. Qin, M. D. Norman, Geochemical evidence for excess iron in the mantle beneath Hawaii. Science 306, 91 (2004).

95. W. I. Ridley, The petrology of the Las Canada volcanoes, Tenerife, Canary Islands. Contributions to Mineralogy and Petrology 26, 124 (1970).

96. M. M. Hirschmann, M. S. Ghiorso, L. E. Wasylenki, P. D. Asimow, E. M. Stolper, Calculation of peridotite partial melting from thermodynamic models of minerals and melts. I. Review of methods and comparison with experiments. Journal of Petrology 39, 1091 (1998).

97. C. D. K. Herd, Basalts as probes of planetary interior redox state. Reviews in Mineralogy and Geochemistry 68, 527 (2008).

98. Y. Bottinga, D. F. Weill, The viscosity of magmatic silicate liquids: a model calculation. American Journal of Science 272, 438 (1972). 